\title{
ESPÉCIES DE ABELHAS (HYMENOPTERA, APOIDEA) E TIPIFICAÇÃO DOS MÉIS POR ELAS PRODUZIDOS EM ÁREA DE CERRADO DO MUNICÍPIO DE PIRASSUNUNGA, ESTADO DE SÃO PAULO.
}

DANIELA DE ALMEIDA

Dissertação apresentada à Escola Superior de Agricultura "Luiz de Queiroz", Universidade de São Paulo, para obtenção do Título de Mestre em Ciências, Área de Concentração: Entomologia.

PIRACICABA

Estado de São Paulo - Brasil

Setembro - 2002 


\title{
ESPÉCIES DE ABELHAS (HYMENOPTERA, APOIDEA) E TIPIFICAÇÃO DOS MÉIS POR ELAS PRODUZIDOS EM ÁREA DE CERRADO DO MUNICÍPIO DE PIRASSUNUNGA, ESTADO DE SÃO PAULO.
}

\author{
DANIELA DE ALMEIDA \\ Zootecnista
}

Orientador: Prof. Dr. Luís CARLOS MARCHINI

\begin{abstract}
Dissertação apresentada à Escola Superior de Agricultura "Luiz de Queiroz”, Universidade de São Paulo, para obtenção do Título de Mestre em Ciências, Área de Concentração: Entomologia.
\end{abstract}

PIRACICABA

Estado de São Paulo - Brasil

Setembro - 2002 
Dados Internacionais de Catalogação na Publicação (CIP) DIVISÃO DE BIBLIOTECA E DOCUMENTAÇÃO - ESALQ/USP

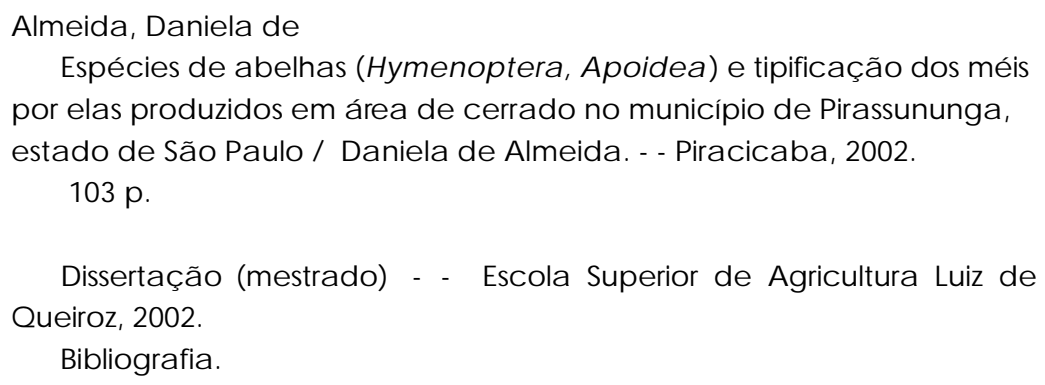

1. Abelha 2. Cerrado 3. Mel 4. Polén 5. Propriedade fisic o-química I. Título

CDD 638.1

\section{"Permitida a cópia total ou parcial deste documento, desde que citada a fonte - $\mathrm{O}$ autor"}


Aos meus pais, Sandra e David,

que com amor, carinho e dedicação,

sempre me apoiaram em todas as

etapas de minha vida.

A os meus tios Cristina e Marcílio pela prontidão

com que sempre me ajudaram.

Ao meu querido esposo Hernan pelo constante apoio, incentivo, amor e compreensão. 


\section{AGRADECIMENTOS}

Meus sinceros agradecimentos às pessoas e instituições que contribuíram para o desenvolvimento deste trabalho. Em especial:

Ao Prof. Dr. Luís Carlos Marchini pela orientação, amizade, confiança e principalmente pelo apoio e paciência concedidos a todo momento;

À Escola Superior de Agricultura "Luiz de Queiroz", em especial ao Setor de Entomologia pelo acolhimento e oportunidade para a realização deste trabalho;

Aos professores do curso de pós-graduação em Entomologia, pela boa vontade e ensinamentos transmitidos;

Ao Prof. Dr. Evoneo Berti Filho pelo auxílio na elaboração do "summary";

Ao Prof. Dr. Sinval Silveira Neto, pela grande contribuição e orientação prestada quanto a metodologia do trabalho e análises faunísticas;

À Dra. Augusta Carolina de C. C. Moreti pela amizade, disposição e análises polínicas.;

Ao Prof. Dr. Vinícius Castro Souza do Laboratório de Sistemática Vegetal da ESALQ/USP pela identificação das espécies vegetais;

À todos os companheiros do Laboratório de Insetos Úteis, principalmente a Geni da Silva Sodré pela constante colaboração e amizade.

Às bibliotecárias da ESALQ pela ajuda na elaboração e correções das referências bibliográficas;

À Faculdade de Zootecnia e Engenharia de Alimentos (FZEA/USP - Campus Pirassununga/SP) pela oportunidade de realização desta pesquisa em suas áreas remanescentes de cerrado;

À Prof. Dra. Catarina Abdala Gomide, do Departamento de Zootecnia da FZEA/USP Pirassununga/SP, pela amizade, carinho e grande ajuda nas análises físico-químicas; 
À Prof. Dra. Estela Gaglianone Moro, do Departamento de Zootecnia da FZEA/USP Pirassununga/SP, pela amizade, carinho e grande ajuda nas coletas de abelhas e organização das colméias de Apis mellifera L.;

Aos Prof. Dr. Marcus Antônio Zanetti e Dr. José Aparecido Cunha pela orientação e desenvolvimento das análises de minerais, realizadas no Laboratório de minerais do Departamento de Zootecnia, da FZEA/USP - Pirassununga/SP;

À equipe do Prof. Dr. João Maria Franco de Camargo, em especial a Maria Cristina Gaglianone, do Departamento de Entomologia da FFCLRP/USP - Ribeirão Preto/SP, pela identificação dos insetos.

À Prof. Dra. Maria José O. Campos e Prof. Dr. Edilberto Giannotti do Instituto de Biociências da UNESP - Rio Claro/SP, pela atenção e auxílio na pesquisa de referências bibliográficas,

À Fundação de Amparo à Pesquisa do Estado de São Paulo (FAPESP - Processo: 99/12818-9), pelo apoio ao projeto e bolsa concedida; e ao acessor responsável, pela atenção, correções e sugestões valiosas despendidas a esta pesquisa;

Finalmente, à todos os meus familiares e amigos espirituais que me apoiaram neste caminho. 


\section{SUMÁRIO}

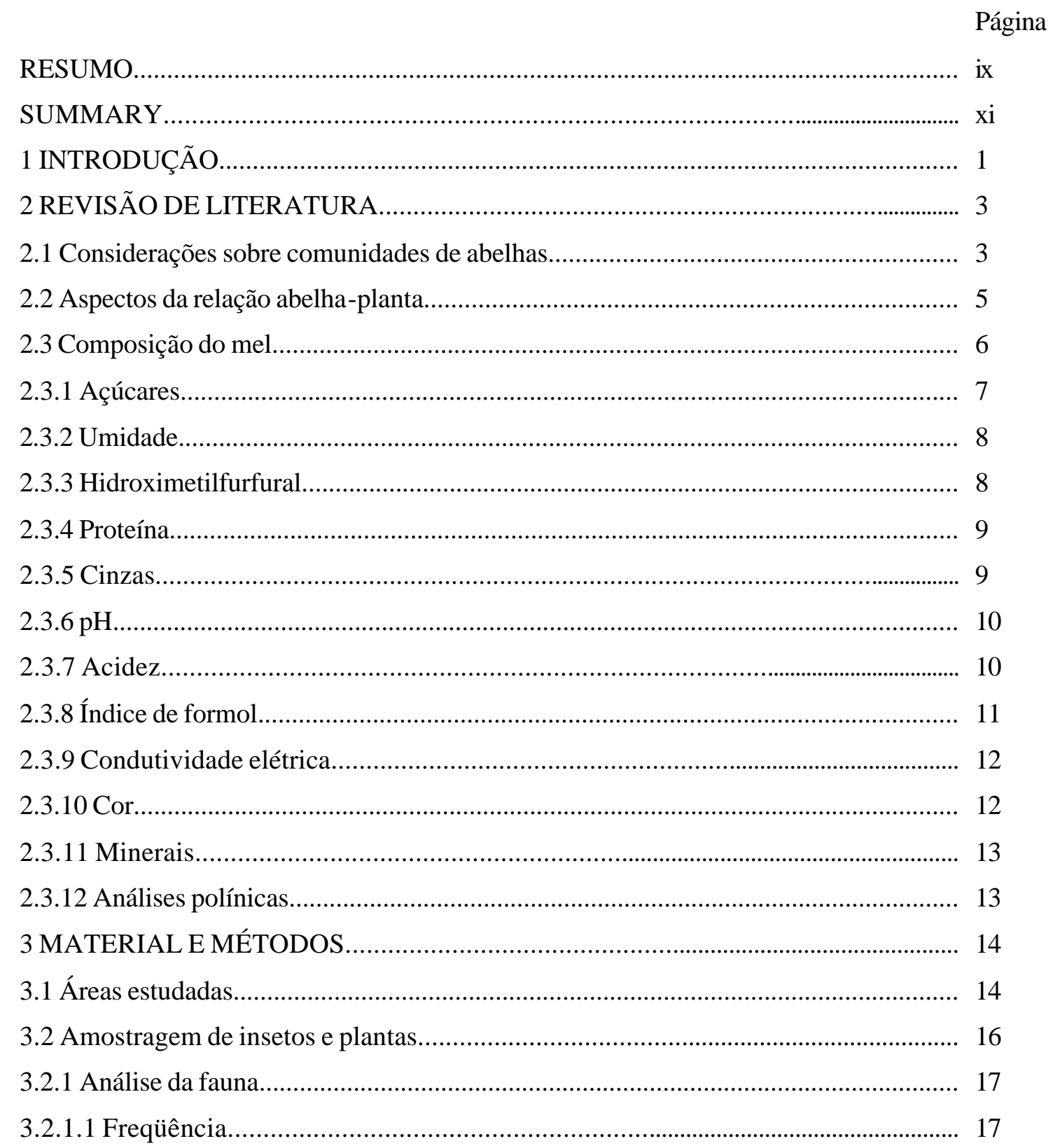




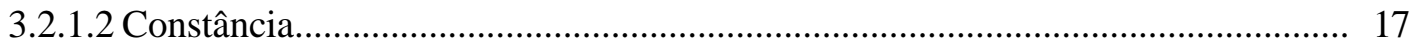

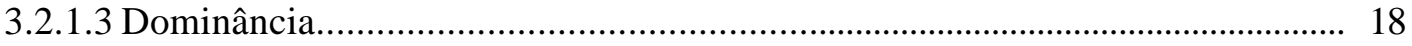

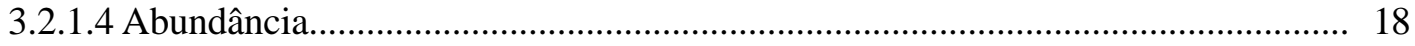

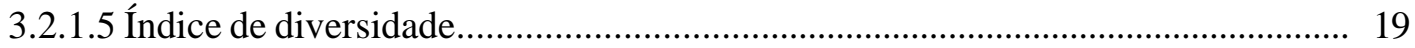

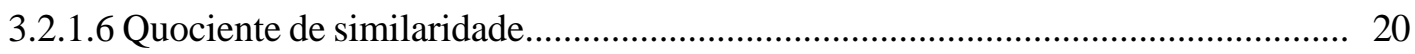

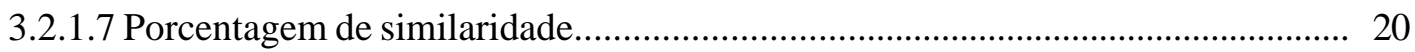

3.3 Localização e marcação das colônias................................................................... 20

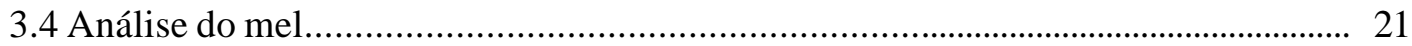

3.4.1 Açúcares totais, redutores e sacarose .................................................................. 21

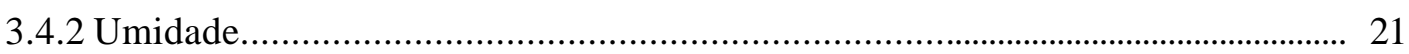

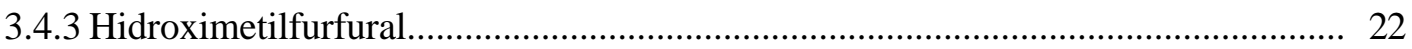

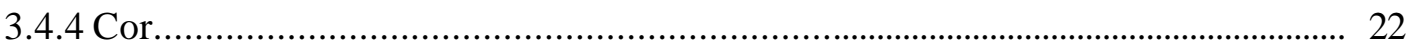

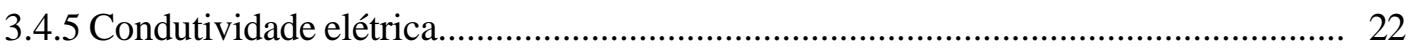

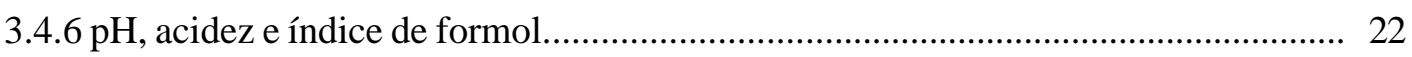

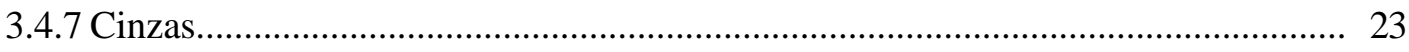

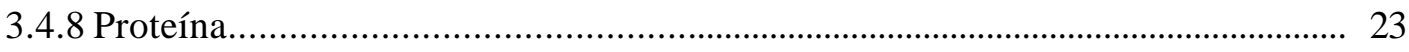

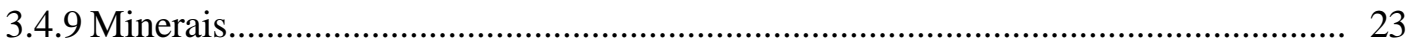

3.4.10 Análises polínicas do mel e do grão de pólen.................................................... 23

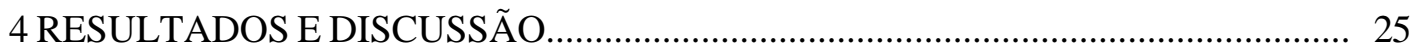

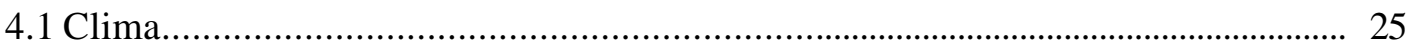

4.2 Composiç̧ão da flora e da fauna de abelhas.......................................................... 26

4.3 Composição físico-química das amostras de mel...................................................... 48

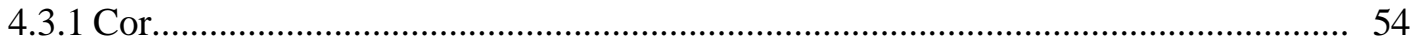

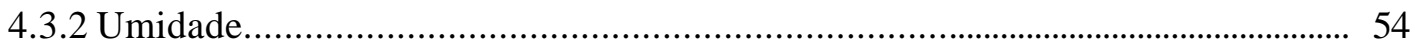

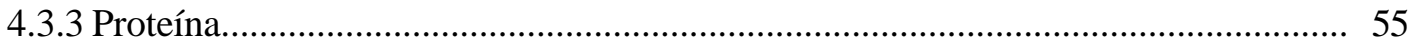

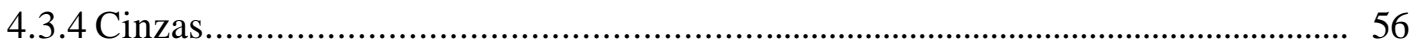

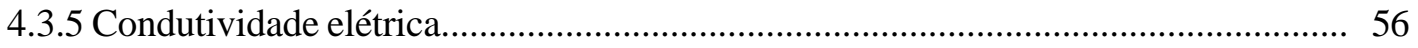

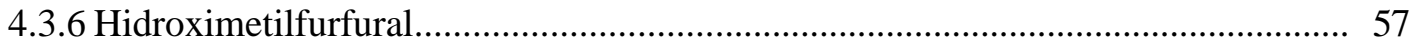

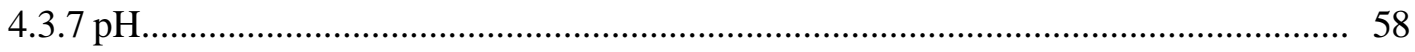

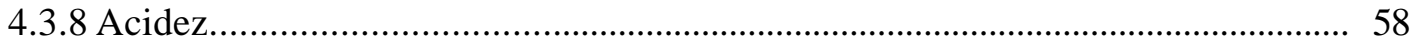

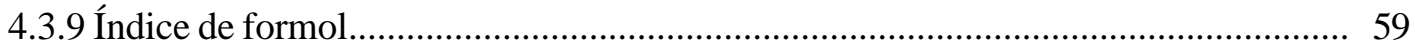

4.3.10 Açúcares totais, redutores e sacarose......................................................... 59 


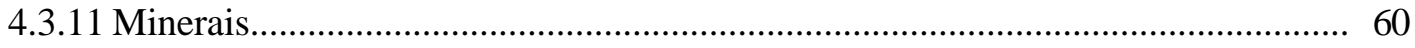

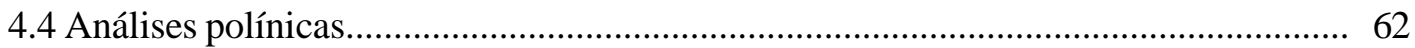

4.4.1 Análises polínicas das amostras de mel................................................................. 62

4.4.2 Análises polínicas das amostras mensais do pólen retirado dos coletores

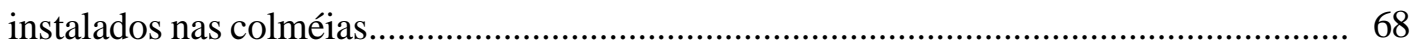

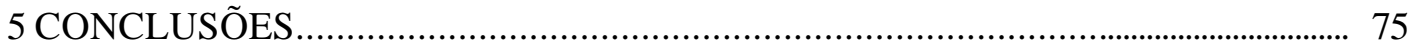

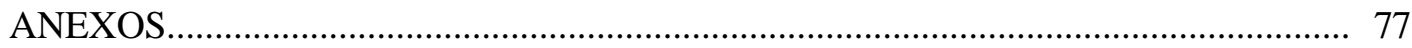

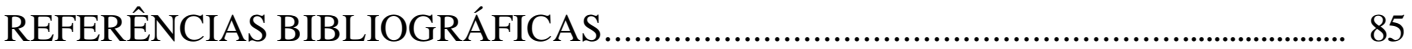




\section{ESPÉCIES DE ABELHAS (HYMENOPTERA, APOIDEA) E TIPIFICAÇÃO DOS MÉIS POR ELAS PRODUZIDOS EM ÁREA DE CERRADO DO MUNICÍPIO DE PIRASSUNUNGA, ESTADO DE SÃO PAULO.}

Autor: DANIELA DE ALMEIDA

Orientador: Prof. Dr. LUIS CARLOS MARCHINI

\section{RESUMO}

A comunidade de abelhas associada a uma área de cerrado do Campus da Universidade de São Paulo, no município de Pirassununga-SP foi estudada no período de julho de 2000 a julho de 2002, por meio de amostragem sistemática das abelhas em plantas com floração realizadas quinzenalmente, e com concomitante tipificação dos méis produzidos pelas espécies de abelhas que apresentaram um número significativo de indivíduos coletados. Foram coletados 511 indivíduos, pertencentes a 51 espécies e a 31 gêneros de 4 famílias de Apoidea. A comunidade de abelhas no cerrado seguiu o padrão geral encontrado nas comunidades neotropicais, apresentando muitas espécies com poucos indivíduos e poucas espécies com muitos indivíduos. A família Apidae (sensu latu) foi a mais rica em espécies e a mais abundante. Foram encontradas plantas com períodos prolongados de florescimento lado a lado com plantas de períodos curtos, de modo que praticamente o ano todo tem-se plantas em floração, proporcionando recursos tróficos para as abelhas durante todos os meses. As abelhas visitantes foram coletadas em 52,86\% das 140 espécies de plantas em floração, sendo a família Asteraceae a que obteve um maior número de espécies de plantas visitadas pelos insetos (18,92\%). Didymopanax vinosum 
(Araliaceae) foi a espécie vegetal com maior número de abelhas visitantes. Nas espécies de meliponídios estudadas obteve-se baixa produção, justificando o número restrito de colônias encontradas nas áreas. Os meses de maior produção de mel, para a Apis mellifera ocorreram de agosto a novembro, em contrapartida entre os meses de dezembro a fevereiro não foi possível a coleta de amostra. As médias dos parâmetros físico-químicos análisados, das amostras de méis provenientes das duas áreas de cerrado, se enquadram nos padrões de normas em vigor. Através das análises polínicas verificou-se que as abelhas também visitaram áreas vizinhas aos locais onde se encontravam as colméias, utilizando-se principalmente de Eucalyptus sp. e Citrus sp. 


\section{SPECIES OF BEES (HYMENOPTERA: APOIDEA) AND CARACTERIZATION OF THE HONEYS PRODUCED BY THEM IN THE “CERRADO”AREA OF THE MUNICIPALITY OF PIRASSUNUNGA, STATE OF SÃO PAULO, BRAZIL}

AUTHOR: DANIELA DE ALMEIDA

ADVISER: PROF. DR. LUÍS CARLOS MARCHINI

\section{SUMMARY}

This research deals with the community of bees from the "cerrado" área of the Campus of the University of São Paulo, in Pirassununga, State of São Paulo, Brazil. The bees occurring on flowering plants were fortnightly sampled from July 2000 to July 2002. The honeys produced by the most frequent bee species were characterized as well. The 511 collected specimens were composed by 51 species and 31 genera of 4 families of the Apoidea. The bee community of the "cerrado" followed the same general pattern of the neotropical communities, presenting many species with few individuals and few species with many individuals. The family Apidae ("sensu latu") was the most abundant one with the highest number of species. One observed long flowering period plants together with short flowering ones, thus providing nutritional resources for the bees the year round. Visiting bees were collected in $52.86 \%$ of the 140 flowering plant species, most of them (18.92\%) from the family Asteraceae. However Didimopanax vinosum (Araliaceae) was the plant species presenting the highest number of visiting bees. Concerning the species of meliponids studied the honey production was low due to the restricted number of colonies found in the area. As to Apis mellifera the honey production 
was higher from August to November, but it was impossible to collect samples from December to February. The mean of the physicochemical parameters used to analyse the honey samples from the two "cerrado" areas do fit with the standard rules. Through pollen analyses one observed that the bees have visited mainly plants of Eucalyptus sp. and Citrus sp. in the neighboring areas to their hives. 


\section{INTRODUÇÃ̃o}

Os estudos faunísticos são de extrema importância para o conhecimento das relações entre os seres vivos. Avaliações da diversidade tanto da fauna como da flora dos diversos ecossistemas é o ponto de partida para pesquisas mais específicas (Dantas et al., 1998).

O cerrado é uma formação xeromórfica que cobre cerca de $20 \%$ do território brasileiro, sendo que após a floresta amazônica, esta é a fisionimia vegetal mais representativa do Brasil (Eiten, 1972). No Estado de São Paulo, o cerrado aparece na forma de pequenas "manchas" esparsas, sendo mais contínuas ao norte do estado (Alonso, 1977).

A riqueza em plantas e animais tem um valor incalculável como patrimônio natural e é o resultado da evolução ocorrida em um determinado tempo cujas condições não mais serão repetidas (Tilman, 1996). Apesar disso, a redução da diversidade devido a simplificação dos ecossistemas e/ou por introdução de produtos tóxicos é o efeito direto ou indireto mais importante e irreversível das atividades humanas ao longo do século XX. Esses ecossistemas, embora não percam necessariamente a produção em biomassa, normalmente reduzem sua diversidade praticamente em todas as ocasiões (Dourojeanni, 1990; Halffter \& Ezcurra, 1996).

As abelhas pertencem a Ordem Hymenoptera e Superfamília Apoidea. Estima-se que existem mais de 4 mil gêneros e cerca de 25 a 30 mil espécies distribuídas nas diferentes regiões do mundo (Griswold et al., 1995).

Os Apoídeos são elementos impotantíssimos tanto para o homem como para o meio ambiente, seja pelos produtos de valor comercial fornecidos (mel, própolis, cera e geléia real) mas principalmente pela ação da polinização, por contribuir para o aumento da produção de frutos e sementes de diversos vegetais de interesse agroflorestal. Além disso, nos ecossistemas naturais desempenham papel importante na manutenção das comunidades de plantas e animais, por serem eficientes polinizadores de muitas espécies de angiospermas, que por sua vez, são responsáveis pela produção de alimentos utilizados por aves e mamíferos (Jazen, 1980; Wiese, 1985; Free, 1993).

As estratégias que contemplem a conservação de ecossistemas tropicais, como o cerrado, agregam aspectos econômicos e sociais concretos, tais como: manutenção e regularização dos mananciais hídricos que abastecem as grandes cidades, conservação da diversidade existente para uso futuro (especialmente na indústria farmacêutica) e exploração 
imediata ou atual dos recursos florestais múltiplos (mel, madeira, plantas ornamentais, plantas medicinais, frutíferas, caça controlada, etc.). Entretanto, a conservação destes ecossistemas envolve necessariamente alternativas de uso que permitam retorno econômico (Godoy \& Bawa, 1993; Godoy et al., 1993). Alternativas que propõem a obtenção de produtos que possam ser repostos pelo próprio ecossistema num ciclo definido, podem possibilitar renda aos proprietários da terra, e ao mesmo tempo manter o equilíbrio desejado destes ecossistemas (Reis e Mariot, 1999).

Pela sua natureza, a apicultura é uma atividade conservadora das espécies, sendo uma das poucas atividades agropecuárias que preenche todos os requisitos do tripé da autosustentabilidade: o econômico, porque gera renda para o agricultor; o social, porque ocupa mão-de-obra familiar no campo; e o ecológico, porque não se desmata para criar abelhas (Alcoforado-Filho, 1998)

Apesar da importância das abelhas em diferentes ecossistemas, as mudanças causadas por atividades antrópicas têm promovido alterações nas condições do seu habitat, comprometendo a diversidade devido a destruição de locais usados para nidificação, redução na disponibilidade dos recursos tróficos e eliminação de colônias naturais (O’Toole, 1993; Kerr et al., 1996; Matheson et al.,1996).

Devido o interesse pela apicultura no Estado de São Paulo, e a escassez de informações sobre a composição da fauna de abelhas que ocorre em vegetação de cerrado, pesquisas nessas áreas se fazem necessárias, tanto para determinar padrões das comunidades de abelhas, como para possibilitar estratégias futuras de utilização racional da fauna apícola e de conservação das espécies dessa região.

O objetivo deste trabalho é conhecer a composição das espécies de abelhas e das plantas visitadas, contribuindo para o conhecimento da estrutura da comunidade de abelhas de duas áreas de cerrado do Campus da Universidade de São Paulo, no município de Pirassununga, SP ( $21^{\circ} 57^{\prime} 02^{\prime} \mathrm{S}, 47^{\circ} 27^{\prime} 50^{\prime} \mathrm{W}$ e $630 \mathrm{~m}$ de altitude), além da caracterização físico-química e polínica do mel produzido pelas espécies de abelhas identificadas como as mais importantes pa o referido local, dentro do universo das abelhas melíferas de interesse comercial. 


\section{REVISÃO DE LITERATURA}

\subsection{Considerações sobre comunidades de abelhas}

A comunidade é o agrupamento natural das populações de diferentes espécies com capacidade de sobrevivência e sustentação própria, localizado em uma determinada região geográfica ou biótopo. As associações biológicas entre essas espécies são denominadas de biocenoses (Silveira-Neto et al., 1976).

O conhecimento da fauna de abelhas e suas relações com as flores é de importância fundamental para o conhecimento de alguns elementos da estrutura de comunidade. Isto pode ser definido por vários parâmetros, entre os quais inclui-se diversidade de espécies e padrões de dominância, estrutura trófic a e diversidade de tipos reprodutivos (Heithaus, 1974).

Nos estudos sobre comunidades de abelhas a abordagem desses padrões é facilitada pela possibilidade de observação e captura de um grande número de indivíduos que utilizam recursos distintos e mensuráveis (Heithaus, 1979).

Um dos aspectos importantes nos estudos ecológicos sobre insetos é o número de espécies e de indivíduos existentes na comunidade, assim como, a comparação entre diferentes comunidades (Lewis \& Taylor, 1976).

A maior parte da teoria ecológica sobre comunidade é baseada no presuposto de que os recursos são limitados, e que a competição que necessariamente resulta desses recursos, afeta a estrutura das comunidades (Campos, 1989).

A composição taxonômica e a diversidade de espécies são dis modos possíveis de descrever uma comunidade (Begon et al., 1996). Os taxonomistas que trabalham exclusivamente com abelhas seguem a classificação tradicional para o nível de família com as modificações propostas por Roig-Alsina \& Michener (1993). Esses autores estudaram as relações filogenéticas entre Apidae e Anthophoridae, concluindo que os anthoforídeos devem ser incluídos em Apidae. De acordo com essa classificação, a composição da categoria de famílias de abelhas que ocorrem no Brasil passou a ser Andrenidae, Apidae, Colletidae, Halictidae e Megachilidae. 1

\footnotetext{
${ }^{1}$.DUKE, A. Explorações botânicas e entomológicas no Estado do Ceará. Revista Trimestral do Instituto do Ceará, v. 24, p. 3-61, 1910.
} 
O procedimento de amostragem das abelhas para estudos ecológicos pode ser baseado em diferentes métodos. Entre esses, Roubik (1989) destaca a utilização de ninhos armadilhas, iscas atrativas com substâncias odoríferas, armadilha luminosa, armadilha tipo Malaise e captura direta nas flores.

As amostragens periódicas das abelhas nas flores permitem diversas análises no estudo da estrutura de comunidade, gerando informações sobre a diversidade das espécies de abelhas e plantas, amplitude e sobreposição nos recursos utilizados, interações entre espécies e atividade sazonal das abelhas (Knoll, 1990).

No Brasil, os primeiros levantamentos relacionandos a abelhas e flores foram os realizados por Ducke ${ }^{1}$, citado por Viana (1992), no Estado do Pará. No final da década de 60, Sakagami et al. (1967) desenvolveram, no estado do Paraná, um método para obter amostras padronizadas de abelhas (Hymenoptera: Apoidea) coletadas nas flores. A metodologia preconiza a coleta individual das abelhas nas flores ou em vôo, seguida por uma varredura em cada planta com flores através de redes entomológicas, sem qualquer tipo de escolha, permitindo a obtenção de dados qualitativos e quantitativos das comunidades de abelhas e plantas visitadas (Sakagami et al., 1967; Sakagami \& Matsumura, 1967).

Praticamente todos os estudos de comunidades de abelhas desenvolvidos no Brasil, nos últimos 30 anos (aproximadamente 50 levantamentos) basearam-se na metodologia citada. Os resultados estão publicados em artigos e teses provenientes de diversos grupos de pesquisadores brasileiros (Sakagami \& Laroca, 1971; Cortopassi-Laurino, 1982; Imperatriz-Fonseca et al., 1989, Ramalho et al., 1989; Campos, 1989; Camargo \& Mazucato, 1984; Camillo \& Garófalo, 1989; Silveira, 1989; Bortoli \& Laroca, 1990; Knoll, 1990; Wittmann \& Hoffmann, 1990; Martins, 1990; Pedro, 1992; Viana, 1992; Cure et al., 1993; Barbola \& Laroca, 1993; Schwartz Filho, 1993; Silveira \& Rocha, 1993; Castro, 1994; Carvalho \& Marques, 1995; Sofia, 1996; Carvalho et al., 1997; Zanella et al., 1998; Oliveira, 1998; Mateus, 1998; Carvalho \& Marchini, 1999a; b; Carvalho, 1999; Castro, 2001).

\subsection{Aspectos da relação abelha-planta}

Entre todos os possíveis agentes polinizadores das plantas, as abelhas destacam-se por sua dependência em visitar flores para obterem seus alimentos: pólen e néctar, enquanto a 
maioria dos outros polinizadores potenciais só visitam as flores para satisfazerem suas necessidades imediatas e quase sempre não as tem como suas única fontes de alimento. As abelhas, de um modo geral, alimentam-se quase que exclusivamente de pólen e néctar e precisam visitar grandes quantidades de flores diariamente para satisfazerem suas necessidades individuais, das crias e/ou da colônia. Esse trabalho incansável de visitação às flores faz das abelhas os principais agentes polinizadores das plantas(Corbet et al., 1991; Free, 1993).

A eficiência polinizadora de qualquer visitante floral está intimamente relacionada com a biologia floral da planta e o comportamento do animal. Durante milhões de anos as flores desenvolveram mecanismos como pétalas coloridas, odores e recompensas de néctar, pólen, essências e óleos para atraírem interessados e obterem polinização(Freitas, 1998).

As características das flores visitadas pelas abelhas são muito variadas, mas geralmente possuem coloração brilhante ou refletem o ultravioleta, são aromáticas e fornecem quantidades moderadas de néctar (Proctor et al., 1996).

Segundo Simpson \& Neff (1981), o néctar é a substância mais importante na atração das abelhas pelas plantas, embora os óleos utilizados na composição de alimentos, as ceras e resinas utilizadas na construção de ninhos, também sejam eficientes na atratividade da flor. As flores das plantas consideradas nectaríferas devem secretar abundantemente o néctar com concentração elevada de açúcares (Castro, 1994).

As principais condições para uma planta ser considerada apícola, de acordo com Castro (1994), são: ser abundante na região, florescer copiosamente e de preferência por um período prolongado e possuir néctar e/ou pólen acessíveis às abelhas. Por outro lado, Silveira (1983) considera como flora apícola o conjunto de plantas que fornecem alimento para as abelhas em uma determinada região.

Bawa (1983) observou que os padrões de florescimento são variáveis e apresentam implicações em muitos aspectos da organização e estrutura das comunidades. Essas variações aparentemente são moldadas por um conjunto de pressões seletivas, como a competição interespecífica por polinizadores, a disponibilidade de polinizadores, a seleção contra o fluxo gênico interespecífico e a natureza das recompensas florais oferecidas.

A atratividade de uma florada pode ser influenciada pela quantidade do pólen produzido, a concentração e abundância das flores, o número de insetos competidores, a distância entre a florada e o ninho e a preferência inata da espécie. Entretanto, esses fatores ainda estão sujeitos a 
variações como o tamanho da flor, a umidade relativa do ar, a umidade do solo, a temperatura, a altitude, as horas do dia e a duração do dia (Bawa, 1983; Castro, 1994).

A maioria da flora encontrada em muitas comunidades depende das abelhas para efetuar a polinização, como várias espécies de Caesalpiniaceae e Fabaceae. Para representantes das famílias Bignoniaceae, Lamiaceae e Scrophulariaceae a ausência das abelhas poderia causar o desaparecimento dessas plantas nas áreas onde normalmente são encontradas (Neff \& Simpson, 1993).

Como em outros tipos de vegetação tropical, as abelhas representam os principais polinizadores de plantas do cerrado, constituindo o grupo mais importante, tendo sido observadas como polinizadoras de 60 a $75 \%$ das espécies estudadas por Silberbauer-Gottsberger \& Gottsberger, 1988.

\subsection{Composição do mel}

O mel é resultado da desidratação e transformação do néctar das plantas pelas abelhas. A quantidade de mel que pode ser obtida de uma determinada planta varia com os fatores que influenciam a produção e a concentração de néctar e, ainda, com a concentração e proporções de seus carboidratos, com a quantidade de flores da área e com o número de dias em que as flores estão secretando néctar (Crane, 1975).

A composição do mel depende, basicamente, da composição do néctar de cada espécie vegetal produtora, conferindo-lhe características específicas enquanto que as condições climáticas e o manejo do apicultor têm influência menor (White Júnior, 1978).

As características físico-químicas e polinícas do mel ainda são pouco conhecidas, principalmente nas regiões tropicais onde existe elevada diversidade de flora apícola associada às taxas elevadas de umidade e temperatura (Sodré, 2000).

É de fundamental importância a caracterização dos méis visando a criação de padrões, segundo os fatores edafo-climáticos e florísticos das regiões, estabelecendo critérios comparativos nas análises, e controlando possíveis fraudes desse produto (Crane, 1990).

Os trabalhos de análises físico-químicas de méis visam comparar os resultados obtidos com padrões ditados por órgãos oficiais internacionais, ou com os estabelecidos pelo próprio país, deixando claro não só uma preocupação com a qualidade do mel produzido internamente, 
como também, torna possível a fiscalização de méis importados com relação a sua alteração (Marchini, 2001).

\subsubsection{Açúcares}

Os açúcares encontrados no mel são: glicose, frutose, sacarose, maltose, isomaltose, eilose, questose, melezitose, rafinose, dextrantiose, 4 glicosildextrantriose e um oligossacarídeo. Estes açúcares influenciam na viscosidade, higroscopicidade, granulação e valor energético dos méis (White Júnior, 1979).

Os monossacarídeos constituem a maior parte do mel, variando de $85 \%$ a $95 \%$ da sua composição. Entre eles a glicose, por ter pouca solubilidade, determina a tendência da cristalização do mel, e a frutose por ter alta higroscopicidade possibilita a doçura do mel, segundo White Júnior, 1979; Horn et al., 1996; Seemann \& Neira, 1988.

Entre os dissacarídeos a sacarose representa, em média, 2 a $3 \%$ dos carboidratos e quando superior a este valor, geralmente indica um mel verde ou adulterado. Ela pertence aos oligossacarídeos e quando sofre a hidrólise, pela ação de ácidos diluídos ou enzimas (invertase), resulta em dois monossacarídeos frutose e glicose (Vidal \& Fregosi, 1984).

Em trabalhos desenvolvidos por: Dozo (1980); Salashinski et al. (1980); Nauta (1983); Poncini \& Wimmer (1983); Archentini (1984); Tuveri \& Prosperi (1985); Amaral et al. (1986); Colin et al. (1986); Moraes \& Mantovani (1986); Hankin (1987); Lower (1987a,b); Mesallan \& El-Shaarawy (1987); Olek et al. (1987); Cornejo (1988); Del Lungo et al. (1991); Martinez et al. (1993); Bastos \& Silva (1994); Komatsu (1996); Komatsu \& Marchini (1998); Andrade et al. (1999); Costa et al. (1999); Uñates et al. (1999); Sodré (2000) e Marchini (2001) é possível observar valores para açúcares redutores de 56,2 a $95 \%$ e para sacarose de 0,4 a $11 \%$.

\subsubsection{Umidade}

$\mathrm{Na}$ composição do mel a água constitui o segundo componente em quantidade, geralmente variando de 15 a $21 \%$, dependendo do clima, origem foral e colheita antes da completa desidratação. Normalmente o mel maduro tem menos de $18,5 \%$ de água. O conteúdo de água no mel é, sem dúvida, uma das características mais importantes, por influenciar na sua 
viscosidade, peso específico, maturidade, cristalização, sabor, conservação e palatabilidade conforme Seemann \& Neira, 1988. Segundo White Júnior (1978) os microorganismos osmofílicos (tolerantes ao açúcar), presentes nos corpos das abelhas, no néctar, no solo, nas áreas de extração e armazenamento podem provocar fermentação no mel quando o teor de água for muito elevado.

Autores como: Flechtmann et al. (1963); Phadke (1967); El-Sherbiny et al. (1980); Butta et al. (1983); Nauta (1983); Poncini \& Wimmer (1983); Archentini (1984); Poncini et al.(1984); Tuveri \& Prosperi (1985); Colin et al. (1986); Faraji-Haremi \& Hosseini (1987); Hankin (1987); Vit (1988); Kassaye \& Gardegaba (1989); Moraes et al. (1989); Cortopassi-Laurino \& Gelli (1991); Stonoga \& Freitas (1991); Bastos e Silva (1994); Vit et al. (1994); Komatsu (1996); Rendón (1996); Bogdanov et al. (1997); Abdelnur et al. (1998); Costa et al. (1999); Azeredo \& Azeredo (1999); Sodré (2000) e Marchini (2001), obtiveram teor de água, em porcentagens, que se encontram dentro da faixa de variação de 13 a 30,5\%.

\subsubsection{Hidroximetilfurfural}

O hidroximetilfurfural (HMF) é formado pela reação de certos açúcares em presença de ácidos. O seu conteúdo pode aumentar com a elevação da temperatura, com armazenamento do mel, adição de açúcar invertido, podendo ser afetado pela acidez, pH, água e minerais no mel de acordo com citação de White Júnior, 1976; Seemann \& Neira, 1988; Salinas et al., 1991.

Conforme Veríssimo (1988) o HMF é um indicador de qualidade no mel, visto que, quando elevado indica uma queda no seu valor nutritivo, pela destruição, por meio de aquecimento, de algumas vitaminas e enzimas que são termolábeis.

Os valores de HMF encontrados por Wootton \& Ryall (1975); White Júnior (1980); Thrasyvoulou et al. (1982); Butta et al. (1983); Nauta (1983); Piazza \& Accorti (1983); Spettoli et al. (1983); Temiz (1983); Reio \& Englund (1985); Tuveri \& Prosperi (1985); Hase \& Aida (1986); Thrasyvoulou (1986); Lower (1987a,b); Mesallan \& El-Shaarawy (1987); Tabio et al. (1987); Balenovic et al. (1988); Cornejo (1988); Papoff et al. (1988); Vit (1988); Bricage (1989);

Frias-Tejera \& Torre (1990); Del Lungo et al. (1991); White Júnior (1991); Escobar-Martinez et al. (1992); Sancho et al. (1992); Martinez et al. (1993); Thrasyvoulou et al. (1994); Marchini et 
al. (1996); Rendón (1996); Bogdanov et al. (1997); Issa et al. (1998); Costa et al. (1999); Sodré (2000) e Marchini (2001) estão numa faixa de variação de 0,5 a $241 \mathrm{mg} / \mathrm{kg}$ de mel.

\subsubsection{Proteína}

Apesar do pouco conhecimento sobre as características do material proteico, a ocorrência de proteína em mel é utilizada na detecção de adulteração do produto comercial (Crane, 1975).

Dentre os aminoácidos encontrados no mel, a prolina é o que está presente em maior quantidade, representando cerca de $50-85 \%$ do total.

Segundo os trabalhos de White Júnior \& Rudyj (1978); Archenti (1984); Almeida e Marchini (1986); Amaral et al. (1986); Imperatriz- Fonseca et al. (1987); Lower (1987b); Mesallan \& El-Shaarawy (1987); Escobar-Martinez et al. (1992); Baldi Coronel et al. (1993); Peng \& Pan (1994); Komatsu (1996); Bath \& Singh (1999); Sodré (2000) e Marchini (2001) os valores de proteína estão compreendidos numa faixa de variação entre 0,2 a 2,8\%.

\subsubsection{Cinzas}

O teor de cinzas expressa a riqueza do mel em minerais, e constitui-se num parâmetro bastante utilizado nas determinações que visam verificar sua qualidade. Os sais minerais encontrados no mel podem ser modificados por fatores relativos às abelhas, ao apicultor, clima, solo e flora (Lasceve \& Gonnet, 1974).

Segundo Bogdanov (1999) o conteúdo de cinzas no mel é um critério de qualidade e está relacionado com a sua origem botânica. Assim o mel de origem floral tem menos cinzas que o mel de "honeydew".

Vermeulen \& Pelerents (1965) relataram a possibilidade de modificações do espectro mineral do mel devido a uma quantidade maior do pólen, mel prensado ou colhido de favo com pólen.

Para Ortiz (1988) o conteúdo de cinzas está correlacionado com a cor do mel, pois quanto mais escuro é o mel mais cinzas ele contém. 
Em trabalhos para determinar o teor de cinzas, autores como: Ibrahim et al. (1977); Accorti et al. (1986); Olek et al. (1987); Ortiz (1988); Pamplona (1989); Baldi Coronel et al. (1993); Bastos e Silva (1994); Rendón (1996); Mendes et al.(1998); Al-Khalifa \& Al-Arify (1999); Sodré (2000) e Marchini (2001) observaram valores que estão numa faixa de variação de 0,02 a $0,9 \%$ para méis de diferentes origens.

\subsection{6 pH}

$\mathrm{O}$ pH determinado no mel refere-se aos íons hidrogênio presentes numa solução e pode influenciar na formação de outros componentes, como na velocidade de produção do hidroximetilfurfural (HMF) (Vidal \& Fregosi, 1984).

Todos os méis são ácidos e o pH é influenciado pela origem botânica, pela concentração de diferentes ácidos e pelo cálcio, sódio, potássio, e autros constituintes das cinzas (Seeman \& Neira, 1988; Frías \& Hardisson, 1992).

Em trabalhos para determinar o pH de diferentes tipos de méis Flechtmann et al. (1963); Poncini \& Wimmer (1983); Spettoli et al. (1983); Temiz (1983); Faraji-Haremi \& Hosseini (1987); Lower (1987,b); Olek et al. (1987); Gómez et al. (1990); Peréz et al. (1990); CortopassiLaurino \& Gelli (1991); Escobar-Martinez et al. (1992); Fernández-Salguero \& Gómez (1992); Frías \& Hardisson (1992); Baldi Coronel et al. (1993); Crecente \& Latorre (1993); Gomez et al. (1993); Martinez et al. (1993); Bastos \& Silva (1994); Thrasyvoulou \& Manikis (1995); Horn et al. (1996); Rendón (1996); Andrade et al. (1999); Sodré (2000) e Marchini (2001) obtiveram valores que estão compreendidos entre 2,3 e 6,7.

\subsubsection{Acidez}

A acidez é um importante componente do mel pois contribui para a sua estabilidade, frente ao desenvolvimento de microorganismos.

Os ácidos dos méis estão dissolvidos em solução aquosa e produzem íons de hidrogênio que promovem a sua acidez ativa, permitindo assim, indicar as condições de armazenamento e o processo de fermentação (Cornejo, 1988).

Foram encontrados no mel os ácidos: acético, benzóico, butírico, cítrico, fenilacético, fórmico, glucônico, isovalérico, láctico, maléico, oxálico, propiônico, piroglutânico, succínico 
valérico. O ácido glucônico em equilíbrio com a glucono-lactona, formado pela ação da glicose oxidase, é o principal deles (Seemann \& Neira, 1988).

Segundo Frias \& Hardisson (1992) a ação de transformação é mais lenta em méis mais densos e é influenciada pela quantidade de ácidos obtidos no tempo que transcorre entre a coleta do néctar e o máximo do volume do néctar que é depositado nos favos.

Verificando a acidez de diferentes tipos de méis White Júnior (1976); Butta et al. (1983); Nauta (1983); Spettoli et al. (1983); Temiz (1983); Tuveri \& Prosperi (1985); Pfau \& Ruhle (1986); Faraji-Haremi \& Hosseini (1987); Mesallan \& El-Shaarawy (1987); Olek et al. (1987); Cornejo (1988); Peréz et al. (1990); Del Lungo et al. (1991); Sancho et al. (1992); FernándezSalguero \& Gómez (1992); Baldi Coronel et al. (1993); Crecente \& Latorre (1993); Gomez et al. (1993); Kim et al. (1993); Carvalho et al. (1998); Mendes et al. (1998); Andrade et al. (1999); Uñates et al. (1999); Sodré (2000) e Marchini (2001) encontraram valores que estão na faixa de 8,2 a $50,0 \mathrm{meq} / \mathrm{kg}$.

\subsection{8 Índice de formol}

O índice de formol é importante no mel por representar, predominantemente, os compostos aminados, permitindo assim, avaliar o conteúdo em peptídios, proteínas e aminoácidos (McGregor, 1979).

É um importante componente indicador de adulteração, pois quando muito baixo pode indicar a presença de produtos artificiais, enquanto excessivamente alto, mostra que as abelhas foram alimentadas com hidrolizado de proteínas (Simal \& Huidobro, 1984). Assim, o índice de formol pode ser utilizado para comprovar a autenticidade do mel.

Os autores Temiz (1983); Komatsu (1996); Carvalho et al. (1998); Andrade et al. (1999) obtiveram valores que estão entre 0,4 e 21,5 meq/100g para diferentes tipos de méis.

Sodré (2000) e Marchini (2001) encontraram valores entre 1,67 e 29 ml/kg para méis silvestres e de flores de eucalipto.

\subsubsection{Condutividade elétrica}


A condutividade elétrica pode ser utilizada como método suplementar na determinação da origem botânica do mel (Aganin, 1971).

A condutividade elétrica tem correlação com o conteúdo de cinzas, $\mathrm{pH}$, acidez, sais minerais, além da proteína e outras substâncias presentes no mel (Stefanini, 1984; Crane, 1990; Bogdanov, 1999).

Autores como: Persano-Oddo et al. (1995); Thrasyvoulou \& Manikis (1995); Horn et al. (1996); Rendón (1996); Campos (1998); Carvalho et al. (1998); Andrade et al. (1999); Carvalho et al. (2000); Sodré (2000) e Marchini (2001) obtiveram valores de condutividade elétrica de méis de diferentes origens entre 90 e $2110 \mathrm{uS}$.

\subsubsection{Cor}

A cor é uma das características do mel que mais influencia na preferência do consumidor, que, na maioria das vezes, escolhe o produto apenas pela aparência. Tal é a relevância deste parâmetro que o International Trade Forum (1977) considerou a cor como uma das características do mel que tem particular importância no mercado internacional.

A cor do mel está correlacionada com a sua origem floral, processamento e armazenamento, fatores climáticos durante o fluxo do néctar e a temperatura na qual o mel amadurece na colméia (Seemann \& Neira, 1988).

Segundo Bath \& Singh (1999) a proporção de frutose, glicose, conteúdo de nitrogênio e aminoácidos livres, a reação de substâncias polifenólicas como sais de ferro, o conteúdo de minerais e a instabilidade da frutose em solução ácida, são fatores que determinam a velocidade do escurecimento do mel.

Os autores Escobar-Martinez et al. (1992); Baldi Coronel et al. (1993); Gomez et al (1993); Campos (1998); Carvalho et al. (1998); Azeredo \& Azeredo (1999); Uñates et al. (1999) e Carvalho et al. (2000) analisaram a cor de méis de diferentes origens e obtiveram uma predominância da cor clara sobre a escura.

\subsubsection{Minerais}


O conteúdo de minerais, muitas vezes referido como metais, também é considerado na maioria das análises físico-químicas dos méis. Os minerais influem diretamente na coloração do mel, estando presente em maior concentração nos méis escuros em comparação com os claros.

Já foram identificados no mel inúmeros elementos químicos: $\mathrm{K}, \mathrm{Na}, \mathrm{Ca}, \mathrm{Mg}, \mathrm{Mn}, \mathrm{Ti}, \mathrm{Co}$, Mo, Fe, Cu, Li, Ni, Pb, Sn, Zn, Os, Ba, Ga, Bi, Ag, Au, Ge, Sr, Be, Va, Zn (White Júnior, 1979).

Em trabalhos sobre minerais no mel: Smith (1966); Varju (1970); Shavonov \& Ibrishimov (1975); White Júnior (1979); D’Ambrosio \& Marchesini (1982);Ivanov \& Chervenakova (1984); Gajek et al. (1987); Marchini et al. (2000) e Marchini (2001) encontraram níveis bastante variáveis em função da origem botânica e solo.

\subsubsection{Análises polínicas}

O conhecimento da origem floral dos méis é muito importante para a caracterização do produto. Assim, a análise polínica do mel é um importante instrumento para o reconhecimento das plantas apícolas utilizadas pelas abelhas, como suprimento de néctar e pólen (Hower, 1953).

O pólen que aparece no mel, constitui importante indicador de sua origem botânica e, principalmente, geográfica e é coletado involuntariamente pelas abelhas no momento da coleta do néctar (Barth, 1989). Por meio da análise quantitativa de grãos de pólen, é possível estabelecer a proporção com que cada planta nectarífera contribui para a constituição do mel (Iwama \& Melhem, 1979).

Trabalhos desenvolvidos por Santos (1961, 1964, 1974); Barth (1970 a,b,c, 1971, 1989, 1990); Durkee (1971); Cortopassi-Laurino \& Gelli (1991); Freitas (1991); Seijo et al. (1992); Bastos et al. (1995); Magalhães et al. (1996); Marchini et al. (1997); Bastos (1998); Moreti et. al. (1998, 2000); Carvalho et. al. (1999) e Costa et al. (1999) evidenciam a importância do pólen encontrado no mel, para o conhecimento da origem botânica e geográfica da planta fornecedora, aumentando assim, a utilização desses recursos tróficos. 


\section{MATERIAL E MÉTODOS}

\section{1 Áreas estudadas}

O desenvolvimento da pesquisa se deu em áreas remanescentes de cerrado do Campus da Universidade de São Paulo, no município de Pirassununga-SP, situado entre as coordenadas $21^{\circ} 57^{\prime} 02$ 'S , $47^{\circ} 27^{\prime} 50^{\prime \prime} \mathrm{W}$ e $630 \mathrm{~m}$ de altitude.

A área total do Campus compreende cerca de 2.269 ha, ocupados por diferentes fisionomias de cerrado, além de áreas de cultivo e pastagens. As florestas preservadas (cerrado sensu strictu, cerradão e floresta ciliar) correspondem a 30\% da área total ou 705 ha, enquanto as áreas de pastagens e cultivos ocupam proximadamente $70 \%$ da área total ou 1.620 ha (Figura 1).

Foram avaliadas duas áreas distintas: 1- cerradão que possui aproximadamente 56ha, sendo uma floresta secundária onde a ação antrópica está sendo controlada a mais de 20 anos, estando ausente qualquer ocorrência de fogo neste período. Nesta área o solo é classificado como Latossolo Vermelho-Escuro (Formação Pirassununga-Plio-Pleistoceno), texturas variando de barro-argiloso-arenoso, argilo-arenoso grosso e fino até solo argiloso, onde o dossel da vegetação alcança alturas de 15 a 20m; 2- cerrado senso strictu que localiza-se a $1 \mathrm{~km}$ do remanescente do cerradão e é caracterizada por flora arbustiva, com no máximo $6 \mathrm{~m}$ de altura, além de lianas e várias espécies herbáceas. Este fragmento possui cerca de 93 ha e o solo é do tipo Latossolo-Vermelho-Amarelo, texturas variando do argilo-arenoso grosso e fino até solo arenoso.

FINA (1999) constatou na presente área uma composição florística bastante variada com 167 espécies, distribuídas em 118 gêneros e 52 famílias. As famílias mais ricas são as Myrtaceae (15 espécies), Rubiaceae (14) e Fabaceae (10), os gêneros mais ricos Miconia e

Psychotria com 6 espécies cada e Myrcia e Eugenia, com 4 espécies cada, sendo, segundo a literatura, vários destes gêneros, fontes de néctar e pólen para diferentes espécies de abelhas. 

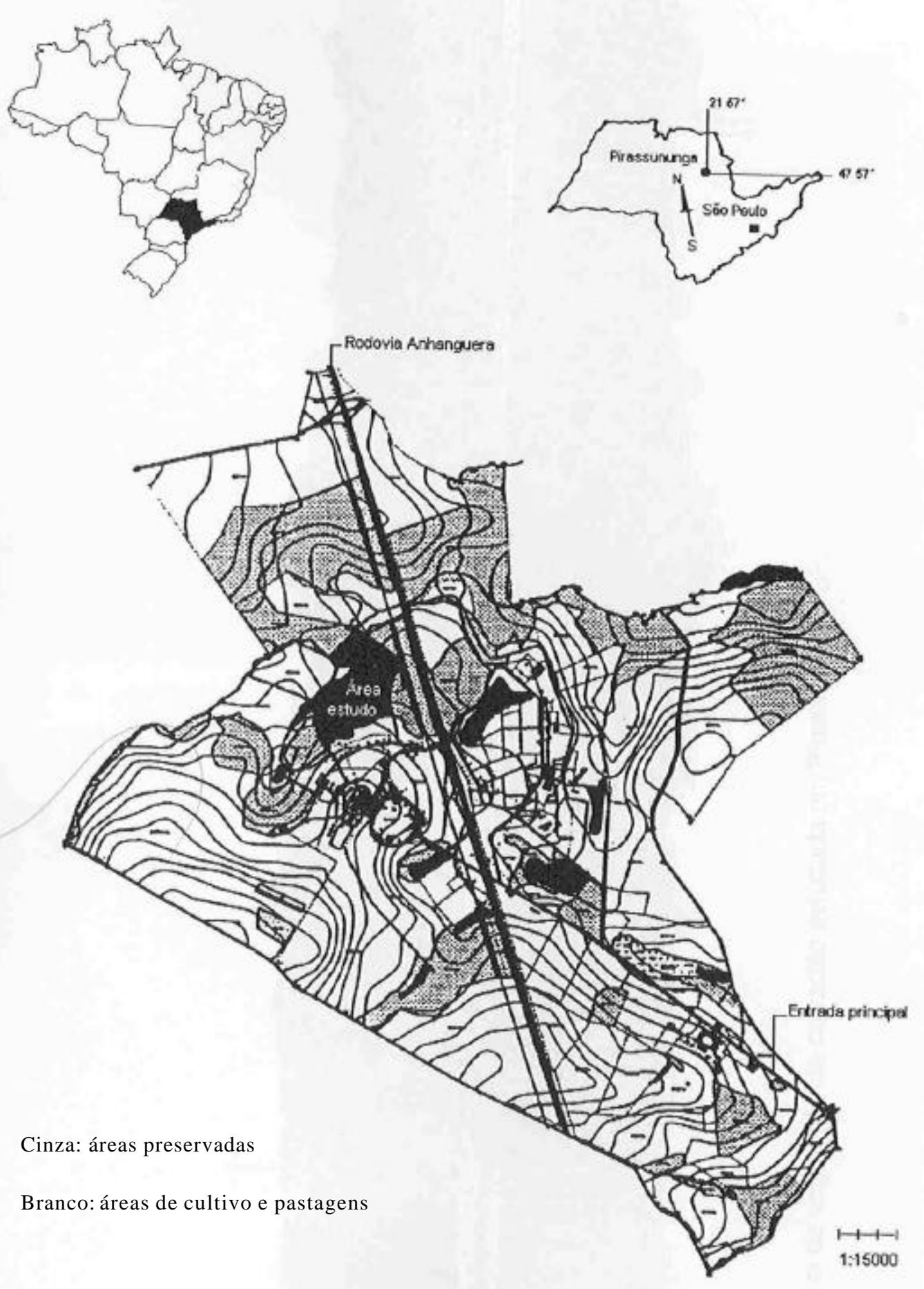

Figura 1 - Localização do município de Pirassununga-SP, Campus da Universidade de São Paulo, destacando-se a área estudada. 


\subsection{Amostragem de insetos e plantas}

Os levantamentos quinzenais das abelhas e das plantas visitadas por elas teve início em agosto/2000 e conclusão em julho/2001, sendo realizado por 2 coletores, utilizando-se de redes entomológicas. Os coletores deslocaram-se ao longo de trilhas pré-determinadas, com 3.000 metros de extensão e dois metros de largura baseando-se na metodologia estabelecida por Sakagami et al. (1967) e Carvalho (1999). As coletas foram realizadas das 6 às 18 horas, iniciando, cada coleta, num local da extensão desta trilha, capturando as abelhas que visitavam as plantas em floração, ou as que estivessem voando nas proximidades. O percurso foi realizado duas vezes durante as coletas (manhã e tarde), sendo gastos de 5 a 10 minutos por planta.

As abelhas coletadas foram mortas com éter e colocadas em sacos plásticos, sendo anotada a data e o período da coleta (manhã/tarde), bem como, a planta visitada. Todo o material coletado foi levado ao laboratório, os espécimes montados em alfinetes entomológicos e agrupados para posterior identificação.

A classificação dos espécimes capturados foi realizada por comparação do material existente na coleção de insetos do museu que se encontra no Departamento de Entomologia, Fitopatologia e Zoologia Agrícola da ESALQ - Piracicaba/SP, e quando necessário foi devidamente encaminhado para especialistas pertinentes, Prof. Dr. João Maria Franco de Camargo (Departamento de Entomologia - FFCLRP/USP-Ribeirão Preto/SP) e Prof. Dr. Edilberto Giannotti (Instituto de Biociências - UNESP-Rio Claro/SP).

As plantas coletadas foram todas organizadas na forma de exsicata e direcionadas ao Prof. Dr. Vinícius Castro Souza (Laboratório de Sistemática Vegetal - ESALQ/USPPiracicaba/SP), especialista pertinente a sua identificação.

A posição taxonômica adotada foi baseada em Roig-Alsina \& Michener (1993) para as categorias de Família, Subfamílias e Tribos. Nos casos em que esses dois últimos táxons não foram referidos pelos autores, seguiu-se o esquema encontrado em Finnamore \& Michener (1993) e Griswold et al. (1995). A sistemática para gêneros de Meliponinae foi baseada em Camargo e Pedro (1992).

Foram registrados os dados climáticos (temperatura, umidade relativa do ar e pluviosidade) e dados sobre o período e condições do florescimento das plantas presentes na área em estudo. 


\subsubsection{Análise da Fauna}

A fauna foi caracterizada pelo número de espécies, gêneros e famílias de abelhas coletadas na trilha de coleta pré-estabelecido.

Todas as informações foram digitadas em planilhas, de acordo com a seguinte ordem: número de exemplar, mês da coleta, período, família, subfamília, tribo, gênero e espécie, além da espécie e família vegetal onde foi coletado.

\subsubsection{Freqüência}

A freqüência $(f)$ das espécies foi determinada pela participação percentual do número de indivíduos de cada espécie, em relação ao total coletado: form.(1) ( Silveira Neto et al., 1976).
$f=$
$\left(\mathrm{n}_{\mathrm{i}}\right.$
N)
$\mathrm{X}$
100

Onde:

$\mathrm{n}_{\mathrm{i}}=$ número de indivíduos da espécie $\mathrm{i}$;

$\mathrm{N}=$ número total de indivíduos.

De acordo com os resultados obtidos foram estabelecidas classes de freqüência para cada espécie, por meio de Intervalos de Confiança (IC a 5\% de probabilidade):

a) Pouco Frequiente $(\mathrm{PF})=f<$ o limite inferior $(\mathrm{LI})$ do $\mathrm{IC}_{5 \%}$.

b) Freqüente $(\mathrm{F})=f$ situado dentro do $\mathrm{IC}_{5 \%}$.

c) Muito Freqüente $(\mathrm{MF})=f>$ o limite superior $(\mathrm{LS})$ do $\mathrm{IC}_{5 \%}$.

\subsubsection{Constância}

Calculada por meio da porcentagem de ocorrência das espécies no levantamento (Silveira Neto et al., 1976) utilizando-se a form.(2): 
(2)

$$
\mathrm{C}=\left(\mathrm{c}_{\mathrm{i}} / \mathrm{Nc}\right) \times 100
$$

Onde:

$\mathrm{C}=$ porcentagem de constância;

$\mathrm{c}_{\mathrm{i}}=$ número de coletas contendo a espécie $\mathrm{i}$;

$\mathrm{Nc}=$ número total de coletas efetuadas.

De acordo com os percentuais obtidos, as espécies serão separadas em categorias, segundo a classificação de Bodenheimere, segundo Silveira-Neto et al. (1976), o IC a 5\% em:

a) Espécies constantes (W): C> o limite superior (LS) do $\mathrm{IC}_{5 \%}$;

b) Espécies acessórias (Y): C entre os limites (LI e LS) do $\mathrm{IC}_{5 \%}$;

c) Espécies acidentais (Z): $\mathrm{C}<$ o limite inferior (LI) do $\mathrm{IC}_{5 \%}$;

\subsubsection{Dominância}

A dominância consiste na capacidade, ou não, da espécie em modificar, em seu benefício, o impacto recebido do ambiente, podendo assim, causar o aparecimento, ou desaparecimento de outros organismos: form.(3)

$$
\mathrm{LD}=(1 / \mathrm{S}) \times 100
$$

\section{Onde:}

$\mathrm{LD}=$ limite da dominância;

$\mathrm{S}=$ número total de espécies.

Uma determinada espécie foi considerada como dominante quando seu limite inferior (Li) foi maior que o inverso do número total de espécies multiplicado por 100, de acordo com Sakagami \& Matsumura (1967).

\subsubsection{Abundância}


O número total das espécies amostradas foi considerado como a bundância (S) no ambiente (Ludwig \& Reynolds, 1988). As espécies foram distribuídas em classes de abundância baseadas no Intervalo de Confiança (IC) do número de indivíduos (n) ao nível de 5\% e 1\% de significância, conforme Bicelli et al. (1989). Os limites de classes considerados são:

a) $\operatorname{Raro}(r)=n$ menor que o limite inferior do $\mathrm{IC}_{1 \%}$;

b) Disperso $(d)=n$ entre os limites inferiores dos $\mathrm{IC}_{1 \%}$ e $\mathrm{IC}_{5 \%}$;

c) Comum (c) $=n$ situado dentro do $\mathrm{IC}_{5} \%$;

d) Abundante $(a)=n$ situado entre os limites superiores dos $\mathrm{IC}_{5 \%}$ e $\mathrm{IC}_{1 \%}$;

e) Muito abundante $(m)=n$ maior que o limite superior do $\mathrm{IC}_{1 \%}$;

As espécies que apresentarem os maiores valores nas classes de freqüência, constância, abundância e dominância foram consideradas como dominantes na área em estudo.

\subsubsection{5 Índice de diversidade}

Diferentes índices expressam a diversidade de uma área ou região, explorando de forma diferente os componentes da diversidade. Neste estudo foi utilizado o seguinte índice:

Índice $H^{\prime}$ (Shannon-Wiener): form.(4)

$$
H^{\prime}=-\Sigma p_{i}\left(\ln p_{i}\right)
$$

Onde:

$H$ '= componente de "riqueza" de espécies;

$p_{i}=$ freqüência relativa da espécie $i$ dada por $n_{i} / \mathrm{N}$;

$n i=$ número de indivíduos da espécie $i$;

$\mathrm{N}=$ número total de indivíduos;

$\ln =$ logaritmo neperiano.

O índice $H^{\prime}$ é um dos melhores para uso em comparações de comunidades, caso não haja interesse em separar os dois componentes da diversidade, abundância e equitabilidade. 


\subsubsection{Quociente de similaridade}

Foi proposto para indicar a semelhança entre duas comunidades, em termos de composição de espécies: form.5 (Silveira Neto et al., 1976).

$$
\mathrm{QS}=2 \mathrm{j} / \mathrm{a}+\mathrm{b}
$$

Este valor multiplicado por100 expressa a porcentagem.

Onde:

$\mathrm{a}=$ número de espécies no habitat $\mathrm{A}$, ou número de levantamentos com a espécie

a.

$\mathrm{b}=$ número de espécies no habitat $\mathrm{B}$, ou número de levantamentos com a espécie $\mathrm{b}$.

$\mathrm{j}$ = número de espécies encontradas em ambos os habitats, ou número de levantamentos contendo, simultaneamente, as duas espécies.

\subsubsection{Porcentagem de similaridade}

Foi calculada pela somatória dos menores valores da porcentagem do total de indivíduos, comparando as duas comunidades: form.(6) (Silveira Neto et al., 1976).

$$
\% \mathrm{~S}=\min (\mathrm{a}, \mathrm{b}, \ldots, \mathrm{x})
$$

(6)

\subsection{Localização das colônias de abelhas}

Durante os meses março, abril e maio de 2001 foram feitas as coletas de enxames visando a produção de mel, para realização das análises físico-químicas e polínicas. Foram 
coletados ninhos das abelhas identificadas, durante os levantamentos, como as mais importantes para o referido local, dento do universo das espécies melíferas de interesse comercial.

\subsection{Análise do mel}

Cinco colônias de cada espécie de abelha considerada importante para cada uma das 2 áreas em estudo, foram transferidas para caixas apropriadas, mantidas dentro das respectivas áreas e avaliadas, mensalmente, quanto a composição química e física dos seus méis.

Para que não ocorresse mistura de mel formado nos diferentes meses de coleta, foi adotado o critério de retirada total do mel maduro produzido a cada mês, em 2 quadros de melgueira previamente marcados, para as abelhas do gênero Apis e, para as demais espécies, foram retiradas amostras de mel depositado em potes de alimentação numa área devidamente marcada.

Os favos foram centrifugados e o mel decantado e filtrado antes de se iniciar as análises físico-químicas: açúcares, umidade, $\mathrm{HMF}$, cor, condutividade elétrica, $\mathrm{pH}$, teor de cinzas, proteínas, minerais e análise polínica, sendo possível tipificar o mel produzido nas duas áreas, possibilitando montar um banco de dados sobre o padrão de composição de méis produzidos nas áreas de cerrado estudadas.

As análises físico-químicas e polínicas dos méis produzidos por Apis mellifera e as demais meliponas foram realizadas no Laboratório de Insetos Úteis do Departamento de Entomologia, Fitopatologia e Zoologia Agrícola da Escola Superior de Agricultura "Luiz de Queiroz", campus de Piracicaba, da Universidade de São Paulo, com exceção da análise de minerais que foi desenvolvida no Laboratório de Minerais do Departamnento de Zootecnia da Faculdade de Zootecnia e Engenharia de Alimentos/USP - Pirassununga/SP, sob a orientação do professor Dr. Marcus Antônio Zanetti e Dr. José Aparecido Cunha.

\subsubsection{Açúcares totais, redutores e sacarose (\%)}


A determinação dos açúcares totais, redutores e sacarose (\%) foi realizada por meio do método estabelecido por Somogyi (Nelson, 1944).

\subsubsection{Umidade (\%)}

A umidade das diferentes amostras de méis foi determinada, logo após sua colheita, pelo refratômero manual marca ATAGO (luz natural, temperatura ambiente) específico para mel. O referido aparelho dispõe de uma escala, que expressa diretamente o valor da umidade(\%), sendo feita uma correção em função da temperatura num termômetro a ele acoplado externamente. Este aparelho foi adaptado a partir do refratômetro Abbe e possui um alto contraste no campo de visão (Atago Co. Ltda., 1988).

O método baseia-se no fenômeno da refração (relação entre as velocidades da luz no vácuo e numa substância) que um raio de luz incidente sofre ao incidir na solução de mel, que contém sólidos solúveis.

\subsubsection{Hidroximetilfurfural $(\mathrm{mg} / \mathrm{kg})$}

O hidroximetilfurfural foi determinado conforme a metodologia de White (1979) modificada por Bogdanov et al. (1997).

\subsubsection{Cor (nm)}

Para a verificação da cor do mel foi utilizado o Método de Bianchi (1986), com medição espectrofotométrica e tabela de Pfund.

\subsubsection{Condutividade elétrica (uS)}

A condutividade elétrica foi medida em solução de $20 \%$ de matéria seca de mel a $20^{\circ} \mathrm{C}$ (Rédon, 1996). Para tanto utilizou-se o condutivímetro, modelo HI8820, na obtenção dos dados. 


\subsection{6 pH, Acidez (meq/kg) e índice de formol $(\mathrm{ml} / \mathrm{kg})$}

Os três parâmetros foram determinados em seqüência, segundo a metodologia adotada pelo Laboratório do Centro de Apicultura Tropical do Instituto de Zootecnia de Pindamonhangaba, SP (Moraes \& Teixeira, 1998).

\subsubsection{Cinzas $(\%)$}

$\mathrm{O}$ teor de cinzas foi determinado por meio da calcinação em mufla a $550^{\circ} \mathrm{C}$ até um peso constante (Bogdanov et al., 1997).

\subsubsection{Proteína $(\%)$}

A proteína do mel foi determinada seguindo-se as normas analíticas do Instituto Adolfo Lutz (Pregnolato, 1985).

\subsubsection{Minerais (ppm)}

Os diferentes minerais contidos no mel foram determinados a partir das cinzas das amostras dos méis, em solução de $\mathrm{HCl}$ a $50 \%$, por espectrofotometria de emissão em chama e sistemas de injeção em fluxo contínuo, conforme Bergamin Filho et al. $^{2}$, citado por Pamplona (1989), com espectrofotômetro Micronal, modelo B262; bomba peristáltica modelo B332 e sistema de injeção: injetor computador, microcomputador Saci.

\subsubsection{Análise polínica do mel e do grão de pólen}

Adotou-se para esta análise o Método da Acetólise (Louveaux et al., 1970), que consiste

\footnotetext{
${ }^{2}$ BERGAMIM FILHO, H.; REIS, B.F.; ZAGATTO, E.A.G. A new device for improving sensitivy and stabilization in flow injection analysis. Analytica Chimica Acta, v. 97, p. 427-431, 1978.
} 
no tratamento químico do grão de pólen, eliminando a intina, o citoplasma e as substâncias aderentes aos grãos fossilizando-os artificialmente, ficando a exina mais transparente e mais própria para o estudo de seus detalhes.

Para preparação das lâminas (3 repetições para cada amostra) foram utilizadas amostras dos méis coletados durante o mês. Quanto aos grãos de pólen, foram colhidas amostras mensais, provenientes de coletores, colocados nas colméias no decorrer de cada coleta de mel. As amostras foram homogeneizadas e uma parcela de $1 \mathrm{~g}$ foi utilizada para a confecção das lâminas (também 3 repetições).

A identificação dos pólens foi feita com base nos laminários de referência confeccionados com o pólen das plantas coletadas nas áreas de estudo e também de laminários já existentes no laboratório em que o trabalho vinha sendo desenvolvido.

Contou-se também para a identificação do material com o auxílio da Dra. Augusta Carolina de C. C. Moreti, do Instituto de Zootecnia de Nova Odessa-SP e da Dra. Mônica Barth, do Instituto Oswaldo Cruz-RJ.

Análise qualitativa - por meio dessa análise foram determinadas as espécies botânicas (ou tipos polínicos), levando-se em consideração aspectos morfológicos dos grãos quando comparados com laminário de referência preparado a partir das plantas coletadas das áreas em estudo e do existente no Setor de Apicultura da ESALQ/USP.

Análise quantitativa - foi efetuada mediante contagem de 300 a 500 grãos de pólen por amostra e agrupados por espécies botânicas e/ou tipos polínicos. Essa contagem é caracterizada por agrupar os grãos de pólen em quatro classes de frequiência, ou seja: pólen dominante com presença em mais de $45 \%$ do total đe grãos, pólen acessório em 15 a 44\%, pólen isolado importante entre 3 e 15\% e pólen isolado ocasional em menos de 3\% (Barth, 1970a,b,c; Louveaux et al., 1970, 1978). 


\section{RESULTADOS E DISCUSSÃO}

\subsection{Clima}

Pelos dados de temperatura, umidade e precipitação, fornecidos pelo Departamento de Proteção ao Vôo (DPV) da Academia da Força Aérea (AFA), que encontra-se próxima a área estudada, no período de agosto/2000 a julho/2001, foi possível verificar que a temperatura média máxima foi $26,6^{\circ} \mathrm{C}$ no mês de fevereiro e a média mínima foi $18^{\circ} \mathrm{C}$ no mês de julho, não sendo registrada a ocorrência de geadas. O mês que apresentou maior média em umidade foi dezembro (73\%) e o de menor média foi outubro (59\%). A precipitação total anual foi de 1.307,7 mm, correspondendo o mês de dezembro ao mais chuvoso, com total de 304,3 mm e junho ao mais seco, com total de 3,5 mm.(Figura 2).

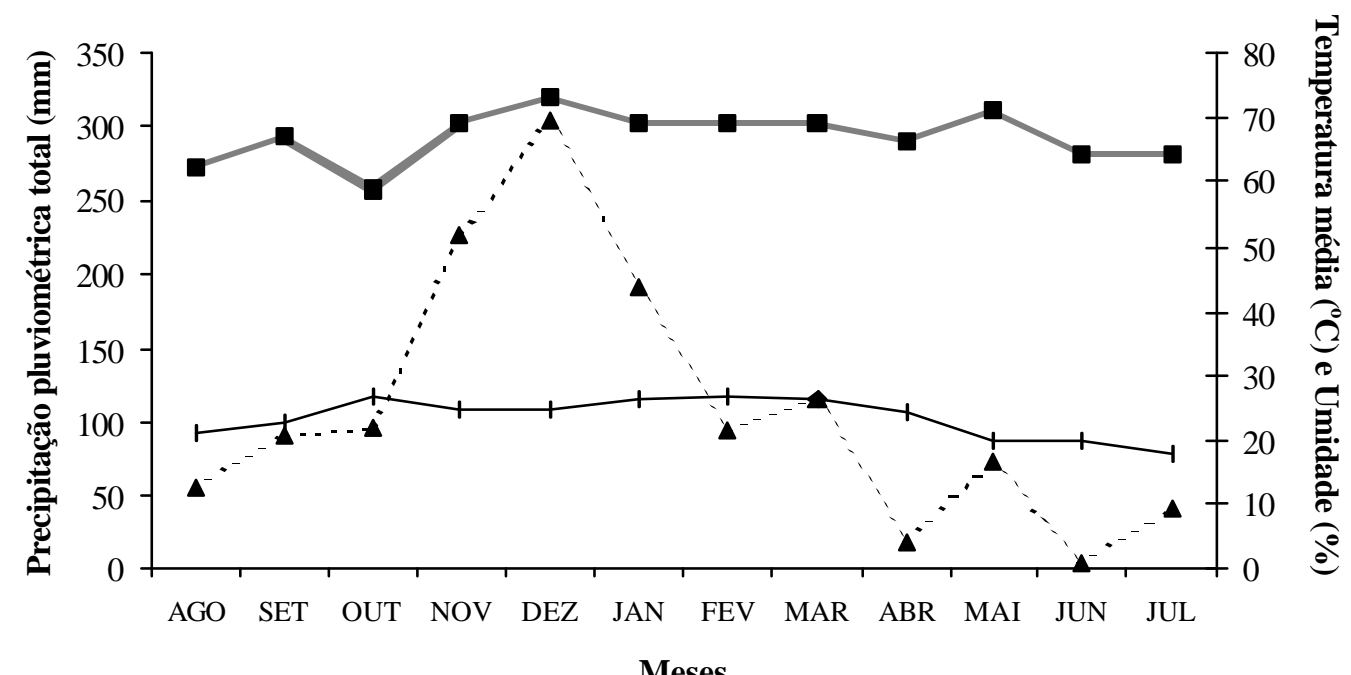

Meses

-. - - - Precipitação $(\mathrm{mm}) \longrightarrow$ Temperatura média $(\mathrm{oC}) \longrightarrow$ Umidade relativa $(\%)$

Figura 2 - Média mensal da temperatura $\left({ }^{\circ} \mathrm{C}\right)$, umidade relativa $(\%)$ e precipitação pluviométrica acumulada (mm) obtida de agosto/2000 a julho/2001 - Pirassununga/SP. 
Pela análise dos dados pode-se dizer que a região de Pirassununga está sob ação de um clima tropical, sazonal, com verão chuvoso (outubro a março) e inverno seco (abril a setembro), classificado como Cwa (Koeppen, 1948), pois apresenta temperatura média do mês mais frio entre $18^{\circ} \mathrm{C}$ e $-3^{\circ} \mathrm{C}$; no período mais seco a precipitação é menor que $30 \mathrm{~mm}$ e a temperatura média do mês mais quente é superior a $22^{\circ} \mathrm{C}$. Historicamente a região apresenta temperatura média anual de $22^{\circ} \mathrm{C}$ e a pluviosidade média anual é próxima a $1.200 \mathrm{~mm}$.

Verifica-se ainda a presença de estiagem no mês de junho, além de uma maior amplitude térmica no período mais seco, acompanhado de maior amplitude de precipitação.

Finna (1999) constatou semelhante padrão climático na mesma área de estudo durante 1996 e 1997.

\subsection{Composição da flora e da fauna de abelhas}

Obteve-se com as coletas um total de 261 amostras de plantas nas duas áreas de cerrado, distribuídas em 41 famílias, 96 gêneros e 140 espécies, sendo 54 referentes ao cerradão (cerrado1) e 82 referentes ao cerrado "sensu strictu" (cerrado2). Apenas 5 espécies foram comuns a ambas as áreas (Tabela 1).

Tabela 1. Relação das espécies de plantas coletadas nas áreas de cerrado, no município de Pirassununga-SP, de agosto/2000 a julho/2001.

\begin{tabular}{ccccc}
\hline \multirow{2}{*}{ Família } & * Área & Código & & Período \\
& de & Da & Espécies & de \\
& Coleta & Amostra & & Soleta \\
\hline \multirow{2}{*}{ Acanthaceae } & Cerrado-2 & $\mathbf{1}$ & Ruellia geminiflora H.B.K. & Janeiro \\
& & & Temnadenia violácea (Vell.) Miers & Outubro \\
& Cerrado-1 & $\mathbf{2}$ & Condylocarpon isthmicum (Vell.) A.DC. & Novembro \\
& Cerrado-2 & $\mathbf{3}$ & Tabernaemontana sp. & Janeiro \\
& Cerrado-1 & $\mathbf{4}$ & Prestonia coalita (Vell.) Woodson & Janeiro
\end{tabular}


Tabela 1. Relação das espécies de plantas coletadas nas áreas de cerrado, no município de Pirassununga-SP, de agosto/2000 a julho/2001.

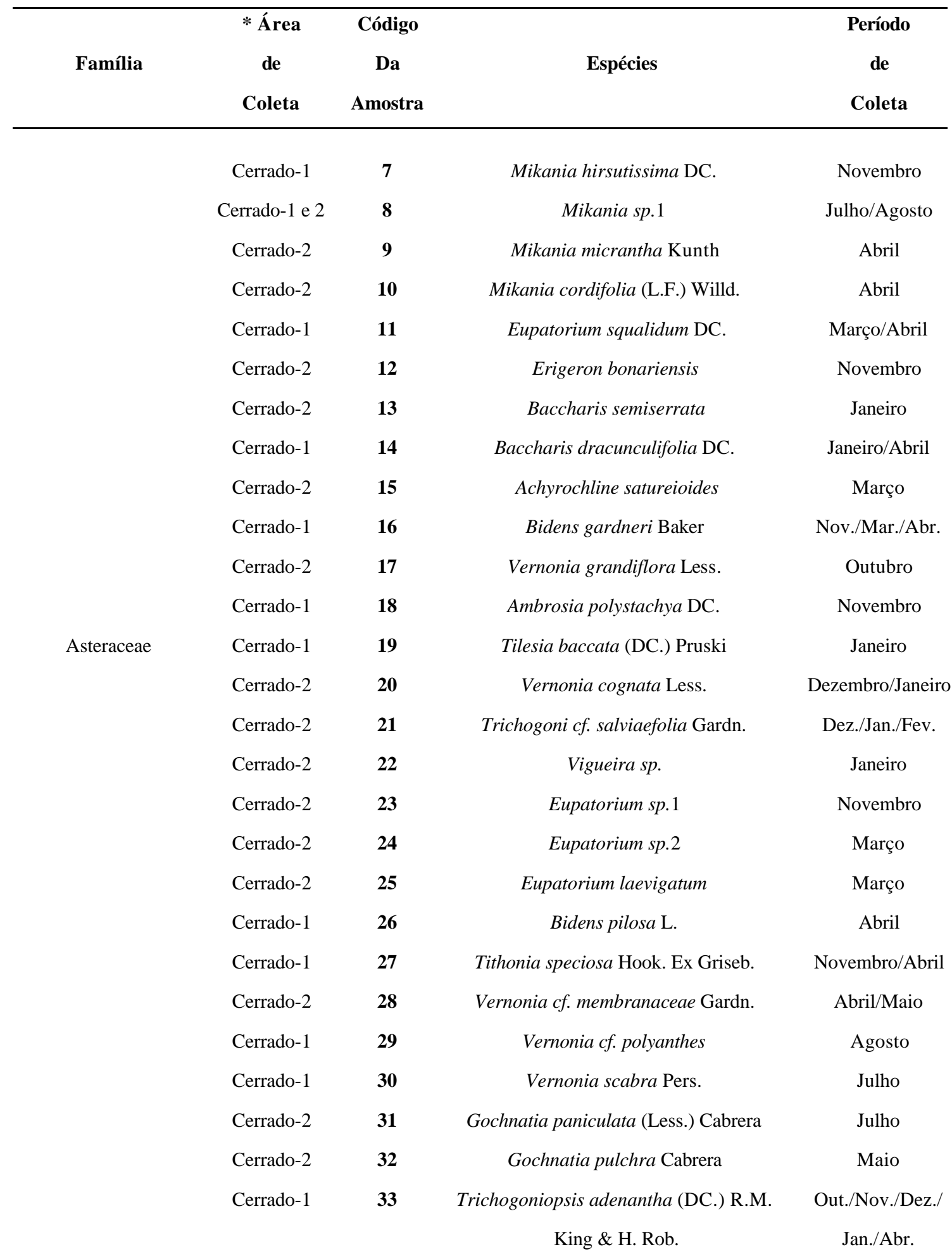


Tabela 1. Relação das espécies de plantas coletadas nas áreas de cerrado, no município de Pirassununga-SP, de agosto/2000 a julho/2001.

\begin{tabular}{|c|c|c|c|c|}
\hline Família & $\begin{array}{c}\text { * Área } \\
\text { de } \\
\text { Coleta }\end{array}$ & $\begin{array}{c}\text { Código } \\
\text { da } \\
\text { Amostra }\end{array}$ & Espécies & $\begin{array}{c}\text { Período } \\
\text { de } \\
\text { Coleta }\end{array}$ \\
\hline \multirow[t]{3}{*}{ Araliaceae } & Cerrado-2 & 34 & $\begin{array}{l}\text { Didymopanax vinosum } \\
\text { (Cham \& Schltdl) March. }\end{array}$ & $\begin{array}{c}\text { Março/Abril/Maio/ } \\
\text { Junho/Julho }\end{array}$ \\
\hline & Cerrado-2 & 35 & Jacaranda decumens & Setembro \\
\hline & Cerrado-2 & 36 & Memora sp. & Novembro/Janeiro \\
\hline \multirow[t]{4}{*}{ Bignoniaceae } & Cerrado-2 & 37 & Pithecoctenium crucigerum (L.) Gentry & Janeiro \\
\hline & Cerrado-2 & 38 & Arrabidaea brachypoda & Jan./Fev./M ar. \\
\hline & Cerrado-1 & 39 & Arrabidaea pulchela & Setembro \\
\hline & Cerrado-2 & 40 & Pyrostegia venusta & Junho/Julho \\
\hline \multirow[t]{2}{*}{ Boraginaceae } & Cerrado-1 & 41 & Heliotropium transalpinum Vell. & Novembro \\
\hline & Cerrado-1 & 42 & Cordia trichotoma (Vell.) Amab. ex Steud. & Junho \\
\hline \multirow[t]{3}{*}{ Bombacaceae } & Cerrado-1 & 43 & Eriotheca gracilipes (K. Schum.) A. Robyns & Maio \\
\hline & Cerrado-2 & 44 & Senna macranthera & Março \\
\hline & Cerrado-1 & 45 & Senna splendida & Março/Abril \\
\hline \multirow[t]{4}{*}{ Caesalpiniaceae } & Cerrado-2 & 46 & Bauhinia holophylla (Bong.) Steud. & Dezembro/Janeiro \\
\hline & Cerrado-2 & 47 & Chanaecrista vestita & Janeiro \\
\hline & Cerrado-1 & 48 & Chanaecrista nictitans & Janeiro \\
\hline & Cerrado-2 & 49 & Dimorphandra mollis Benth. & Novembro \\
\hline Caryocaraceae & Cerrado-2 & 50 & Caryocar brasiliense & Junho/Out./Nov. \\
\hline Clusiaceae & Cerrado-2 & 51 & Kielmeyra coriacea Mart. & Novembro \\
\hline \multirow[t]{2}{*}{ Commelinaceae } & Cerrado-1 & 52 & Dichorisandra incurva Mart. & Março \\
\hline & Cerrado-2 & 53 & Commelina sp. & Novembro \\
\hline
\end{tabular}


Tabela 1. Relação das espécies de plantas coletadas nas áreas de cerrado, no município de Pirassununga-SP, de agosto/2000 a julho/2001.

\begin{tabular}{|c|c|c|c|c|}
\hline Família & $\begin{array}{c}\text { * Área } \\
\text { de } \\
\text { Coleta }\end{array}$ & $\begin{array}{c}\text { Código } \\
\text { da } \\
\text { Amostra }\end{array}$ & Espécies & $\begin{array}{c}\text { Período } \\
\text { de } \\
\text { Coleta }\end{array}$ \\
\hline \multirow[t]{2}{*}{ Convolvulaceae } & Cerrado-2 & 54 & Evolvulus cf. barbadus & Novembro \\
\hline & Cerrado-2 & 55 & Merremia macrocalix (Ruiz \& Pav.) O’Donell & Março/Abril/Maio \\
\hline Cochlosperniaceae & Cerrado-2 & 56 & Cochlospernum regium & Agosto \\
\hline \multirow[t]{2}{*}{ Euphorbiaceae } & Cerrado-1 & 57 & Croton floribundus & Outubro \\
\hline & Cerrado-1 & 58 & Sebastiania brasiliensis (L.) Spreng. & Setembro \\
\hline \multirow[t]{4}{*}{ Erythroxylaceae } & Cerrado-1 & 59 & Erythroxyluris sp. & Setembro \\
\hline & Cerrado-2 & 60 & Acosmium subelegans & Outubro \\
\hline & Cerrado-2 & 61 & Andira laurifolia & Setembro \\
\hline & Cerrado-2 & 62 & Centrosema bracteatun Benth. & Nov./Dezembro \\
\hline \multirow[t]{6}{*}{ Fabaceae } & Cerrado-1 & 63 & Centrosema pubescens Benth. & Abril \\
\hline & Cerrado-2 & 64 & Crotalaria micans Link & Janeiro \\
\hline & Cerrado-2 & 65 & Dalbergia miscolobium Benth. & Janeiro \\
\hline & Cerrado-2 & 66 & Bowdichia virgilioides Kunth & Junho/Julho \\
\hline & Cerrado-2 & 67 & Hyptis eriophylla & Fevereiro \\
\hline & Cerrado-1 & 68 & Hyptis umbrosa Salzm. ex. Benth. & Março \\
\hline \multirow[t]{3}{*}{ Lamiaceae } & Cerrado-2 & 69 & Hyptis crinita Benth. & Junho/Julho \\
\hline & Cerrado-1 & 70 & Hyptus cf. multibracteata Benth. & Março \\
\hline & Cerrado-2 & 71 & Peltodon tomentosus Pohl & Fevereiro \\
\hline Lytuaceae & Cerrado-1 & 72 & Diplusodon virgatus Pohl & Abril \\
\hline
\end{tabular}


Tabela 1. Relação das espécies de plantas coletadas nas áreas de cerrado, no município de Pirassununga-SP, de agosto/2000 a julho/2001.

\begin{tabular}{|c|c|c|c|c|}
\hline \multirow{3}{*}{ Família } & * Área & Código & \multirow{3}{*}{ Espécies } & \multirow{3}{*}{$\begin{array}{c}\text { Período } \\
\text { de } \\
\text { Coleta }\end{array}$} \\
\hline & De & Da & & \\
\hline & Coleta & Amostra & & \\
\hline \multirow{6}{*}{ Malpighiaceae } & Cerrado-2 & 73 & Peixotoa cf. tomentosa Adr. Juss. & Maio/Outubro \\
\hline & Cerrado-2 & 74 & Byrsonima intermedia A. Juss. & Out./Novembro \\
\hline & Cerrado-2 & 75 & Byrsonima coccolobifolia H.B.K. & Outubro \\
\hline & Cerrado-2 & 76 & Heteroperys byrsonimifolia Adr. Juss. & Setembro \\
\hline & Cerrado-2 & 77 & Tetrapterys $c f$. mucronata & Janeiro \\
\hline & Cerrado-2 & 78 & Baristeriopsis adenopoda (A. Juss) & Abril \\
\hline \multirow{7}{*}{ Malvaceae } & Cerrado-1 & 79 & Wissadula subpetala (Kuntze) R. E. Fr. & Abril/Maio \\
\hline & Cerrado-1 & 80 & Pavonia malacophila (Link \& Otto) Garcke & Janeiro/Maio \\
\hline & Cerrado-1 & 81 & Pavonia communis A. St-Hil. & Janeiro \\
\hline & Cerrado-1 & 82 & Sida planicaulis Cav. & Dezembro \\
\hline & Cerrado-1 & 83 & Sida glaziovii K. Schum. & Outubro \\
\hline & Cerrado- 1 e 2 & 84 & Sida rhombifolia & Novembro \\
\hline & Cerrado-2 & 85 & Peltaea speciosa (Kunth) Krapovicks \& Cristóbal & Dez./Janeiro \\
\hline \multirow{4}{*}{ Melastomataceae } & Cerrado-1 & 86 & Miconia langsdorffii Cogn. & Outubro \\
\hline & Cerrado-2 & 87 & Miconia stenostachia DC. & Abril/Junho \\
\hline & Cerrado-2 & 88 & Tibouchina cf. gracilis Ganche & Novembro \\
\hline & Cerrado-2 & 89 & Tibouchina granulosa Cogn. & Fevereiro/Maio \\
\hline \multirow{6}{*}{ Mimosaceae } & Cerrado-1 & 90 & Anadenanthera macrocarpa (Benth) Brenan & Outubro \\
\hline & Cerrado-2 & 91 & Mimosa nuda Benth. & Dezembro a Março \\
\hline & Cerrado-2 & 92 & Mimosa debilis Humb. \& Boup. & Janeiro \\
\hline & Cerrado-2 & 93 & Stryphmodendron obvatum Benth. & Novembro \\
\hline & Cerrado-1 & 94 & Acacia polyphyla DC. & Janeiro/Fevereiro \\
\hline & Cerrado-1 & 95 & Inga vera Willd. & Julho \\
\hline
\end{tabular}


Tabela 1. Relação das espécies de plantas coletadas nas áreas de cerrado, no município de Pirassununga-SP, de agosto/2000 a julho/2001.

\begin{tabular}{|c|c|c|c|c|}
\hline Família & $\begin{array}{c}\text { * Área } \\
\text { de } \\
\text { Coleta }\end{array}$ & $\begin{array}{c}\text { Código } \\
\text { Da } \\
\text { Amostra }\end{array}$ & Espécies & $\begin{array}{c}\text { Período } \\
\text { de } \\
\text { Coleta }\end{array}$ \\
\hline \multirow{6}{*}{ Myrtaceae } & Cerrado-2 & 96 & Campomanesia pubescens (DC.) O. Berg. & Agosto/Setembro \\
\hline & Cerrado-2 & 97 & Myrcia rufipes DC. & Outubro \\
\hline & Cerrado-1 & 98 & Myrcia tomentosa (Aubl.) DC. & Outubro \\
\hline & Cerrado-2 & 99 & Myrcia bella O.Berg. & Outubro \\
\hline & Cerrado-2 & 100 & Eugenia bimarginata DC. & Maio \\
\hline & Cerrado-2 & 101 & Eugenia aurata $\mathrm{O}$. Berg & Maio \\
\hline \multirow[t]{2}{*}{ Ochnaceae } & Cerrado-1 & 102 & Ouratea castanaefolia Engl. & Setembro \\
\hline & Cerrado-2 & 103 & Ouratea spectabilis & Mai./Jun./Jul./Ago. \\
\hline \multirow[t]{2}{*}{ Oxalidaceae } & Cerrado-2 & 104 & Oxalys physocalyx Zucc. & Out./Dez./Jan. \\
\hline & Cerrado-2 & 105 & Oxalys hirsutissima Mart. Ex Zucc. & Dezembro \\
\hline Onagraceae & Cerrado-2 & 106 & Ludwigia sericea (Camb.) Hara & Maio \\
\hline Poaceae & Cerrado-1 & 107 & Brachiaria sp. & Dezembro \\
\hline Polygalaceae & Cerrado-2 & 108 & Bredemeyera floribunda Willd. & Jan./Fev./Mai. \\
\hline \multirow[t]{2}{*}{ Rhamnaceae } & Cerrado-1 & 109 & Govania acalyphoides Reiss. & Março \\
\hline & Cerrado-1 & 110 & Borreria capitata & Outubro a Janeiro \\
\hline \multirow[t]{2}{*}{ Rubiaceae } & Cerrado-1 & 111 & Psychotria stachyoides Benth. & Outubro \\
\hline & Cerrado-2 & 112 & Tocoyena formosa (Cham. f. Schltdl) K. Shum & Novembro \\
\hline Rutaceae & Cerrado-2 & 113 & Zarthoxylum rhoifolium Lau. & Setembro \\
\hline
\end{tabular}


Tabela 1. Relação das espécies de plantas coletadas nas áreas de cerrado, no município de Pirassununga-SP, de agosto/2000 a julho/2001.

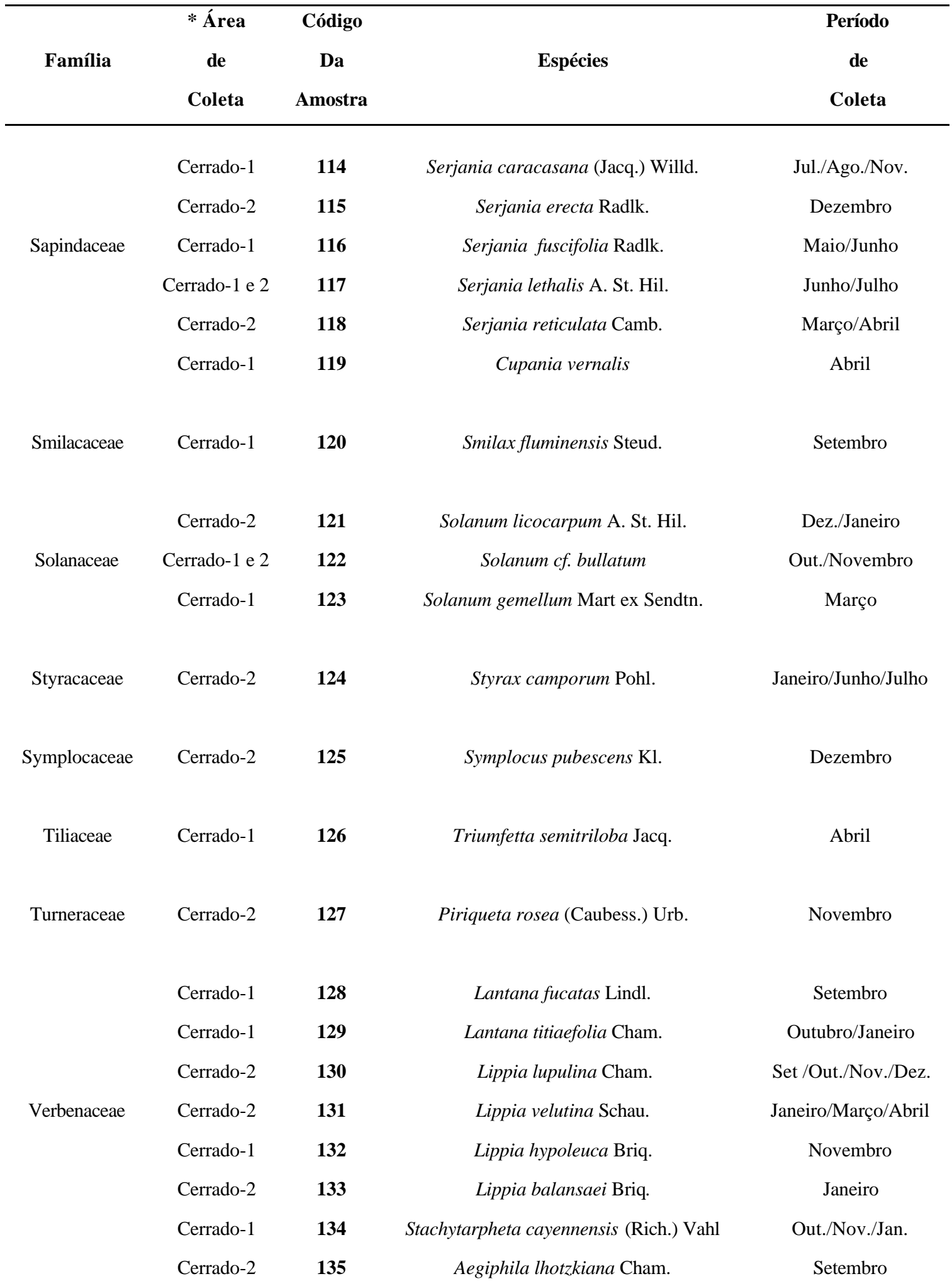


Tabela 1. Relação das espécies de plantas coletadas nas áreas de cerrado, no município de Pirassununga-SP, de agosto/2000 a julho/2001.

\begin{tabular}{ccccc}
\hline \multirow{2}{*}{ Família } & *área & Código & & Período \\
& $\begin{array}{c}\text { de } \\
\text { Coleta }\end{array}$ & $\begin{array}{c}\text { Da } \\
\text { Amostra }\end{array}$ & Espécies & $\begin{array}{c}\text { De } \\
\text { Coleta }\end{array}$ \\
\hline \multirow{2}{*}{ Violaceae } & Cerrado-1 & $\mathbf{1 3 6}$ & Hybarthus communis (A. St-Hil) Taub. & Nov./Dez. \\
& & & & \\
& Cerrado-2 & $\mathbf{1 3 7}$ & Qualea cordata Spreng. & Outubro \\
Vochysiaceae & Cerrado-2 & $\mathbf{1 3 8}$ & Qualea multiflora Mart. & Out./Nov. \\
& Cerrado-2 & $\mathbf{1 3 9}$ & Qualea grandiflora Mart. & Out./Nov. \\
& Cerrado-2 & $\mathbf{1 4 0}$ & Vchysia cf. tucanorum & Janeiro \\
\hline
\end{tabular}

* - Cerrado-1: Cerradão

* - Cerrado-2: Cerrado senso strictu

No presente trabalho encontrou-se 19 famílias representadas por apenas 1 espécie, 14 famílias com 2 a 5 espécies, 21 famílias com 6 a 8 espécies e a família Asteraceae com 27 espécies (Figura 3).

As famílias que apresentaram maior representatividade foram Asteraceae, Verbenaceae, Fabaceae e Malvaceae, que também se encontram dentre as mais representativas em outras áreas de cerrado estudadas, como Triângulo Mineiro (Goodland \& Ferri, 1979), Brasília (Ratter, 1980), Mogi-Guaçu (Mantovani \& Mateus, 1993), Santa Rita do Passa Quatro (Batalha, 1997) e Luiz Antônio (Mateus, 1998).

Dentre os gêneros de maior riqueza destacam-se Vernonia e Serjania (5 espécies cada), Mikania, Eupatorium, Hyptis e Lippia (4 espécies cada).

Das principais famílias monotípicas, citadas por Goodland \& Ferri (1979) como características nos cerrados, foram observadas no presente estudo Caryocaceae (Caryocar brasiliense) e Clusiaceae (Kielmeyra coryaceae).

Finna (1999), realizou um estudo florístico nas mesmas áreas e obteve 167 espécies, distribuídas em 118 gêneros e 52 famílias, destas, 25 famílias foram representadas por apenas 1 espécie, 18 famílias apresentaram entre 2 e 5 espécies e 9 famílias possuíam entre 6 e 15 espécies. 


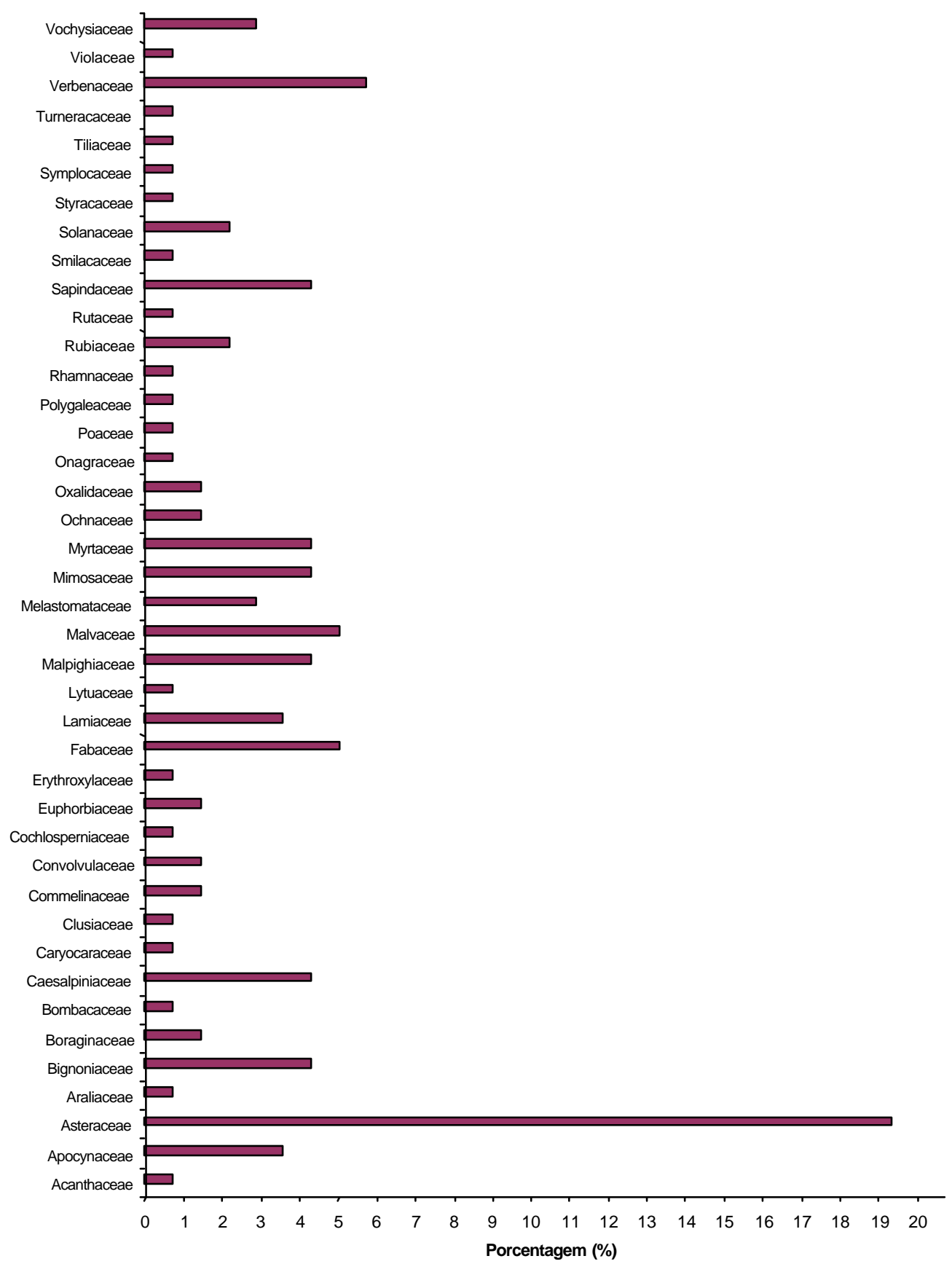

Figura 3 - Porcentagem do número de espécies de plantas por família encontradas nas áreas de cerrado do município de Pirassununga-SP, de agosto/2000 a jullho/2001.

As abelhas visitantes foram coletadas em 52,86\% (74 espécies) das 140 espécies de plantas em floração, sendo a família Asteraceae a que obteve um maior número de espécies de plantas visitadas pelos insetos $(18,92 \%)$ (Figura 4). 


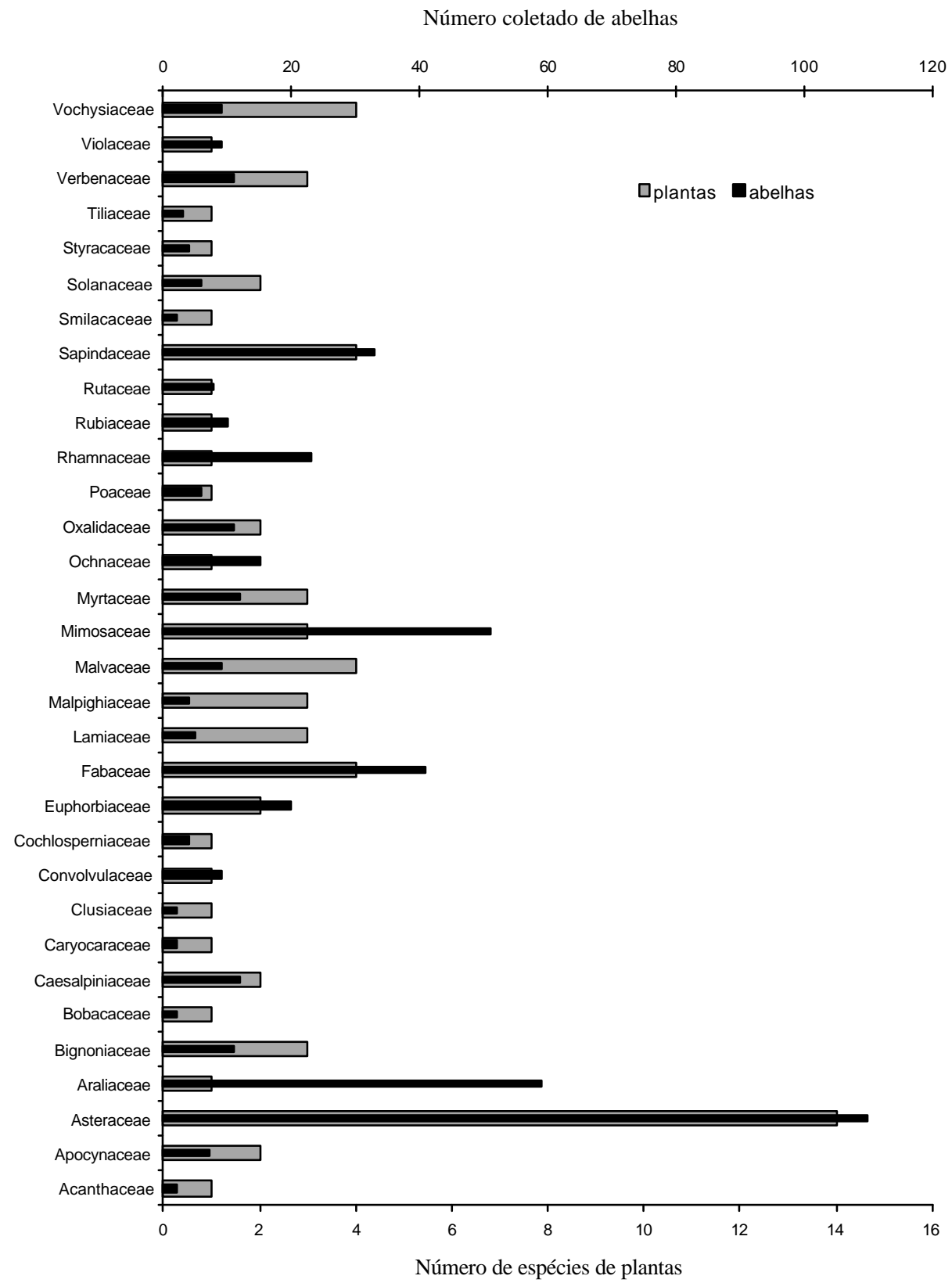

Figura 4 - Distribuição do número de espécies vegetais e do número de abelhas coletado por família de plantas visitadas em áreas de cerrado, Pirassununga-SP, de agosto/2000 a julho/2001.

A comunidade de abelhas foi representada por 51 espécies, 31 gêneros, 14 tribos, 7 subfamílias e 4 famílias com um total de 511 indivíduos coletados, sendo 200 referentes ao cerradão e 311 ao cerrado "sensu strictu” (Tabela 2). 
Tabela 2. Espécies e números de abelhas relacionadas com os meses, período e espécies vegetais em que foram coletadas, nas diferentes áreas de cerrado, no município de Pirassununga-SP, de agosto/2000 a julho/2001.

\begin{tabular}{|c|c|c|c|c|c|}
\hline Espécies das abelhas coletadas & $\begin{array}{c}\text { *1 Código das Espécies }^{\text {Vegetais }} \\
\text { Vet }\end{array}$ & $\begin{array}{c}\text { Período Manhã/ } \\
\text { Tarde }\end{array}$ & $\begin{array}{c}\text { Total de Espécimes } \\
\text { Coletados }\end{array}$ & Mês de Coleta & $\begin{array}{c}*^{2} \text { Área de } \\
\text { Coleta }\end{array}$ \\
\hline \multicolumn{6}{|l|}{ APIDAE } \\
\hline \multicolumn{6}{|l|}{ Apinae, Apini } \\
\hline \multirow[t]{4}{*}{1 - Apis mellifera Linnaeus, 1758} & $3-9-10-11-17-24-28-29-33-$ & $\mathrm{M} / \mathrm{T}$ & 159 & Todos os meses & Cerrado \\
\hline & $34-40-46-57-60-65-69-90-$ & & & & 1 e 2 \\
\hline & 91-94-100-103-109-113-114- & & & & \\
\hline & $117-118-119-124-135$ & & & & \\
\hline \multicolumn{6}{|l|}{ Apinae, Centridini } \\
\hline $\mathbf{2}-$ Centris(Centris) collaris & 121 & $\mathrm{~T}$ & 1 & Março & Cerrado2 \\
\hline 3 - Centris (centris) nitens Lepeletier, 1841 & $20-56-137$ & $\mathrm{M} / \mathrm{T}$ & 3 & Nov/Dez/Jan & Cerrado2 \\
\hline 4 - Epicharis rustica & 74-121-138 & $\mathrm{M} / \mathrm{T}$ & 10 & Set/Out/Nov/Dez & Cerrado2 \\
\hline 5 - Epicharis (Epicharitides) cockerelli Friese, 1900 & 74 & M & 1 & Novembro & Cerrado2 \\
\hline
\end{tabular}


Tabela 2. Espécies e números de abelhas relacionadas com os meses, período e espécies vegetais em que foram coletadas, nas diferentes áreas de cerrado, no município de Pirassununga-SP, de agosto/2000 a julho/2001.

\begin{tabular}{ccccc}
\hline & ${ }^{* 1}$ Código das Espécies & Período Manhã $/$ & Total de Espécimes & Mês de Coleta \\
Espécies das abelhas coletadas de & Vegetais & Tarde & Coletados & Coleta
\end{tabular}

\section{Apinae, Eucerini}

6 - Thygater (Thygater) analis (Lepeletier, 1841)

7 - Melissodes (Eplectica) Sexcinta (Lepeletier, 1841)

8-Melissodes $s p$.

9 - Melissoptila (Ptilomelissa) cnecomala (Moure, 1944)

\section{Apinae, Exomalopsini}

10 - Exomalopsis (Exomalopsis) aureopilosa (Spinola, 1854)

11 - Exomalopsis (Exomalopsis) fulvopilosa (Spinola, 1854)

12 - Exomalopsis (Megomalopsis) fulvofasciata Smith, 1879

13 - Exomalopsis sp.

14 - Paratetrapedia (Xanthopedia) tricolor Michener \& Moure, 1957

$\begin{array}{ccccc}138 & \text { M } & 1 & \text { Novembro } & \text { Cerrado2 } \\ 91-126 & \text { M } & 2 & \text { Março/Abril } & \text { Cerrado1 } \\ 138 & \mathrm{~T} & 1 & \text { Novembro } & \text { Cerrado2 } \\ 20-25-85 & \mathrm{M} & 3 & \text { Jan/Mar/Dez } & \text { Cerrado2 }\end{array}$

$\begin{array}{ccccc}20 & \text { M } & 1 & \text { Dezembro } & \text { Cerrado2 } \\ 25-55-56 & \mathrm{M} & 4 & \text { Mar/Mai/Ago } & \text { Cerrado2 } \\ 9-20-46-55-121 & \mathrm{M} / \mathrm{T} & 9 & \text { Jan/Abr/Mai/Dez } & \text { Cerrado2 } \\ 57-82-91-94-134 & \mathrm{M} / \mathrm{T} & 7 & \text { Jan/Mar/Out/Dez } & \text { Cerrado 1 e 2 } \\ 20-75 & \mathrm{M} / \mathrm{T} & 2 & \text { Out/Dez } & \text { Cerrado2 }\end{array}$


Tabela 2. Espécies e números de abelhas relacionadas com os meses, período e espécies vegetais em que foram coletadas, nas diferentes áreas de cerrado, no município de Pirassununga-SP, de agosto/2000 a julho/2001.

\begin{tabular}{|c|c|c|c|c|c|}
\hline Espécies das abelhas coletadas & $\begin{array}{c}{ }^{* 1} \text { Código das Espécies } \\
\text { Vegetais }\end{array}$ & $\begin{array}{c}\text { Período } \\
\text { Manhã/ Tarde }\end{array}$ & $\begin{array}{c}\text { Total de Espécimes } \\
\text { Coletados }\end{array}$ & Mês de Coleta & $\begin{array}{c}\text { *2 Área de } \\
\text { Coleta }\end{array}$ \\
\hline \multicolumn{6}{|l|}{ Apinae, Tetrapediini } \\
\hline 15 - Tetrapedia (Tetrapedia) rugulosa Friese, 1899 & $\begin{array}{c}3-16-20-27-46-58-82-90- \\
91-110-118-123-134\end{array}$ & $\mathrm{M} / \mathrm{T}$ & 23 & Setembro a Maio & Cerrado 1 e 2 \\
\hline \multicolumn{6}{|l|}{ Apinae, Ceratinini } \\
\hline 16 - Ceratina (Crewella) maculifrons Smith, 1854 & $1-20-61-70-82-91$ & & 9 & $\mathrm{Jan} / \mathrm{Mar} / \mathrm{Set} / \mathrm{Dez}$ & Cerrado1 e 2 \\
\hline 17 - Ceratina (Crewella) sp. & $\begin{array}{c}20-24-25-36-38-61-82- \\
104-105-134\end{array}$ & $\mathrm{M} / \mathrm{T}$ & 15 & Jan/Mar/Set/Nov/Dez & Cerrado 1 e 2 \\
\hline 18 - Ceratina (Ceratinula) sp. 1 & 110 & $\mathrm{M} / \mathrm{T}$ & 3 & Jan/Out/Nov & Cerrado1 \\
\hline 19 - Ceratina (Ceratinula sp. 2 & $80-100-110$ & M & 3 & Mar/Mai/Dez & Cerrado1 \\
\hline 20 - Ceratina (Calloceratina) chloris (Fabricius, 1804) & 134 & M & 1 & Novembro & Cerrado1 \\
\hline \multicolumn{6}{|l|}{ Xylocopinae, Xylocopini } \\
\hline 21 - Xylocopa (Megaxylocopa) frontalis (Olivier, 1789) & $121-138$ & $\mathrm{M} / \mathrm{T}$ & 2 & Nov/Dez & Cerrado2 \\
\hline 22 - Xylocopa virescens (Lepeletier, 1841) & $66-121$ & M & 2 & $\mathrm{Jul} / \mathrm{Dez}$ & Cerrado2 \\
\hline 23 - Xylocopa hirsutissima (Fabricius, 1775) & 136 & M & 1 & Dezembro & Cerrado1 \\
\hline 24 - Xylocopa nogueirai Hurd \& Moure, 1961 & 60 & $\mathrm{~T}$ & 1 & Outubro & Cerrado2 \\
\hline
\end{tabular}


Tabela 2. Espécies e números de abelhas relacionadas com os meses, período e espécies vegetais em que foram coletadas, nas diferentes áreas de cerrado, no município de Pirassununga-SP, de agosto/2000 a julho/2001.

\begin{tabular}{ccccc}
\hline & $*^{1}$ Código das Espécies & Período & Total de Espécimes & Mês de Coleta \\
Espécies das abelhas coletadas & Vegetais & Manhã/ Tarde & Coletados & Coleta \\
& & & \\
\hline
\end{tabular}

\section{Bombinae, Bombini}

25 - Bombus (Fervidobombus) morio (Swederus, 1787)

$20-46-56-138$

$\mathrm{M} / \mathrm{T}$

Ago/Nov/Dez

Cerrado 2

\section{Meliponinae, Meliponini}

26 - Tetragonisca angustula angustula (Latreille, 1811)

27 - Plebeia droryana (Friese, 1900)

20-34-36-66-103-107-113

34-50-99-107-109

28 - Paratrigona lineata (Lepeletier, 1836)

29 - Nannotrigona testaceicornis (Lepeletier, 1836)

30 - Cephalotrigona capitata (Smith, 1854)

31 - Leurotrigona muelleri (Friese, 1900)

32 - Trigona spinipes (Fabricius, 1793)

33 - Trigona hyalinata (Lepeletier, 1836)

$\begin{array}{cc}20-34-36-66-103-107-113 & \mathrm{M} / \mathrm{T} \\ 34-50-99-107-109 & \mathrm{M} / \mathrm{T} \\ 25-33-34-40-66-96-113-120 & \mathrm{M} / \mathrm{T} \\ 90 & \mathrm{~T} \\ 11-34-119 & \mathrm{M} / \mathrm{T} \\ 3-17-34-99 & \mathrm{M} / \mathrm{T} \\ 5-34-47-51-66-78-81-103- & \mathrm{M} / \mathrm{T} \\ 107-113-117-131 & \\ 34-43-50-55-57-69-90-91- & \mathrm{M} / \mathrm{T} \\ 104-117-139 & \end{array}$

$7 \quad$ Ago/Nov/Dez $\quad$ Cerrado 2

\section{.}


Tabela 2. Espécies e números de abelhas relacionadas com os meses, período e espécies vegetais em que foram, nas diferentes áreas de cerrado, no município de Pirassununga-SP coletadas, de agosto/2000 a julho/2001.

\begin{tabular}{|c|c|c|c|c|c|}
\hline Espécies das abelhas coletadas & $\begin{array}{c}\text { *1 Código das Espécies } \\
\text { Vegetais }\end{array}$ & $\begin{array}{c}\text { Período } \\
\text { Manhã/ Tarde }\end{array}$ & $\begin{array}{c}\text { Total de Espécimes } \\
\text { Coletados }\end{array}$ & Mês de Coleta & $\begin{array}{c}\text { *2 Área de }^{2} \\
\text { Coleta }\end{array}$ \\
\hline \multicolumn{6}{|l|}{ Meliponinae, Meliponini } \\
\hline 34 - Scaptotrigona sp. gr. Depilis (Moure, 1942) & 8-10-29-33-34-94-109-113 & $\mathrm{M} / \mathrm{T}$ & 34 & $\begin{array}{c}\text { Jan/Mar/Abr/Mai/Jul/ } \\
\text { Ago/Set/Out }\end{array}$ & Cerrado1 e 2 \\
\hline 35 - Schwarziana Quadripunctata (Lepeletier, 1836) & 57 & M & 1 & Outubro & Cerrado1 \\
\hline 36 - Melipona Quadrifasciata (Lepeletier, 1836) & 9-96-140 & $\mathrm{M}$ & 3 & Fev/Abr/Set & Cerrado2 \\
\hline
\end{tabular}

\section{HALICTIDAE}

\section{Halictinae, Augochlorini}

37 - Pseudoaugochloropsis graminea (Fabricius, 1804)

20-136

8-10-11-20-28-32-38-

$\mathrm{M} / \mathrm{T}$

Maio e Dezembro

Cerrado1 e 2

38 - Augochloropsis cupreola (Cockerell, 1900)

$$
100-126
$$

$\mathrm{M} / \mathrm{T}$

an/Mar/Abr/Mai/Ago/

Cerrado1 e 2

39 - Augochlora (Augochlora) faxiana Cockerell, 1900

$10-110$

40 - Augochloropsis hebescens (Smith, 1879)

114-119-136

41 - Ceratalictus theius (Schrottky, 1910)

11-34-60-123-136

$\mathbf{4 2}$ - Rhectomia sp.

$$
\text { Nov/Dez }
$$

Mar/Abr/Out

Jan/Abr/Nov/Dez

Cerrado1

Fev/Mar/Out/Dez

Cerrado1 e 2

Outubro

Cerrado1 
Tabela 2. Espécies e números de abelhas relacionadas com os meses, período e espécies vegetais em que foram coletadas, nas diferentes áreas de cerrado, no município de Pirassununga-SP, de agosto/2000 a julho/2001.

\begin{tabular}{ccccc}
\hline & $*^{1}$ Código das Espécies & Período & Total de Espécimes & Mês de Coleta \\
Espécies das abelhas coletadas & Vegetais & Manhã/ Tarde & Coletados & Coleta \\
& & & \\
\hline
\end{tabular}

\section{Halictinae, Halictini}

43 - Dialictus $s p$.

Novembro

Cerrado1

\section{MEGACHILIDAE}

Megachilinae, Megachilini

44 - Coelioxys sp.

$11-25-46-94$

20

45 - Megachile anthidioides Rdoskowiski, 1874

46 - Megachile (Leptorachis) cf. paulistana Schrottky, 1902

47 - Megachile sp.

Megachilidae, Anthidiini

48 - Hypanthidium sp1

49 - Hypanthidium $s p 2$
$20-68$

20-25
91
$\mathrm{M} / \mathrm{T}$

M

$\mathrm{M} / \mathrm{T}$

$\mathrm{T}$

T

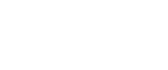

4
1
8
1

$\begin{array}{cc}\text { Jan/Mar/Abr/Dez } & \text { Cerrado1 e } 2 \\ \text { Dezembro } & \text { Cerrado2 } \\ \text { Jan/Fev/Out/Dez } & \text { Cerrado1 e 2 } \\ \text { Março } & \text { Cerrado1 }\end{array}$

M

M

$\begin{array}{lc}\text { Março e Dezembro } & \text { Cerrado1 e } 2 \\ \text { Março e Dezembro } & \text { Cerrado2 }\end{array}$


Tabela 2. Espécies e números de abelhas relacionadas com os meses, período e espécies vegetais em que foram coletadas, nas diferentes áreas de cerrado, no município de Pirassununga-SP, de agosto/2000 a julho/2001.

\begin{tabular}{lcccc}
\hline & ${ }^{* 1}$ Código das Espécies & Período & Total de Espécimes & Mês de Coleta \\
Espécies das abelhas coletadas & Vegetais & Manhã/ Tarde & Coletados & Coleta \\
& & & \\
\hline
\end{tabular}

\section{ANDRENIDAE}

Oxainae

50 - Oxaea austera Kug, 1807

$\mathbf{5 1}$ - Oxaea flavescens Kug, 1807

66-103

$\mathrm{M} / \mathrm{T}$

17

Julho/Agosto

Cerrado2

66

$\mathrm{M} / \mathrm{T}$

6

Julho

Cerrado2

$*^{1}$ - De acordo com a Tabela 1

$*^{2}$ - Cerrado-1: Cerradão

$*^{2}$ - Cerrado-2: Cerrado senso strictu 
Com relação ao número de indivíduos coletados por família verificou-se que Apidae foi a mais abundante (84,5\%), seguida de Halictidae (7,5\%), Andrenidae (4,5\%) e Megachilidae $(3,5 \%)$. A maior riqueza em gêneros foi observada em Apidae $(67,8 \%)$, seguida por Halictidae (19,3), Megachilidae (9,7\%) e a menor em Andrenidae (3,2\%). A família com maior diversidade de espécies também foi Apidae (70,6\%), acompanhada por Halictidae (13,7\%), Megachilidae $(11,8 \%)$ e Andrenidae (3,9\%) (Figura 5).

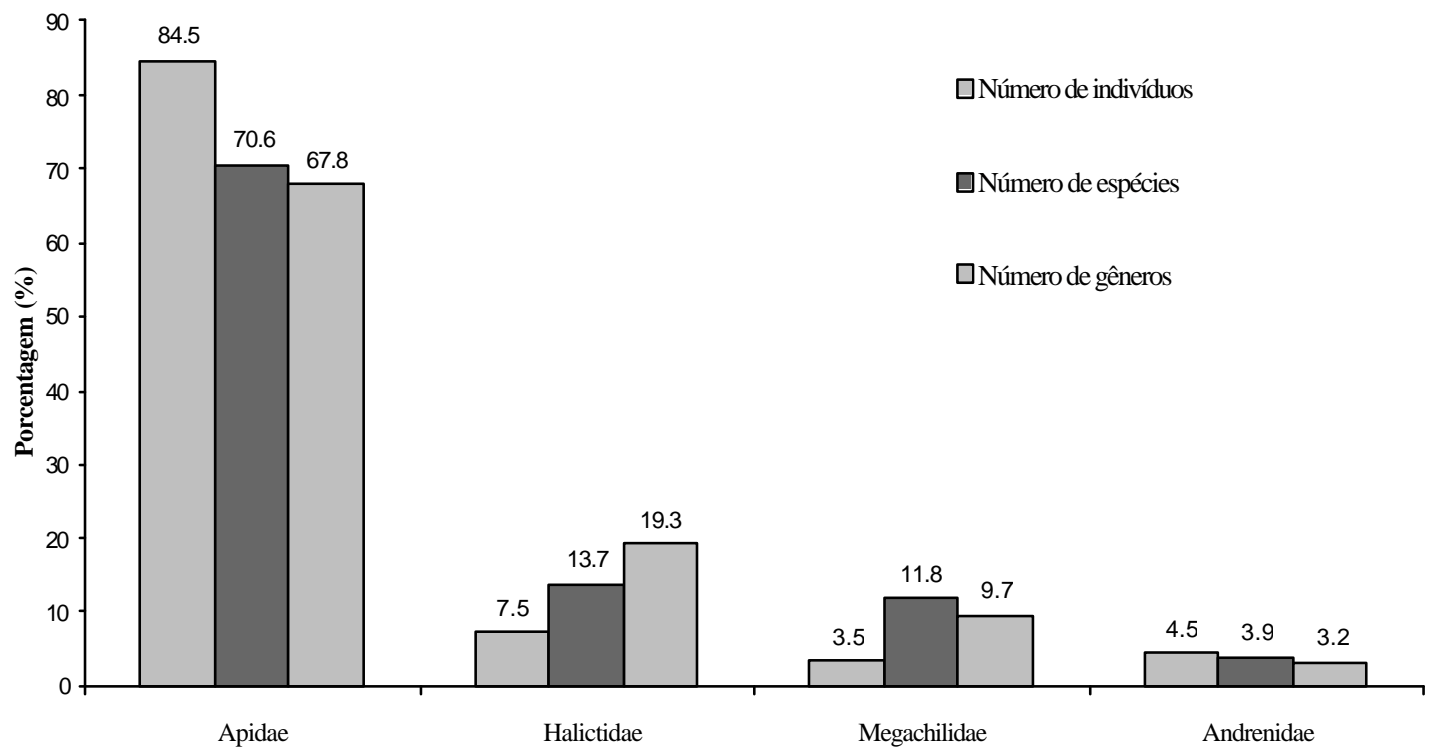

Figura 5 - Distribuição do número de indivíduos, de espécies e de gêneros entre as famílias de abelhas (Apoidea) coletadas nas áreas de cerrado, no município de Pirassununga-SP, entre agosto/2000 e julho/2001.

O estabelecimento de comparações com dados obtidos por outros autores, mesmo para vegetação de cerrado torna-se difícil devido principalmente às diferenças no tipo de coleta e no tamanho das áreas amostradas (Silveira, 1989).

Apesar disso, padrão semelhante foi encontrado em outras áreas de cerrado estudadas: Corumbataí/SP (Campos,1989); Cajurú/SP (Pedro, 1992); Luiz Ântonio/SP (Mateus, 1998). 
Vários fatores podem ser apontados como prováveis causas das variaçãoes no número de espécies de cada família nos diferentes locais (Silveira et al., 1993). Segundo Roubik (1989), condições para nidificação, competição por alimento e a história natural da distribuição geográfica, de cada grupo, são fatores preponderantes.

Entretanto, nenhuma conclusão concreta existe ainda para explicar os padrões observados e a própria existência destes padrões poderia ser questionada (Silveira et al., 1993).

A família Apidae, mesmo em alguns locais em que Apis mellifera foi excluída da análise, apresentou maior número de indivíduos coletados na maioria das áreas de cerrado estudadas, com exceção de Corumbataí-SP (Campos, 1989), onde a Apidae foi a família com a maior abundância de abelhas.

Halictidae ocupa o segundo lugar em riqueza de espécies em 3 áreas de cerrado: Corumbataí (17,1\%), Paraopeba (20,6\%) e Uberlândia (24,4\%). Esta família apresenta distribuição mundial, com alguns gêneros exclusivos da região Neotropical e outros com ampla distribuição, entretanto, são mais diversificados nas regiões temperadas (Michener, 1979).

Knoll (1985) observou uma baixa diversidade de espécies da família Megachilidae no Campus da USP, São Paulo. Fato semelhante foi constatado por Campos(1989), Carvalho (1990) e Mateus (1998) em diferentes áreas de cerrado. Dados obtidos no presente trabalho enfatizaram este mesmo fato.

De acordo com Roubik (1989) fatores citados como determinantes na baixa freqüência do número de espécies de Megachilidae, em alguns estudos, poderiam estar relacionados com a distribuição espacial e temporal restrita das espécies desta família, aliados ao hábito relativamente especializado das visitas florais destas abelhas.

Nos levantamentos realizados no Brasil, a família Andrenidae aparece, invariavelmente, representada por um número baixo de espécies, nas áreas de cerrado (Campos, 1989; Silveira, 1989; Carvalho, 1990; Martins, 1990; Pedro, 1992; Mateus, 1998). Em Pirassununga confirmouse esta tendência, pois a família Andrenidae foi representada por apenas 2 espécies do gênero Oxaea.

No presente trabalho não houve a coleta de nenhum representante da família Colletidade. Sofia (1996) que realizou levantamentos em duas áreas urbanas também não registrou a coleta de nenhum espécime desta família, fato que não ocorreu em outros levantamentos de diferentes áreas de cerrado, como Campos (1989) que encontrou 4 espécies e 
Mateus (1998) que encontrou 5 espécies de Colletidae. Este fato pode sugerir que esta área de cerrado de Pirassununga pode ter sofrido algum tipo de disturbio em sua estrutura.

O Quociente de Similaridade (QS) entre as áreas é $55.1 \%$ e a Porcentagem de Similaridade $(\% \mathrm{~S})$ é $66.6 \%$, com apenas 19 espécies comuns a ambas as áreas. Na primeira área obteve-se o Índice de Diversidade (Shannon-Weaner) $\mathrm{H}=2.3987, \mathrm{~V}(\mathrm{H})=0.0104$, e as espécies predominantes foram: Apis mellifera, Scaptotrigona sp.gr. depilis, Tetrapedia rugulosa e Exomalopsis sp. Para a segunda área encontrou-se $\mathrm{H}=2.8914, \mathrm{~V}(\mathrm{H})=0.0046$, e as espécies predominantes foram: Apis mellifera, Trigona hyalinata, Trigona spinips e Ceratina (Crewella) sp. (Tabelas 3 e 4).

Roubik (1989) considera que, o comportamento eussocial, a perenidade da colônia e os hábitos generalizados de forrageio são características relacionadas com as condições tropicais.

Por outro lado, existe uma tendência de aumento na proporção de espécies de Halictidade em áreas com distúrbios (Laroca et al., 1982).

Quanto as espécies levantadas, 25,5\% foram eussociais e representaram 64\% do número total de indivíduos. Essas abelhas apresentam a capacidade de comunicar as fontes de alimento e possuem colônias populosas (Lindauer \& Kerr, 1960), possibilitando o aparecimento de um número elevado de abelhas nas flores provenientes de uma única colônia (Sakagami et al., 1967).

Tais características poderiam ser usadas como argumento para excluir as abelhas eussociais das análises faunísticas nos estudos de comunidades. Porém, como elas interagem com as outras abelhas e são importantes na distribuição de recursos, Cure et al. (1991) recomendam, tanto a coleta simultânea com as outras abelhas, como a sua inclusão nas análises ecológicas.

Segundo Lindauer \& Kerr (1960), o gênero Trigona apresenta espécies com colônias muito populosas, contendo de 5.000 a 180.000 indivíduos. O sistema de comunicação da fonte alimentar é provavelmente tão eficiente quanto ao de Apis (Kerr et al., 1981), o que justificaria provavelmente o fato de ter sido o segundo gênero mais coletado. $\mathrm{O}$ mesmo resultado também foi obtido por Mateus (1998) no cerrado de Luis Antônio-SP.

Entre as abelhas, Stricker (1979) salienta a vantagem que as abelhas poliléticas apresentam por poderem, em épocas de escassez de alimento, suprirem suas necessidades, utilizando-se de um maior número de espécies de plantas. 
Tabela 3. Número de insetos coletados quinzenalmente, dominância, abundância, freqüência, constância e predominância em levantamentos no cerradão, no município de Pirassununga-SP, de agosto/2000 a julho/2001.

\begin{tabular}{|c|c|c|c|c|c|c|c|c|c|c|c|c|c|c|c|c|c|c|c|c|c|c|c|c|c|c|c|c|c|c|c|}
\hline \multicolumn{32}{|c|}{ Meses } \\
\hline Spp & $\mathbf{J}$ & $\mathbf{J}$ & $\mathbf{F}$ & $\mathbf{F}$ & $\mathbf{M}$ & M & A & 11 & A 1 & M & M & $\mathbf{J}$ & $\mathbf{J}$ & 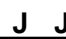 & & A & A & $\mathbf{s}$ & $\mathbf{s}$ & 0 & 0 & $\mathbf{N}$ & $\mathbf{N}$ & D [ & D 1 & $\mathbf{T}$ & D & A & $\mathbf{F}$ & c & $\mathbf{P}$ \\
\hline Coelioxys sp. & & & & & & & & & & & & & & 1 & & & & & & 1 & & & & & & 21 & ND & d & PF & $\mathrm{Y}$ & \\
\hline Megachile (Leptorachis) cf. paulistana & & & & & & & & & & & & & & 3 & & & & & & & & & & & & 31 & ND & c & $\mathrm{F}$ & $\mathrm{z}$ & \\
\hline Hypanthidium sp.1 & & & & & & & & & & & & & & & & & & & 1 & & & & & & & 11 & ND & $\mathrm{r}$ & PF & $\mathrm{z}$ & \\
\hline Megachile sp. & & & & & & & & & & & & & & & & & & 1 & & & & & & & & 11 & ND & $\mathrm{r}$ & PF & z & \\
\hline Melissodes (Ecplectica) sexcinta & & & & & & & & & & & & & & & & & & 1 & & 1 & & & & & & 21 & ND & $d$ & PF & $\mathrm{Y}$ & \\
\hline Rhectomia $\mathrm{sp.}$. & & & & & & & & 1 & 1 & & & & & & & & & & & & & & & & & 11 & ND & $r$ & PF & $\mathrm{z}$ & \\
\hline Exomalopsis sp. & & & & & & & & 3 & 3 & & & & 1 & 1 & & & & 1 & & & & & & & & 6 & D & $\mathrm{a}$ & MF & W & $\mathbf{x}$ \\
\hline Dialictus sp. & & & & & & & & & & 1 & & & & & & & & & & & & & & & & 11 & ND & $\mathrm{r}$ & PF & $\mathrm{z}$ & \\
\hline Tetrapedia (Tetrapedia) rugulosa & & & & & & 1 & 1 & 2 & 2 & 2 & & 2 & 3 & 1 & & & 2 & 2 & & & & 1 & & & & 17 & $\mathrm{D}$ & $\mathrm{ma}$ & MF & W & $\mathbf{x}$ \\
\hline Augochlora (Augochlora) faxiana & & & & & & & & 1 & & & & & & & & & & & 1 & & & & & & & 21 & ND & d & $\mathrm{PF}$ & $\mathrm{Y}$ & \\
\hline Augochloropsis cupreola & & & & & & & & & & & 1 & & & & & & & 1 & & 4 & & & & & & 6 & $\mathrm{D}$ & $\mathrm{a}$ & MF & $\mathrm{Y}$ & \\
\hline Pseudoaugochloropsis graminea & & & & & & & & & & & & 1 & 1 & & & & & & & & & & & & & 21 & ND & $\mathrm{d}$ & $\mathrm{PF}$ & $\mathrm{Y}$ & \\
\hline Augochloropsis hebescens & & & & & & & & & & 1 & & 2 & & 1 & & & & & & & 1 & & & & & 5 & $\mathrm{D}$ & $\mathrm{c}$ & $\mathrm{F}$ & W & \\
\hline Ceratalictus theius & & & & & & & & & & & & 2 & & & & & 1 & 1 & 1 & & & & & & & 5 & $\mathrm{D}$ & $\mathrm{c}$ & $\mathrm{F}$ & w & \\
\hline Ceratina (Ceratinula) sp. 1 & & & & & & & & 1 & 1 & & 1 & & & 1 & & & & & & & & & & & & 31 & ND & c & $\mathrm{F}$ & $\mathrm{Y}$ & \\
\hline Ceratina (Ceratinula) sp. 2 & & & & & & & & & & & & & 1 & & & & & 1 & & & & & 1 & & & 31 & ND & $\mathrm{c}$ & $\mathrm{F}$ & $\mathrm{Y}$ & \\
\hline Ceratina (Calloceratina) chloris & & & & & & & & & & 1 & & & & & & & & & & & & & & & & 11 & ND & $\mathrm{r}$ & $\mathrm{PF}$ & z & \\
\hline Ceratina (Crewella) sp. & & & & & & & & & & & 1 & & 1 & & & & & & & & & & & & & 21 & ND & $d$ & $\mathrm{PF}$ & $\mathrm{Y}$ & \\
\hline Ceratina (Crewella) maculifrons & & & & & & & & & & & & & 1 & & & & & 1 & & & & & & & & 21 & ND & $d$ & PF & $\mathrm{Y}$ & \\
\hline Xylocopa hirsutissima & & & & & & & & & & & & 1 & & & & & & & & & & & & & & 11 & ND & $\mathrm{r}$ & $\mathrm{PF}$ & $z$ & \\
\hline Apis (mellifera) mellifera & 2 & 4 & 4 & & & & 7 & 1 & 19 & & 2 & 3 & & 13 & & & & 20 & & & 2 & 1 & 4 & & & 81 & $\mathrm{D}$ & sa & SF & w & $\mathbf{x}$ \\
\hline Paratrigona lineata & & & & & & & & & & & & & 1 & & & & & & & & & & & & & 11 & ND & $\mathrm{r}$ & $\mathrm{PF}$ & z & \\
\hline Nanotrigona testaceicornis & & & & & & & 2 & & & & & & & & & & & & & & & & & & & 21 & ND & $d$ & $\mathrm{PF}$ & $\mathrm{z}$ & \\
\hline Cephalotrigona capitata & & & & & & & & & & & & & & & & & & & & 1 & 1 & & & & & 21 & ND & $d$ & PF & $\mathrm{Y}$ & \\
\hline Schwarziana quadripunctata & & & & & & & & 1 & 1 & & & & & & & & & & & & & & & & & 11 & ND & $\mathrm{r}$ & $\mathrm{PF}$ & z & \\
\hline Trigona hyalinata & & & & & & & & 3 & 3 & 1 & & & & & & & & & & & & 6 & & & & 10 & $\mathrm{D}$ & $\mathrm{ma}$ & MF & $\mathrm{Y}$ & \\
\hline Trigona spinipes & & & & & & & & & & & & 2 & & 3 & & & & & & & & & & & & 5 & $\mathrm{D}$ & c & $\mathrm{F}$ & $\mathrm{Y}$ & \\
\hline Tetragonisca (angustula) angustula & & 1 & & & & & & & & & & & 2 & & & & & & & & & & & & & 31 & ND & $\mathrm{c}$ & $\mathrm{F}$ & $\mathrm{Y}$ & \\
\hline Scaptotrigona sp. gr. depilis & & 3 & 1 & & & & & 1 & 1 & & & & & 10 & & & & 7 & & & & 1 & & & & 23 & $\mathrm{D}$ & $\mathrm{ma}$ & & w & $\mathbf{x}$ \\
\hline Plebeia droryana & & & & & & & & & & & & & 2 & & & & & 2 & & & & 2 & & & & 6 & D & $\mathrm{a}$ & & $\mathrm{Y}$ & \\
\hline Total & 2 & 8 & 5 & 0 & 0 & 1 & 10 & 3 & 2 & 6 & 5 & 13 & 13 & $34 \quad 0$ & 0 & 0 & 3 & 38 & 3 & 7 & 4 & 11 & 5 & 0 & & 200 & & & & & \\
\hline
\end{tabular}

Dominância (D) - D =dominante / ND = não dominante / SA = super dominante

Abundância (A) - $\mathrm{a}=$ abundante $/ \mathrm{ma}=$ muito abundante $/ \mathrm{sa}=$ super abundante $/ \mathrm{d}=$ disperso $/ \mathrm{c}=\mathrm{comum} / \mathrm{r}=\mathrm{raro}$

Frequência $(\mathbf{F})-\mathrm{MF}=$ muito frequente $/ \mathrm{F}=$ frequente $/ \mathrm{PF}=$ pouco frequente $/ \mathrm{SF}=$ super frequente

Constância $(\mathbf{C})$ - $\mathrm{W}=$ constante $/ \mathrm{Y}=$ acessório $/ \mathrm{Z}=$ acidental

Predominância $(\mathbf{P})$ - $\mathrm{P}=$ espécies predominantes $=\mathrm{D}+\mathrm{a} / \mathrm{sa} / \mathrm{ma}+\mathrm{f} / \mathrm{sf} / \mathrm{mf}+\mathrm{W}$ 
Tabela 4. Número de insetos coletados quinzenalmente, dominância, abundância, freqüência, constância e predominância em levantamentos no cerrado "sensu strictu", no município de Pirassununga-SP, de agosto/2000 a julho/2001.

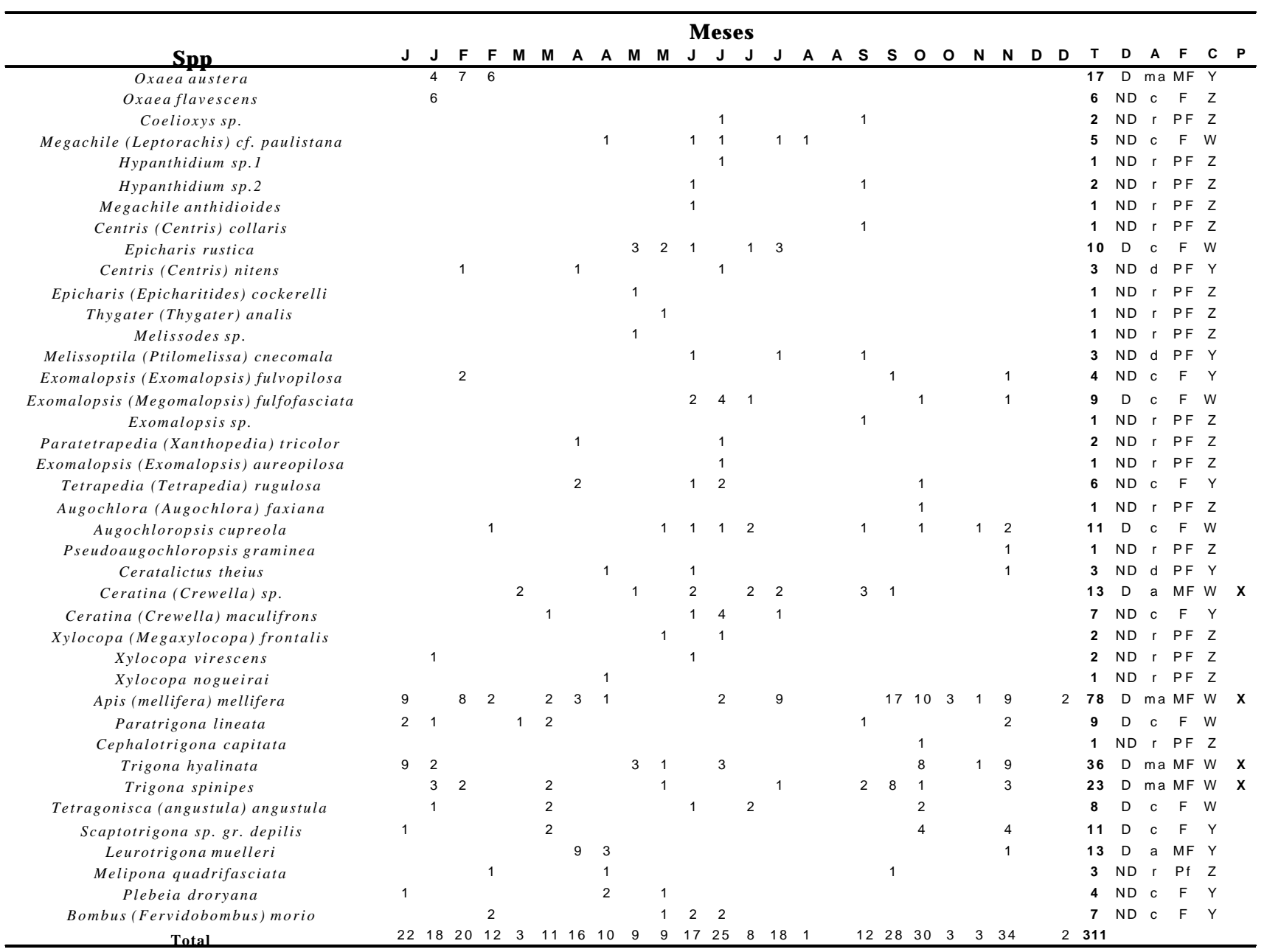

Legenda: Idem Tabela 3 


\subsection{Composição físico-química das amostras de mel}

Foram capturadas dez colméias de Apis mellifera (cinco em cada área do projeto), e quatro colônias de diferentes espécies de meliponas, que se encontram num local intermediário às duas áreas: Mirim (Plebeia droryana); Jataí (Tetragonisca angustula); Mombucão (Cephalotrigona capitata) e Mandaçaia (Melipona quadrifasciata).

Durante o período de maio/2001 a abril/2002 realizou-se a colheita do mel maduro dos quadros marcados das colméias de Apis mellifera, num total de doze coletas, com obtenção de 34 amostras de méis. Com relação às abelhas sem ferrão, foi feita apenas uma coleta em cada colônia, no mês de setembro de 2001, com a obtenção de quantidade bastante reduzida de mel, suficiente para serem feitas apenas parte das análises propostas (Tabela 5).

Tabela 5. Análises físico-químicas das amostras de méis das abelhas sem ferrão, em áreas de cerrado do município de Pirassununga-SP.

\begin{tabular}{cccccccc}
\hline Amostra & $\begin{array}{c}\text { Cor } \\
(\mathbf{n m})\end{array}$ & $\begin{array}{c}\text { HMF } \\
(\mathbf{m g} / \mathbf{k g})\end{array}$ & $\begin{array}{c}\text { Umidad } \\
\mathbf{e}(\boldsymbol{\%})\end{array}$ & $\begin{array}{c}\text { Cinzas } \\
(\boldsymbol{\%})\end{array}$ & $\mathbf{P H}$ & $\begin{array}{c}\text { Acidez } \\
(\mathbf{m e q} / \mathbf{k g}\end{array}$ & $\begin{array}{c}\text { Ind. } \\
\text { Formol } \\
(\mathbf{m l} / \mathbf{k g})\end{array}$ \\
\hline $\mathbf{1}$ & 0,272 -âmbar claro & 7,64 & 31 & 1,18 & 3,83 & 52 & 21,5 \\
$\mathbf{2}$ & 0,157-branco & 8,12 & 25,5 & 0,32 & 3,69 & 26 & 12 \\
$\mathbf{3}$ & 0,182-branco & 3,38 & 27 & 0,52 & 3,62 & 31,5 & 4,5 \\
$\mathbf{4}$ & 0,229-âmbar extra & 1,03 & 34 & 0,54 & 4,52 & 16,5 & 4 \\
& claro & & & & & & \\
\hline
\end{tabular}

1. Mirim (Plebeia droryana) - 2. Jataí (Tetragonisca angustula)

3. Mombucão (Cephalotrigona capitata) - 4. Mandaçaia (Melipona quadrifasciata).

Os resultados apresentados como valor médio de 3 repetições (com exceção da cor), dos caracteres físico-químicos analisados das 34 amostras de méis de Apis mellifera, provenientes das duas áreas de cerrado, são apresentados nas Tabelas de 6 a 10. 
Tabela 6. Identificação das amostras e análise da cor de 16 amostras de mel da área de cerradão do município de Pirassununga-SP, coletadas de maio/2001 a abril/2002.

\begin{tabular}{ccc}
\hline Data de Coleta & $\begin{array}{c}\text { Código da amostra/ } \\
\text { Número da Caixa }\end{array}$ & $\begin{array}{c}\text { Análise de Cor } \\
\text { (nm) }\end{array}$ \\
\hline Junho/2001 & A-2/Cx.-1 & 1.010-escuro \\
Julho/2001 & A-3/Cx.-1 & 0.669-escuro \\
Agosto/2001 & A-6/Cx.-1 & 0.459-escuro \\
Setembro/2001 & A-11/Cx.-1 & 0.106 -branco água \\
Setembro/2001 & A-12/Cx.-2 & 0.102 -branco água \\
Setembro/2001 & A-13/Cx.-3 & 0.108 -branco água \\
Outubro/2001 & A-19/Cx.-1 & 0.146 -extra branco \\
Outubro/2001 & A-20/Cx.-2 & $0.157-$ branco \\
Outubro/2001 & A-21/Cx.-3 & 0.168 -branco \\
Outubro/2001 & A-22/Cx.-4 & 0.183 -branco \\
Outubro/2001 & A-23/Cx.-5 & $0.152-$ branco \\
Novembro/2001 & A-25/Cx.-1 & 0.277 -âmbar claro \\
Novembro/2001 & A-26/Cx.-2 & 0.281 -âmbar claro \\
Novembro/2001 & A-27/Cx.-3 & 0.388 -âmbar \\
Novembro/2001 & A-28/Cx.-4 & 0.517 -escuro \\
Novembro/2001 & A-29/Cx.-5 & 0.435 -escuro \\
\hline
\end{tabular}


Tabela 7. Identificação das amostras e análise da cor de 18 amostras de mel da área de cerrado "sensu strictu" do município de Pirassununga-SP, coletadas de maio/2001 a abril/2002.

\begin{tabular}{|c|c|c|}
\hline Data de Coleta & $\begin{array}{l}\text { Código da amostra/ } \\
\text { Número da Caixa }\end{array}$ & $\begin{array}{c}\text { Análise de Cor } \\
(\mathbf{n m})\end{array}$ \\
\hline Maio/2001 & A-1/Cx.-1 & 0.316-âmbar claro \\
\hline Julho/2001 & A-4/CX. -1 & 0.311-âmbar claro \\
\hline Julho/2001 & A-5/Cx. -2 & 0.319-âmbar claro \\
\hline Agosto/2001 & A-7/CX. -1 & 0.097-branco água \\
\hline Agosto/2001 & A-8/CX. -2 & 0.145-branco \\
\hline Agosto/2001 & A-9/CX. -3 & 0.208-âmbar extra claro \\
\hline Agosto/2001 & A-10/Cx. 4 & 0.178-branco \\
\hline Setembro/2001 & A-14/Cx.-1 & 0.127 -extra branco \\
\hline Setembro/2001 & A-15/Cx.-2 & 0.160-branco \\
\hline Setembro/2001 & A-16/Cx.-3 & 0.173-branco \\
\hline Setembro/2001 & A-17/Cx.-4 & 0.166-branco \\
\hline Setembro/2001 & A-18/Cx.-5 & 0.128 -extra branco \\
\hline Outubro/2001 & A-24/Cx.-3 & 0.189-branco \\
\hline Novembro/2001 & A-30/Cx.-3 & 0.348-âmbar \\
\hline Março/2002 & A-31/Cx.-2 & 0.196-âmbar extra claro \\
\hline Abril/2002 & A-32/Cx.-1 & 0.564-escuro \\
\hline Abril/2002 & A-33/Cx.-2 & 0.603-escuro \\
\hline Abril/2002 & A-34/Cx.-4 & 0.551-escuro \\
\hline
\end{tabular}


Tabela 8. Média de umidade, proteína, cinzas, condutividade elétrica, hidroximetilfurfural (HMF), pH e acidez de amostras de mel das áreas de cerrado do município de PirassunungaSP, coletadas de maio/2001 a abril/2002.

\begin{tabular}{|c|c|c|c|c|c|c|c|}
\hline Amostra* & $\begin{array}{c}\text { Umidade } \\
(\%)\end{array}$ & $\begin{array}{c}\text { Proteína } \\
(\%)\end{array}$ & $\begin{array}{c}\text { Cinzas } \\
(\%)\end{array}$ & $\begin{array}{c}\text { Cond. El. } \\
\text { (uS) }\end{array}$ & $\begin{array}{c}\text { HMF } \\
(\mathrm{mg} / \mathrm{kg})\end{array}$ & $\mathrm{pH}$ & $\begin{array}{c}\text { Acidez } \\
\text { (meq.kg) }\end{array}$ \\
\hline 1 & 17,4 & 0,26 & 0,59 & 1249 & 4,94 & 3,77 & 25 \\
\hline 2 & 19,2 & 0,24 & 0,41 & 1041 & 9,13 & 3,73 & 29 \\
\hline 3 & 16,8 & 0,38 & 0,77 & 1945 & 0 & 4,45 & 33 \\
\hline 4 & 18,6 & 0,25 & 0,33 & 1426 & 6,59 & 3,99 & 31 \\
\hline 5 & 17 & 0,47 & 0,65 & 1619 & 10,63 & 4,02 & 32 \\
\hline 6 & 19,8 & 0,36 & 0,55 & 1320 & 9,58 & 3,71 & 21 \\
\hline 7 & 16,8 & 0,14 & 0,11 & 285 & 3,75 & 3,27 & 14,5 \\
\hline 8 & 16,6 & 0,17 & 0,07 & 432 & 4,34 & 3,3 & 19 \\
\hline 9 & 17,4 & 0,12 & 0,49 & 496 & 4,49 & 3,78 & 22,5 \\
\hline 10 & 17,2 & 0,18 & 0,15 & 357 & 3,14 & 3,67 & 19 \\
\hline 11 & 16,8 & 0,11 & 0,07 & 319 & 1,8 & 3,85 & 11,5 \\
\hline 12 & 18,6 & 0,08 & 0,13 & 406 & 2,4 & 3,42 & 13 \\
\hline 13 & 20,8 & 0,07 & 0,08 & 311 & 2,25 & 3,38 & 11,5 \\
\hline 14 & 17,4 & 0,08 & 0,03 & 284 & 1,5 & 3,37 & 12 \\
\hline 15 & 18,6 & 0,09 & 0,02 & 288 & 0,6 & 3,53 & 12 \\
\hline 16 & 17,8 & 0,1 & 0,17 & 301 & 0,54 & 3,55 & 13 \\
\hline 17 & 16,6 & 0,16 & 0,07 & 227 & 0,75 & 3,96 & 8,5 \\
\hline 18 & 18,3 & 0,09 & 0,15 & 436 & 2,55 & 3,51 & 9 \\
\hline 19 & 18 & 0,18 & 0,09 & 377 & 1,05 & 4,12 & 18 \\
\hline 20 & 18,2 & 0,36 & 0,16 & 364 & 1,8 & 4,17 & 17 \\
\hline 21 & 19,2 & 0,15 & 0,16 & 423 & 1,95 & 3,96 & 17 \\
\hline 22 & 18,4 & 0,11 & 0,22 & 509 & 2,85 & 3,98 & 19 \\
\hline 23 & 17 & 0,16 & 0,11 & 392 & 0,76 & 4,08 & 15 \\
\hline 24 & 18,6 & 0,09 & 0,17 & 479 & 2,55 & 3,95 & 19,5 \\
\hline 25 & 17,5 & 0,23 & 0,35 & 934 & 7,48 & 4,01 & 19 \\
\hline 26 & 18,5 & 0,47 & 0,3 & 807 & 2,25 & 4,04 & 25,5 \\
\hline 27 & 19,3 & 0,32 & 0,47 & 1300 & 6,74 & 4,27 & 31 \\
\hline 28 & 18,3 & 0,49 & 0,75 & 2200 & 4,44 & 4,45 & 35 \\
\hline 29 & 18,1 & 0,37 & 0,52 & 1549 & 2,55 & 4,44 & 22,5 \\
\hline 30 & 19,6 & 0,36 & 0,43 & 1049 & 3,89 & 3,95 & 6 \\
\hline 31 & 17,3 & 0,17 & 0,09 & 468 & 11,45 & 3,78 & 17 \\
\hline 32 & 17,4 & 0,24 & 0,19 & 1003 & 3,96 & 4,25 & 46 \\
\hline 33 & 17,6 & 0,46 & 0,47 & 1281 & 2,06 & 4,26 & 45 \\
\hline 34 & 17,8 & 0,4 & 0,39 & 1104 & 1,03 & 4,19 & 41 \\
\hline Média & 18,01471 & 0,232647 & 0,285588 & 793,5588 & 3,699706 & 3,887059 & 21,47059 \\
\hline DP & 1,008789 & 0,133764 & 0,216895 & 540,6827 & 3,018868 & 0,335148 & 10,31103 \\
\hline IC & 0,339085 & 0,044962 & 0,072905 & 181,74 & 1,014734 & 0,112653 & 3,465852 \\
\hline Máximo & 20,8 & 0,49 & 0,77 & 2200 & 11,45 & 4,45 & 46 \\
\hline Mínimo & 16,6 & 0,07 & 0,02 & 284 & 0 & 3,27 & 6 \\
\hline
\end{tabular}

* As identificações das amostras encontram-se nas Tabelas 6 e 7. 
Tabela 9. Média de índice de formol, açúcares totais, redutores e sacarose de amostras de mel das áreas de cerrado do município de Pirassununga-SP, coletadas de maio/2001 a abril/2002.

\begin{tabular}{|c|c|c|c|c|}
\hline Amostra* & $\begin{array}{c}\text { Ind. Form. } \\
(\mathrm{mg} / \mathrm{kg})\end{array}$ & $\begin{array}{c}\text { Totais } \\
(\%)\end{array}$ & $\begin{array}{c}\text { Redutores } \\
(\%)\end{array}$ & $\begin{array}{c}\text { Sacarose } \\
(\%)\end{array}$ \\
\hline 1 & 9 & 73,0 & 70,1 & 2,8 \\
\hline 2 & 10 & 72,4 & 70,7 & 1,6 \\
\hline 3 & 9,5 & 75,8 & 73,4 & 2,3 \\
\hline 4 & 13,5 & 78,8 & 76,3 & 2,4 \\
\hline 5 & 11 & 78,2 & 76,4 & 1,7 \\
\hline 6 & 10 & 73,7 & 72,5 & 1,1 \\
\hline 7 & 4 & 77,1 & 76,2 & 0,9 \\
\hline 8 & 5,5 & 78,1 & 77,0 & 1,0 \\
\hline 9 & 6 & 77,4 & 75,9 & 1,4 \\
\hline 10 & 4,5 & 79,3 & 77,6 & 1,6 \\
\hline 11 & 5 & 76,5 & 69,6 & 6,5 \\
\hline 12 & 3,5 & 75,2 & 70,1 & 4,8 \\
\hline 13 & 4 & 74,9 & 68,7 & 5,9 \\
\hline 14 & 4,5 & 77,3 & 71,7 & 5,3 \\
\hline 15 & 5,5 & 76,8 & 72,0 & 4,5 \\
\hline 16 & 6 & 77,1 & 73,7 & 3,2 \\
\hline 17 & 8 & 77,8 & 76,7 & 1,0 \\
\hline 18 & 6,5 & 78,7 & 77,0 & 1,6 \\
\hline 19 & 8 & 79,0 & 78,0 & 0,9 \\
\hline 20 & 15 & 77,6 & 75,7 & 1,8 \\
\hline 21 & 9,5 & 78,2 & 76,9 & 1,2 \\
\hline 22 & 5,5 & 78,7 & 66,7 & 11,4 \\
\hline 23 & 9 & 80,5 & 69,4 & 10,5 \\
\hline 24 & 7 & 81,2 & 72,0 & 8,7 \\
\hline 25 & 16 & 77,5 & 68,9 & 8,2 \\
\hline 26 & 17,5 & 76,1 & 69,1 & 6,6 \\
\hline 27 & 12,5 & 78,5 & 72,3 & 5,9 \\
\hline 28 & 10 & 79,7 & 68,1 & 11,0 \\
\hline 29 & 11 & 81,2 & 73,9 & 6,9 \\
\hline 30 & 14,5 & 78,7 & 69,2 & 9,0 \\
\hline 31 & 4 & 75,7 & 75,5 & 0,2 \\
\hline 32 & 18 & 84,1 & 73,3 & 10,3 \\
\hline 33 & 19 & 82,4 & 74,7 & 7,3 \\
\hline 34 & 16 & 85,0 & 76,2 & 8,4 \\
\hline Média & 9,3676471 & 78,005882 & 73,102941 & 4,530303 \\
\hline DP & 4,558224 & 2,768759 & 3,283244 & 3,5136264 \\
\hline IC & 1,5321584 & 0,930665 & 1,1035986 & 1,181037 \\
\hline Máximo & 19 & 85,0 & 78,0 & 11,4 \\
\hline Mínimo & 3,5 & 72,4 & 66,7 & 0,2 \\
\hline
\end{tabular}

* As identificações das amostras encontram-se nas Tabelas 6 e 7. 
Tabela 10. Média dos minerais (ppm) de amostras de mel das áreas de cerrado do município de Pirassununga-SP, coletadas de maio/2001 a abril/2002.

\begin{tabular}{|c|c|c|c|c|c|c|c|c|c|}
\hline Amostra* & $\mathbf{P}$ & $\mathrm{Ca}$ & $\mathrm{Zn}$ & $\mathrm{Cu}$ & $M n$ & $\mathrm{Mg}$ & $\mathrm{Fe}$ & $\mathrm{K}$ & $\mathrm{Na}$ \\
\hline 1 & 73,54 & 224,25 & 2,07 & 1,38 & 10,95 & 107,25 & 12,51 & 7250 & 55 \\
\hline 2 & 108 & 173,8 & 2,69 & 0,9 & 4,41 & 161,25 & 52,94 & 2750 & 55 \\
\hline 3 & 284,56 & 329,25 & 3,3 & 1,45 & 8,85 & 460,75 & 20,87 & 11500 & 60 \\
\hline 4 & 79,66 & 207,25 & 3,36 & 0,5 & 7,78 & 141,5 & 14,91 & 6000 & 45 \\
\hline 5 & 106 & 169,6 & 1,84 & 0,68 & 8,63 & 169,37 & 14 & 5000 & 70 \\
\hline 6 & 150 & 157,1 & 3,09 & 0,68 & 6 & 230 & 20,07 & 3500 & 80 \\
\hline 7 & 25,52 & 83,25 & 1,59 & 0,28 & 1,61 & 29,75 & 7,35 & 5150 & 5 \\
\hline 8 & 44,82 & 83,25 & 1,35 & 0,73 & 1,7 & 54,75 & 8,04 & 6000 & 15 \\
\hline 9 & 52,35 & 105,25 & 1,38 & 0,96 & 2,12 & 66,5 & 8,6 & 1250 & 20 \\
\hline 10 & 41,05 & 77,75 & 1,22 & 0,53 & 1,38 & 38,75 & 7,33 & 1000 & 10 \\
\hline 11 & 22,69 & 82,5 & 0,74 & 0,15 & 1,75 & 28,25 & 7,48 & 1250 & 10 \\
\hline 12 & 25,99 & 104,75 & 1,04 & 0,09 & 2,18 & 34,75 & 7,27 & 4000 & 15 \\
\hline 13 & 22,22 & 81,5 & 0,68 & 0,08 & 1,52 & 24,5 & 6,61 & 1000 & 10 \\
\hline 14 & 19,87 & 83 & 0,85 & 0,06 & 1,42 & 25,75 & 6,69 & 750 & 5 \\
\hline 15 & 20,34 & 79,75 & 0,93 & 0,39 & 0,83 & 24,25 & 7,05 & 61 & 5 \\
\hline 16 & 30,23 & 85 & 2,6 & 0,07 & 1,15 & 35,5 & 7,38 & 750 & 5 \\
\hline 17 & 23,16 & 86,75 & 1,23 & 0,46 & 0,87 & 25,25 & 7,89 & 250 & 5 \\
\hline 18 & 39,2 & 69,5 & 0,95 & 0,22 & 2,13 & 33,94 & 9,13 & 1000 & 35 \\
\hline 19 & 20,34 & 108,75 & 1,15 & 0,31 & 1,64 & 25,65 & 11,7 & 1250 & 5 \\
\hline 20 & 25,05 & 111,5 & 1,07 & 0,35 & 2,33 & 36,65 & 10,65 & 1750 & 15 \\
\hline 21 & 30,23 & 91,75 & 1 & 0,41 & 1,53 & 32,35 & 9,13 & 1250 & 10 \\
\hline 22 & 33,06 & 104,5 & 1,23 & 0,47 & 2 & 36,65 & 12,5 & 1500 & 20 \\
\hline 23 & 23,64 & 84,25 & 1,06 & 0,44 & 1,48 & 28,4 & 9,63 & 1000 & 20 \\
\hline 24 & 33,52 & 91,5 & 1,24 & 0,49 & 1,91 & 37,65 & 12,03 & 1750 & 30 \\
\hline 25 & 77,31 & 169,25 & 1,91 & 0,84 & 5,85 & 116,25 & 18,95 & 2750 & 50 \\
\hline 26 & 63,18 & 140,5 & 1,95 & 0,72 & 4,7 & 98,5 & 12,93 & 2000 & 40 \\
\hline 27 & 107,44 & 232 & 2,32 & 0,89 & 9,41 & 206,75 & 9,68 & 3750 & 30 \\
\hline 28 & 195,11 & 385,5 & 3,42 & 1,37 & 17,24 & 420 & 10,35 & 6000 & 55 \\
\hline 29 & 131,45 & 277,75 & 2,76 & 1,11 & 10,86 & 266,5 & 14,35 & 4250 & 30 \\
\hline 30 & 89,08 & 175,75 & 2,25 & 0,8 & 6,48 & 150 & 11,78 & 3000 & 30 \\
\hline 31 & 36,35 & 78,75 & 1,37 & 0,38 & 2,39 & 26,95 & 6,83 & 1250 & 15 \\
\hline 32 & 168,74 & 320,25 & 4,24 & 1,14 & 13,41 & 267 & 15,5 & 7750 & 70 \\
\hline 33 & 166,86 & 345,5 & 3,69 & 1,22 & 13,85 & 298,75 & 15,98 & 7750 & 75 \\
\hline 34 & 158,38 & 301,5 & 2,72 & 0,72 & 10,62 & 221 & 10,29 & 7250 & 50 \\
\hline Média & 71,83515 & 155,9559 & 1,890882 & 0,625588 & 5,028824 & 116,5032 & 12,30588 & 3315,029 & 30,88235 \\
\hline D. P. & 63,92112 & 92,69215 & 0,975259 & 0,397494 & 4,514727 & 117,9678 & 8,17931 & 2770,302 & 23,46728 \\
\hline I. C. $/ 0,05 \%$ & 21,48584 & 31,15666 & 0,327814 & 0,13361 & 1,517538 & 39,65258 & 2,749316 & 931,1831 & 7,88807 \\
\hline
\end{tabular}

* As identificações das amostras encontram-se nas Tabelas 6 e 7. 


\subsubsection{Cor}

As cores das 34 amostras de méis analisados são apresentadas nas Tabelas 6 e 7. Observou-se para as amostras analisadas leve predominância das cores branco $(29,4 \%)$ e escuro $(23,5 \%)$, sendo a distribuição das demais muito semelhantes (Figura 6). As cores encontradas estão dentro da norma vigente que pode variar desde o branco até o escuro (Brasil, 2000).
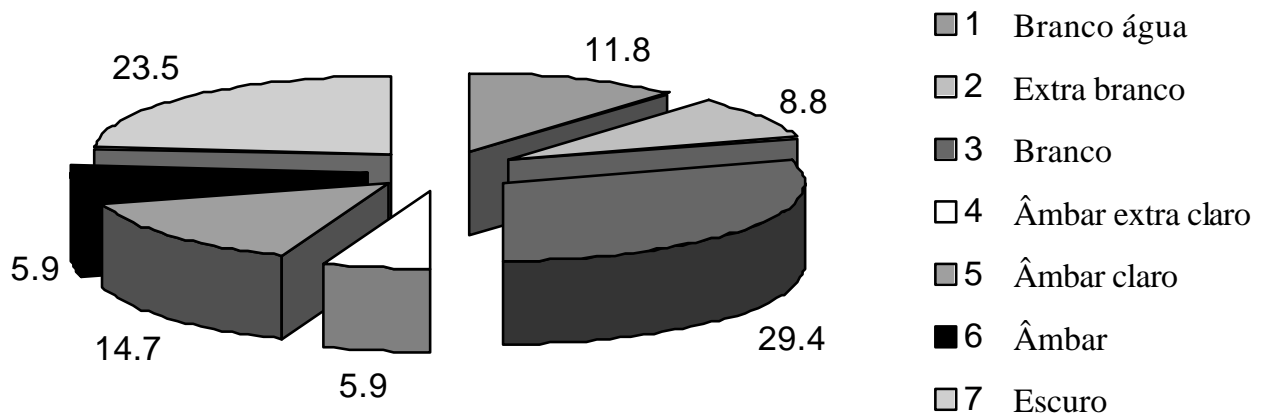

Figura 6 - Porcentagem de classes de cor em amostras de méis do cerrado do município de Pirassununga-SP, coletadas de maio/2001 a abril/2002.

Smith (1967) relata que o tempo de estocagem, a luz, o calor e as possíveis reações enzimáticas podem afetar esta propriedade física.

Segundo Seemann \& Neira (1988) a cor do mel está relacionada com sua origem floral, e é influenciada por fatores climáticos durante o fluxo de néctar e a temperatura da colméia.

\subsubsection{Umidade (\%)}

A umidade (\%) para as 34 amostras de méis analisadas varia de 16,6 a 20,8\% (Tabela 8), com uma média de 18,01 \pm 0,34\% (I.C. a 0,05\%), dentro do limite permitido pela norma vigente que é de $20 \%$, entretanto, $2,94 \%$ das amostras analisadas estão fora desta norma (Figura 7). 


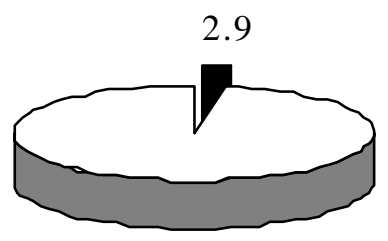

não aceitável

97.1

Figura 7 - Porcentagem de umidade aceitável ou não segundo a legislação brasileira, em amostras dos méis do cerrado do município de Pirassununga-SP, coletadas de maio/2001 a abril/2002.

Os valores obtidos estão próximos aos de Komatsu (1996) que analisou amostras de méis de São Paulo, encontrando valores para a umidade variando de 16,4 a 23,4\%.

Costa et al. (1999) trabalharam com amostras de méis de alguns estados brasileiros e encontraram valores médios de $18,37 \%$.

Marchini (2001) em análises de méis de diferentes municípios de São Paulo encontrou valores médios de 19,1 e 21,19\% para méis de flores silvestres e de eucalipto, respectivamente.

\subsubsection{Proteína $(\%)$}

O conteúdo de proteínas para as 34 amostras de méis analisados varia de 0,07 a 0,49\% (Tabela 8). O valor médio obtido de $0,23 \% \pm 0,04 \%$ (I.C. a $0,05 \%$ ), encontra-se próximo ao padrão internacional que é em média de $0,26 \%$.

Marchini (2001) em análises de méis de diferentes municípios de São Paulo encontrou valores médios de 0,19 e 0,32\% para méis de flores silvestres e de eucalipto, respectivamente.

Conforme Bath \& Singh (1999) a variação para o valor de proteína ocorre em função da origem floral. Os autores constataram 0,036 e 0,65\% para flores de Helianthus annuus $e$ Eucalyptus lanceolatus, respectivamente. Peng \& Pan (1994) encontraram para flores de Ziziphus jujuba, Astragalus sinicus, Sesame sp., flor de algodão dentre outras, variações entre 0,048 e $0,42 \%$. 


\subsubsection{Cinzas $(\%)$}

Os valores de cinzas encontrados nas 34 amostras de méis analisadas, variam de 0,02 a 0,77\% (Tabela 8) com um valor médio de $0,29 \pm 0,07 \%$ (I.C. a $0,05 \%$ ), que está abaixo do limite permitido pela legislação brasileira que estabelece o máximo de $0,6 \%$ para méis de origem floral e 1,2\% para méis de melato. Das amostras analisadas 8,8\% não estão de acordo coma legislação brasileira (Figura 8).

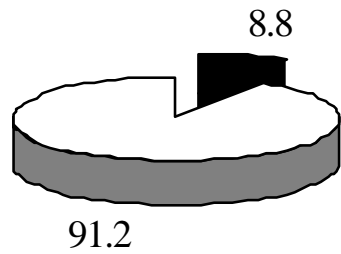

não aceitável

aceitável até $0,6 \%$

91.2

Figura 8 - Porcentagem de teor de cinzas aceitável ou não segundo a legislação brasileira, em amostras dos méis do cerrado do município de Pirassununga-SP, coletadas de maio/2001 a abril/2002.

Sodré (1999) analisando méis do litoral norte da Bahia encontrou resultados semelhantes aos do presente trabalho, com o teor de cinzas variando entre 0,09 a $0,67 \%$.

Marchini (2001) em análises de méis de diferentes municípios de São Paulo encontrou valores médios de 0,24 e 0,16\% para méis de flores silvestres e de eucalipto, respectivamente.

Bogdanov et al. (1999) mencionam que o conteúdo de cinzas é influenciado pela origem botânica.

\subsubsection{Condutividade elétrica (uS)}

Os valores de condutividade elétrica para as 34 amostras de méis análisadas variam de 284 a 2200 uS (Tabela 8), com média de 793,56 \ 181,74uS (I.C. a 0,05\%), que está praticamente no limite máximo permitido das normas internacionais que é de 200 a $800 \mathrm{uS}$, além do fato de 44,1\% das amostras encontrarem-se acima deste limite (Figura 9). 


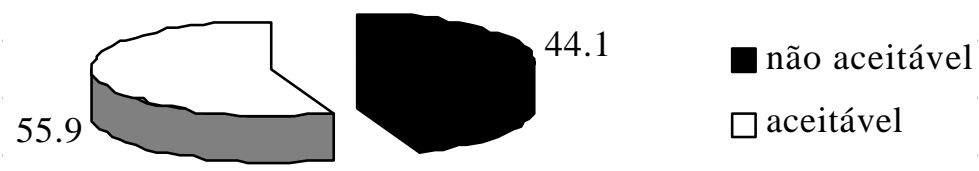

Figura 9 - Porcentagem de condutividade elétrica aceitável ou não segundo as normas internacionais, em amostras dos méis do cerrado do município de Pirassununga-SP, coletadas de maio/2001 a abril/2002.

Sodré (1999) registrou fato semelhante em amostras de méis provenientes do litoral norte da Bahia.

Os dados observados também são semelhantes aos de Horn et al. (1996) que analisaram amostras de méis de diferentes regiões do Brasil e constataram para a condutividade elétrica valores em torno de 100 a $2103 \mathrm{uS}$.

Marchini (2001) em análises de méis de diferentes municípios de São Paulo encontrou valores médios de 568,25 e 1018,65 uS para méis de flores silvestres e de eucalipto respectivamente.

\subsubsection{Hidroximetilfurfural (mg/kg)}

As quantidades de Hidroximetilfurfural (HMF) encontradas nas 34 amostras de méis analisadas (Tabela 8), variam de 0,0 a 11,45 mg/kg, com o valor médio de 3,7 $\pm 1,01 \mathrm{mg} / \mathrm{kg}$ (I.C. a $0,05 \%)$.

Com base nos valores encontrados para HMF, $100 \%$ das amostras analisadas no presente trabalho estão abaixo do valor máximo estabelecido pela norma vigente que é de 60 $\mathrm{mg} / \mathrm{kg}$.

Dayrell \& Vital (1991) analisaram amostras de méis brasileiros pelo método da AOAC e encontraram valores variando de 1,1 a $248,2 \mathrm{mg} / \mathrm{kg}$. Os autores mencionam que os méis de países tropicais possuem alto teor de HMF, tornando-se fundamental a quantificação deste componente para a verificação da qualidade do produto. 
Marchini (2001) em análises de méis de diferentes municípios de São Paulo encontrou valores médios de 19,3 e 17,4 mg/kg para méis de flores silvestres e de eucalipto, respectivamente.

\subsection{7 pH}

$\mathrm{O}$ pH das 34 amostras de méis analisadas variam de 3,27 a 4,45 (Tabela 8), com um valor médio de 3,89 \pm 0,11 (I.C. a 0,05\%). Das amostras analisadas, 97,1\% encontram-se dentro da norma vigente que é de 3,3 a 4,6 (Figura 10).

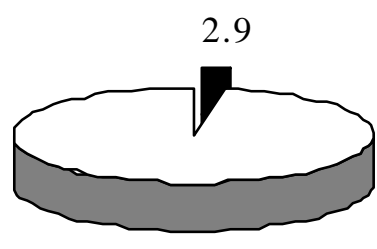

não aceitável

$\square$ aceitável

97.1

Figura 10 - Porcentagem de pH aceitável ou não segundo as normas vigentes, em amostras dos méis do cerrado do município de Pirassununga-SP, coletadas de maio/2001 a abril/2002.

Pamplona (1989) analisando amostras de méis brasileiros encontrou valores variando de 3,1 a 5,3, obtendo como valor médio de $\mathrm{pH} 3,81$.

Marchini (2001) em análises de méis de diferentes municípios de São Paulo encontrou valores médios de 3,2 e 3,6 para méis de flores silvestres e de eucalipto, respectivamente.

\subsubsection{Acidez $(\mathrm{meq} / \mathrm{kg})$}

A acidez da 34 amostras de méis analisadas apresentaram valores variando de 6,0 a 46,0 meq/kg com média de 21,47 $\pm 3,47 \mathrm{meq} / \mathrm{kg}$ (I.C. a 0,05\%), estando todas as amostras em conformidade com a norma vigente que é de no máximo 50 meq/kg (Tabela 8).

Campos et al. (1999) analisando amostras de méis brasileiros encontraram valores variando de 8,20 a $50,0 \mathrm{meq} / \mathrm{kg}$.

Marchini (2001) em análises de méis de diferentes municípios de São Paulo encontrou valores médios de 30,1 e 33,8 para méis de flores silvestres e de eucalipto, respectivamente. 


\subsection{9 Índice de formol}

Os valores encontrados para o índice de formol das 34 amostras de méis analisadas variaram de 3,5 a 19,0 (Tabela 9) com um valor médio de 9,37 $\pm 1,53 \mathrm{ml} / \mathrm{kg}$ (I.C. a 0,05\%), que está dentro de norma vigente que é de 4,5 a $15,0 \mathrm{ml} / \mathrm{kg}$. Obteve-se 14,7\% das amostras analisadas fora dos limites da legislação (Figura 11).

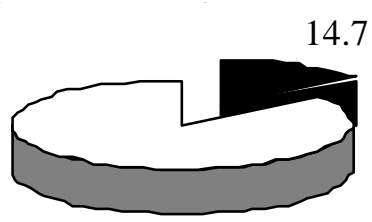

não aceitável

$\square$ aceitável

85.3

Figura 11 - Porcentagem de índice de formol aceitável ou não segundo as normas vigentes, em amostras dos méis do cerrado do município de Pirassununga-SP, coletadas de maio/2001 a abril/2002.

Komatsu (1996) analisando amostras de méis do Estado de São Paulo encontrou para o índice de formol os seguintes valores médios: 13,9 ml/kg (mel de cana-de-açúcar), 6,9 ml/kg (mel de flores silvestres), $6,9 \mathrm{ml} / \mathrm{kg}$ (mel de flores de eucalipto), 6,3 (mel de flores de laranjeira).

Marchini (2001) em análises de méis de diferentes municípios de São Paulo encontrou valores médios de 10,1 e 6,9 ml/kg para méis de flores silvestres e de eucalipto, respectivamente.

\subsubsection{Açúcares totais, redutores e sacarose (\%)}

A quantidade de açúcares totais encontrada nas 34 amostras de méis analisadas variam de 72,4 a 85,5\%, com valor médio de $78 \pm 0,9 \%$ (I.C. a 0,05\%). Para os açúcares totais não existe valor estabelecido nas normas vigentes ( Tabela 9).

Os valores observados estão próximos aos obtidos por Komatsu (1996) que em méis de diferentes origens florais do Estado de São Paulo registrou para açúcares totais uma variação de 
67 a 88,3\%; Campos (1998) que encontrou valores variando de 62 a 77,8\%; Sodré (2000) com valor médio de 71,7\% e Marchini (2001) com médias de 75,2 e 74,9\% para méis de flores silvestres e de eucalipto, respectivamente.

Com relação ao conteúdo de açúcares redutores das 34 amostras analisadas encontrou-se variação de 66,7 a 78\%, com valor médio de 73,1 $\pm 1,1 \%$ (I.C. a 0,05\%). A norma vigente estabelece um valor mínimo de 65\%; não apresentando, o presente trabalho, nenhuma amostra abaixo deste valor (Tabela 9).

Os valores obtidos estão próximos aos encontrados por Komatsu (1996) que em méis de diferentes origens florais do Estado de São Paulo apresentou variações de 53,2 a 80,3\%; Campos (1998) em méis de Minas Gerais com 60,4 a 77,1\% e Marchini (2001) com médias de 72,6 e 72,3\% para méis de flores silvestres e de eucalipto, respectivamente.

A porcentagem de sacarose das 34 amostras analisadas variaram de 0,2 a 11,4\% (Tabela 9), com valor médio de 4,5 $\pm 1,2 \%$ (I.C. a $0,05 \%$ ). A norma vigente estabelece um valor máximo de $6 \%$, com exeção ao mel de melato cujo valor máximo é de $15 \%$. O presente trabalho apresenta $35,3 \%$ das amostras acima de $6 \%$ de sacarose, mas $100 \%$ se encontram abaixo de $15 \%$ de sacarose (Figura 12).

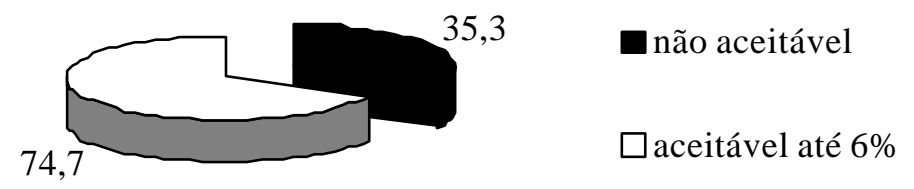

Figura 12 - Porcentagem de sacarose aceitável ou não segundo as normas vigentes, em amostras dos méis do cerrado do município de Pirassununga-SP, coletadas de maio/2001 a abril/2002.

Baldi Coronel et al. (1993) encontraram na Argentina valores para a sacarose de 1 a 13\%; Komatsu (1996) observou valores de até 11,8\% em amostras de méis do Estado de São Paulo; Sodré (2000) e Marchini (2001) obtiveram 2,4\% de sacarose em suas análises, valor esse inferior ao do presente trabalho.

\subsubsection{Minerais (ppm)}


Os valores de minerais (macro e micro elementos) obtidos nas amostras analisadas apresentaram valores variando de amostra para amostra (Tabela 10).

O teor médio de fósforo foi de 71,84 ppm, havendo entretanto, uma grande variação entre os teores das amostras ( 20,34 a 284,56ppm), sendo superior à média de 2,54 ppm encontrada por Pamplona (1989) em amostras de méis de eucaliptos. Marchini (2001) encontrou teor médio de fósforo 35,82 ppm para méis de eucaliptos e 16,65 ppm para méis silvestres .

O potássio foi o elemento encontrado em maior quantidade quando comparado com os demais minerais, fato também registrado por Marchini (2001). A quantidade média foi de 3315ppm (61 a 11500 ppm). Gomez et al. (1993) obtiveram média de 285,6 mg/kg de potássio em amostras de méis de eucaliptos, teores esses muito inferiores às quantidades encontradas, nas amostras de méis, no presente experimento.

Cálcio foi o segundo elemento encontrado em maior quantidade nas amostras, com uma média de 155,96 ppm (69,5 a 385,5 ppm). Gomez et al. (1993) encontraram os teores de $155 \mathrm{mg} / \mathrm{kg}$ de cálcio em amostras de méis de eucaliptos e Marchini (2001) encontrou média de 187,7 ppm (55 a 301 ppm) para méis de eucaliptos e 46,18 ppm (1 a 202 ppm) para méis silvestres.

A quantidade média de magnésio presente nas amostras foi de 116,5 ppm (24,5 a $460,75 \mathrm{ppm}$ ). Esse mineral foi o terceiro elemento obtido em maior quantidade nas amostras de méis. Para Marchini (2001) a média de magnésio foi de 128, 74 ppm (31 a 270 ppm) para méis de eucaliptos e 65,45 ppm (11 a 286 ppm) para méis silvestres

O valor médio de cobre presente nas amostras de méis foi 0,63ppm $(0,07$ a 1,22ppm) sendo inferior aos valores obtidos por Shavonov \& Ibrishimov (1975), que encontraram valores de 1,81 a 8,15 g/g em amostras de méis de diferentes origens florais. Gomez et al. (1993) obtiveram valores médios de $1,738 \mathrm{mg} / \mathrm{kg}$ de cobre em amostras de méis de eucaliptos e Marchini (2001) obteve valores médios nas amostras de méis de eucaliptos de 0,34ppm (0,2 a 0,6ppm) e de 0,32 ppm para silvestres (0,1 a 2,0ppm)

Para o ferro foi encontrado o valor médio de 12,3ppm (6,61 a 52,94ppm). Esses valores foram superiores aos obtidos por Gomez et al. (1993) e Marchini (2001).

O manganês esteve presente na quantidade média de 5,03ppm (0,83 a 17,24ppm), resultado inferior ao obtido por Marchini (2001) com média de 8,43ppm para méis de eucaliptos. 
O zinco ocorreu na quantidade média de $1,89 \mathrm{ppm}(0,68$ a 4,24ppm) para os méis de eucaliptos e 5,45 ppm (1,20 a 48,30 ppm) para os méis silvestres. O teor de zinco encontrado foi superior à quantidade de 0,09 ppm encontrado por Pamplona (1989), ao analisar amostras de méis de Eucalyptus, porém, inferior a quantidade média (2,65 ppm para os méis de eucaliptos e 5,45 ppm para os méis silvestres) encontrada por Marchini (2001).

O sódio foi encontrado na quantidade média de 30,9ppm (5 a 80ppm). Gomes et al. (1993) encontraram a quantidade média de $77,7 \mathrm{mg} / \mathrm{kg}$ de sódio em amostras de méis de eucaliptos na Espanha e Marchini (2001) obteve média de 71,98 ppm (23,7 a 212,5) para méis de eucaliptos e 49,31 ppm $(14,95$ a 202,4) para méis silvestres.

Pamplona (1989) cita que o tipo de clima de cada região influencia no conteúdo mineral do mel, e que amostras de méis provenientes de locais com solo do tipo latossolo roxo eutrófico, apresentaram menores quantidades de ferro e manganês, do que amostras provenientes de solos formados por rochas ácidas e alcalinas.

\subsection{Análises polínicas}

Em geral as análises polínicas qualitativas das 34 amostras de méis, demonstraram uma grande quantidade de grãos de pólen, sendo encontrados tipos polínicos, que contribuíram com importantes dados para a caracterização dos méis das áreas em estudo quanto a sua origem botânica.

Com as análises quantitativas dos grãos de pólen das amostras foi possível demonstrar a importância das espécies vegetais na formação dos méis, classificando-as como pólen dominante (>45\%), pólen acessório (15 a 45\%), pólen isolado importante (3 a 15\%) e pólen isolado ocasional (<3\%) (Louveaux et al., 1978).

\subsubsection{Análises polínicas das amostras de mel}

Os resultados apresentados são referentes a média de contagem do pólen de 3 lâminas, feitas pelo método da acetólise, para cada amostra (Tabelas 11, 12 e 13). 
Tabela 11. Espectro polínico das amostras de méis coletadas no cerradão, durante os meses de maio/2001 a abril/2002, no município de Pirassununga-SP.

\begin{tabular}{|c|c|c|c|c|c|c|c|c|c|c|c|c|c|c|c|c|c|}
\hline \multirow[t]{2}{*}{${ }^{1}$ Imagem } & \multirow[t]{2}{*}{ Espécie botânica ou tipo polínico } & \multicolumn{16}{|c|}{$*^{2}$ Amostras } \\
\hline & & 2 & 3 & 6 & 11 & 12 & 13 & 19 & 20 & 21 & 22 & 23 & 25 & 26 & 27 & 28 & 29 \\
\hline 1 & Mimosaceae - Mimosa caesalpinifolia & & & & & & & & & & & & & & & PII & \\
\hline 2 & Melastomataceae - Tibouchina granulosa & $\mathrm{PA}$ & PII & $\mathrm{PA}$ & & & & & & & & & & & & & \\
\hline 3 & Amaranthaceae - Alternanthera ficoidea & $\mathrm{PA}$ & & & & & & PII & $\mathrm{PIO}$ & $\mathrm{PA}$ & PIO & PII & PII & & & & \\
\hline 4 & Myrtaceae - Eucalyptus sp 1 & & & PA & PA & PA & $\mathrm{PD}$ & PIO & PIO & PIO & PIO & PIO & & PII & PII & PII & PII \\
\hline 5 & Araliaceae - Didymopanax vinosum & & & PA & PA & $\mathrm{PA}$ & $\mathrm{PA}$ & PA & & & $\mathrm{PA}$ & & PII & PIO & & & PII \\
\hline 6 & Tipo polínico não identificado & $\mathrm{PA}$ & & & & & & PIO & PII & & & & & & & & \\
\hline 7 & Solanaceae - Solanum sp. & & PA & & & & & & & PII & PII & PIO & & & & & \\
\hline 8 & Tipo Brassicaceae & & $\mathrm{PD}$ & & & & & & & & & & & & & & \\
\hline 9 & Sapindaceae - Serjania sp. & & & & PII & PII & & PII & & & PIO & PIO & & & PII & & \\
\hline 11 & Asteraceae - Mikania sp. & & & PA & & & & & & & & & & & & & \\
\hline 12 & Mimosaceae - Anadenanthera macrocarpa & & & & PA & PA & & $\mathrm{PD}$ & PA & PA & $\mathrm{PD}$ & $\mathrm{PD}$ & $\mathrm{PA}$ & & & & PII \\
\hline 13 & Rutaceae - Citrus sp 1 & & & & & & & PII & PII & $\mathrm{PA}$ & & & & PII & PII & & \\
\hline 14 & Arecaceae - Astrocaryum sp. & & & & & & & & & & & & & & & & $\mathrm{PA}$ \\
\hline 16 & Asteraceae - Eupatorium sp. & & & & & & & & PIO & PII & & & & & PIO & & \\
\hline 17 & Asteraceae - Mikania hirsutissima & & & & & & & PIO & & & & & & & & & \\
\hline 18 & Euphorbiaceae - Croton $s p$. & & & & & & & PIO & & & & & & & & & \\
\hline 19 & Rutaceae - Citrus sp 2 & & & & & & & & PA & & & PII & & & & & \\
\hline 20 & Asteraceae - Baccharis sp. & & & & & & & & & & PII & & PII & & & & \\
\hline 21 & Apocynaceae - Temnadenia violaceae & & & & & & & & & & & PII & & & & & \\
\hline 22 & Tipo polínico não identificado & & & & & & & & & & & & PII & & & & \\
\hline 23 & Myrtaceae - Eucalyptus sp2 & & & & & & & & & & & & $\mathrm{PA}$ & & PII & & \\
\hline 24 & Tipo polínico não identificado & & & & & & & & & & & & PII & PII & & & \\
\hline 25 & Mimosaceae - Acacia polyphyla & & & & & & & & & & & & & $\mathrm{PD}$ & $\mathrm{PD}$ & & \\
\hline 26 & Tipo Apiaceae & & & & & & & & & & & & & PII & & PII & \\
\hline 27 & Tipo Myrcia & & & & & & & & & & & & & PII & & PA & $\mathrm{PA}$ \\
\hline 28 & Caesalpiniaceae - Delonix regia & & & & & & & & & & & & & & & PA & $\mathrm{PA}$ \\
\hline 29 & Asteraceae - Bidens gardneri & & & & & & & & & & & & & & & $\mathrm{PA}$ & PII \\
\hline
\end{tabular}

$\mathrm{PD}=$ pólen dominante $(>45 \%), \mathrm{PA}=$ pólen acessório $(15 \mathrm{a} 45 \%), \mathrm{PII}=$ pólen isolado importante $(3$ a $15 \%)$ e PIO = pólen isolado ocasional $(<3 \%)$. 
Tabela 12. Espectro polínico das amostras de méis coletadas no cerrado "sensu strictu", durante os meses de maio/2001 a abril/2002, no município de Pirassununga-SP.

\begin{tabular}{|c|c|c|c|c|c|c|c|c|c|c|c|c|c|c|c|c|c|c|c|}
\hline \multirow[t]{2}{*}{ *1'Imagem } & \multirow[t]{2}{*}{ Espécie botânica ou tipo polínico } & \multicolumn{18}{|c|}{$*^{2}$ Amostras } \\
\hline & & 1 & 4 & 5 & 7 & 8 & 9 & 10 & 14 & 15 & 16 & 17 & 18 & 24 & 30 & 31 & 32 & 33 & 34 \\
\hline 1 & Mimosaceae - Mimosa caesalpinifolia & $\mathrm{PA}$ & & & & & & & & & & $\mathrm{PA}$ & & & & PII & $\mathrm{PD}$ & $\mathrm{PD}$ & $\mathrm{PD}$ \\
\hline 2 & Melastomataceae - Tibouchina granulosa & PII & & & & & & & & & & & & & & & & & \\
\hline 3 & Amaranthaceae - Alternanthera ficoidea & $\mathrm{PA}$ & & PA & & & & & & & & & & PA & PII & & PII & PIO & PII \\
\hline 4 & Myrtaceae - Eucalyptus sp 1 & $\mathrm{PA}$ & PII & & $\mathrm{PD}$ & $\mathrm{PA}$ & $\mathrm{PA}$ & PII & $\mathrm{PD}$ & & & & $\mathrm{PA}$ & PII & PII & $\mathrm{PD}$ & & & \\
\hline 5 & Araliaceae - Didymopanax vinosum & PII & PA & & $\mathrm{PA}$ & PA & PII & PA & PII & & & & & PII & PA & PII & & PA & \\
\hline 7 & Solanaceae - Solanum sp. & & & PD & & & & & & & & & & & & & PII & & \\
\hline 8 & Tipo Brassicaceae & & & & & & & & & & & & & & & & & PIO & PII \\
\hline 9 & Sapindaceae - Serjania $s p$. & & PIO & PA & PII & $\mathrm{PA}$ & PA & PA & & & & & PII & PII & PII & PII & PIO & & \\
\hline 10 & Asteraceae - Vernonia polyanthes & & $\mathrm{PD}$ & & & & & & & & & & & & & & & & \\
\hline 11 & Asteraceae - Mikania sp. & & & & PIO & PA & PA & PA & & & & & & & & & & & \\
\hline 12 & Mimosaceae - Anadenanthera macrocarpa & & & & & PII & PII & & PA & $\mathrm{PA}$ & & $\mathrm{PD}$ & $\mathrm{PD}$ & $\mathrm{PA}$ & PII & & & & \\
\hline 13 & Rutaceae - Citrus sp 1 & & & & & & & & & $\mathrm{PD}$ & $\mathrm{PD}$ & PA & & & & & & & \\
\hline 14 & Arecaceae - Astrocaryum sp. & & & & & & & & & & PA & & & & $\mathrm{PA}$ & PIO & & & \\
\hline 15 & Tipo Malvastrum & & & & & & & & & & & PIO & & & & & PIO & & $\mathrm{PIO}$ \\
\hline 16 & Asteraceae - Eupatorium sp. & & & & & & & & & & & & PIO & & & & PIO & PII & PII \\
\hline 17 & Asteraceae - Mikania hirsutissima & & & & & & & & & & & & & PII & & & & & \\
\hline 18 & Euphorbiaceae - Croton sp. & & & & & & & & & & & & & PIO & & & & & \\
\hline 22 & Tipo polínico não identificado & & & & & & & & & & & & & PII & PII & & & & \\
\hline 25 & Mimosaceae - Acacia polyphyla & & & & & & & & & & & & & & & $\mathrm{PA}$ & & PII & \\
\hline 29 & Asteraceae - Bidens gardneri & & & & & & & & & & & & & & $\mathrm{PA}$ & & & & \\
\hline
\end{tabular}

*11 Imagens dos pólens (aumento 40x), em Anexos

$*^{2}$ As identificações das amostras encontram-se nas Tabelas 6 e 7.

$\mathrm{PD}=$ pólen dominante (>45\%), PA = pólen acessório (15 a 45\%), PII = pólen is olado importante ( 3 a 15\%) e PIO = pólen isolado ocasional $(<3 \%)$. 
Tabela 13. Espectro polínico das 4 amostras de méis de abelhas sem ferrão coletadas no cerrado (área intermediaria), durante o mês de setembro/2002, no município de PirassunungaSP.

\begin{tabular}{cccccc}
\hline *1. Imagem & Espécie botânica ou tipo polínico & \multicolumn{5}{c}{$*^{2}$ Amostras } \\
& & $\mathbf{2}$ & $\mathbf{3}$ & $\mathbf{4}$ \\
\hline $\mathbf{3}$ & Amaranthaceae - Alternanthera ficoidea & & & PII & \\
$\mathbf{4}$ & Myrtaceae - Eucalyptus sp 1 & PD & PD & PD & PD \\
$\mathbf{8}$ & Tipo Brassicaceae & & & PII & PIO \\
$\mathbf{9}$ & Sapindaceae - Serjania sp. & & & PII & \\
$\mathbf{1 0}$ & Asteraceae - Vernonia polyanthes & PII & & & \\
$\mathbf{1 2}$ & Mimosaceae - Anadenanthera macrocarpa & & PII & & PII \\
$\mathbf{1 3}$ & Rutaceae - Citrus sp 1 & & & PIO & \\
$\mathbf{1 4}$ & Arecaceae - Astrocaryum sp. & & PIO & & \\
$\mathbf{2 7}$ & Tipo Myrcia & & & PII \\
$\mathbf{3 0}$ & Bombacaceae - Eriotheca gracilips & PII & & & \\
$\mathbf{3 1}$ & Amaranthaceae - Gomphrena celosiodis & PII & PIO & & \\
$\mathbf{3 2}$ & Myrtaceae - Eugenia bimarginata & PA & & & \\
$\mathbf{3 3}$ & Anacardiaceae - Schinus sp. & PII & PA & & \\
$\mathbf{3 4}$ & Melastomataceae - Tibouchina sp. & & PII & & \\
\hline
\end{tabular}

$*^{1}$ Imagens dos pólens (aumento 40x), em Anexos

$*^{2}$ As identificações das amostras encontram-se na Tabelas 5.

PD = pólen dominante ( $>45 \%), \mathrm{PA}=$ pólen acessório (15 a 45\%), PII = pólen isolado importante ( 3 a 15\%) e $\mathrm{PIO}=$ pólen isolado ocasional $(<3 \%)$.

Observou-se como pólen dominante (>45\%) os tipos: Tipo Brassicaceae no cerradão, Eucalyptus sp. (Myrtaceae) e Anadenanthera macrocarpa (Mimosaceae) no cerradão e no cerrado "sensu strictu"; Vernonia polyanthes (Asteraceae), Solanum sp. (Solanaceae), Mimosa caesalpiniaefolia (Mimosaceae) e Citrus sp. (Rutaceae) no cerrado "sensu strictu" (Figuras 13, 14 e 15

Segundo Barth (1970b) uma identificação completa das espécies polínicas, exceto para as espécies mais conhecidas, é uma tarefa bastante complexa e requer um grande conhecimento da vegetação melífera das áreas estudadas, portanto, relata que por este motivo recorre-se ao "tipo polínico", o qual engloba todas as espécies que possuem grãos de pólen iguais ou muito semelhantes, pertencendo ou não, à espécie do mesmo gênero. 


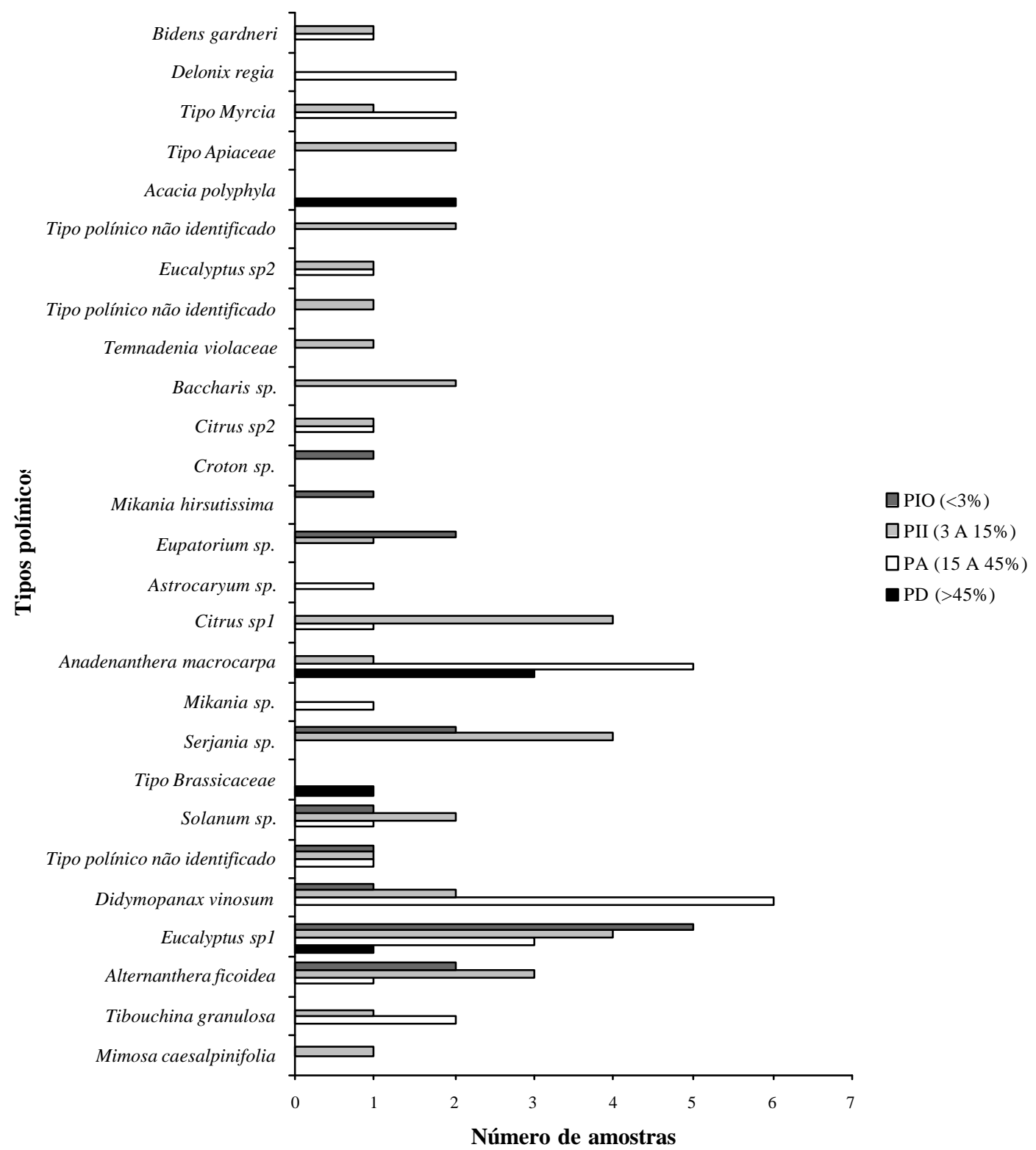

Figura - 13 Classificação dos tipos polínicos quanto a sua ocorrência nas amostras de mel do cerradão do município de Pirassununga-SP, coletadas de maio/2001 a abril/2002.

As espécies mais frequientes, foram Eucalyptus sp1, presentes em $13(81 \%)$ das 16 amostras de méis do cerradão; Adenanthera macrocarpa e Didymopanax vinosum, ambas presentes em 9 (56\%) das amostras. Excluindo-se Eucalyptus sp1, por não se tratar de uma planta nativa do cerrado, a grande freqüência de Adenanthera macrocarpa e Didymopanax vinosum demonstram o potencial apícola destas plantas na área estudada. 


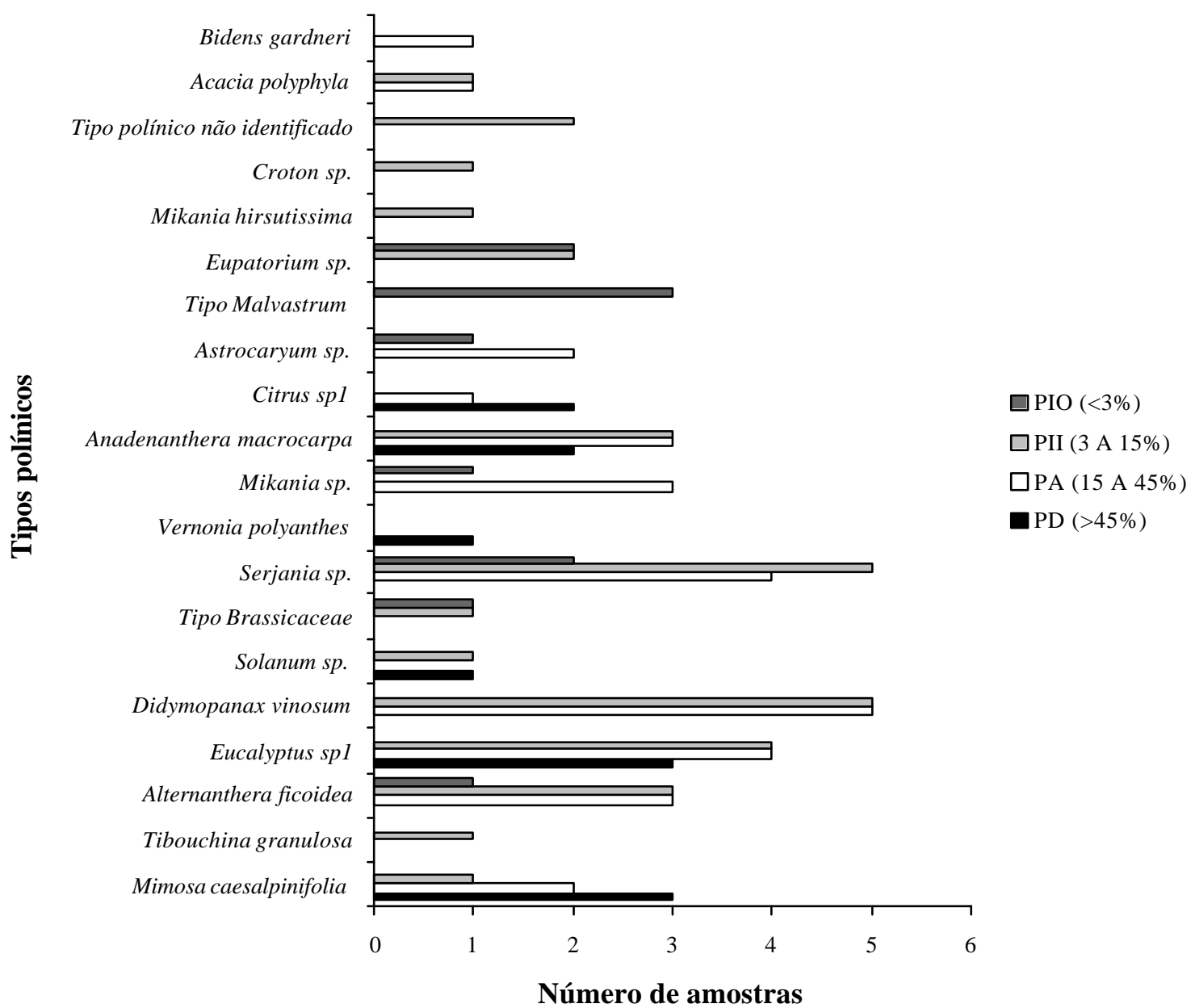

Figura - 14 Classificação dos tipos polínicos quanto a sua ocorrência nas amostras de mel do cerrado "sensu strictu" do município de Pirassununga-SP, coletadas de maio/2001 a abril/2002.

As espécies mais freqüentes, foram Eucalyptus sp1, Didymopanax vinosum e Sejania sp., ambas presentes em $11(61 \%)$ das 18 amostras de méis do cerrado "sensu strictu" e Adenanthera macrocarpa, presente em 8 (45\%) das amostras. Novamente, excluindo-se Eucalyptus sp1, por não se tratar de uma planta nativa do cerrado, a grande freqüência das demais espécies citadas demonstram o potencial apícola destas plantas na área estudada.

Barth (1970b) salienta a importância do pólen dominante e acessório quanto a quantidade de néctar fornecido, ao contr'rio do pólen isolado. 


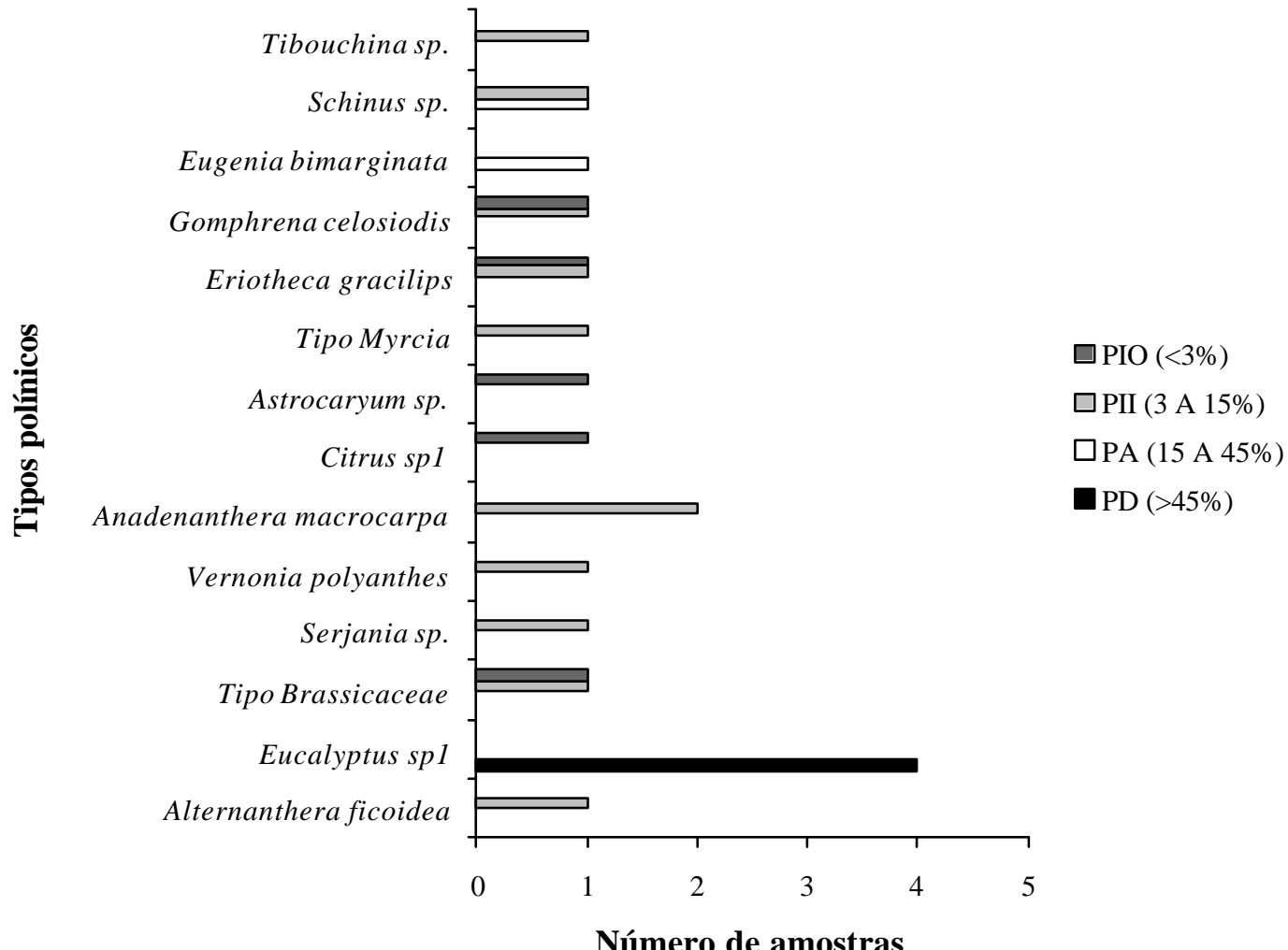

Figura -15 Classificação dos tipos polínicos quanto a sua ocorrência nas 4 amostras de mel de abelhas sem ferrão coletadas no cerrado do município de Pirassununga-SP, em setembro/2002.

Eucalyptus spl apareceu como pólen dominante nas amostras de mel dos 4 tipos diferentes de meliponas. Schinus sp. foi a única espécie encontrada como pólen acessório em uma das amostras; as demais espécies foram observadoas como pólens isolados.

\subsubsection{Análises polínicas das amostras mensais do pólen retirado dos coletores instalados nas colméias}

Os resultados apresentados nas Tabelas 14 e 15 são referentes a média de contagem do pólen de 3 lâminas, para cada amostra proveniente dos coletores instalados nas colméias do cerradão e cerrado "sensu strictu", respectivamente. Em seguida foi calculada uma nova média com os dados obtidos das 5 colméias de cada área de cerrado em estudo 
Tabela 14. Espectro polínico das amostras de pólen, provenientes dos coletores instalados nas colméias do cerradão, coletadas no município de Pirassununga-SP, de maio/2001 a abril/2002.

\begin{tabular}{|c|c|c|c|c|c|c|c|c|c|c|c|c|c|}
\hline \multirow[t]{2}{*}{ *Imagem } & \multirow[t]{2}{*}{ Espécie botânica ou tipo polínico } & \multicolumn{12}{|c|}{ Espectro polínico/mês } \\
\hline & & jan & fev & mar & abr & mai & jun & jul & ago & set & out & nov & dez \\
\hline 3 & Amaranthaceae - Alternanthera ficoidea & & & & & $\mathrm{PA}$ & & & & & & & \\
\hline 4 & Myrtaceae - Eucalyptus sp 1 & & PII & & & & & & & & & & \\
\hline 5 & Araliaceae - Didymopanax vinosum & & & $\mathrm{PD}$ & $\mathrm{PIO}$ & PII & & & & & & & \\
\hline 7 & Solanaceae - Solanum sp. & & PA & & & & & & & & & & \\
\hline 8 & Tipo Brassicaceae & & & & & & & & PII & & & & \\
\hline 11 & Asteraceae - Mikania sp. & & & & PA & & PA & $\mathrm{PD}$ & PIO & & & & \\
\hline 13 & Rutaceae - Citrus sp 1 & PIO & & & $\mathrm{PIO}$ & & & & & $\mathrm{PD}$ & & & \\
\hline 16 & Asteraceae - Eupatorium sp. & & & & & & $\mathrm{PD}$ & & & & & & PD \\
\hline 20 & Asteraceae - Baccharis sp. & $\mathrm{PD}$ & & & & & & & & & & & \\
\hline 29 & Asteraceae - Bidens gardneri & & & PII & & PII & & & & & & & \\
\hline 32 & Myrtaceae - Eugenia bimarginata & & & & PA & & & & & & & & \\
\hline 35 & Euphorbiaceae - Croton urucurana & $\mathrm{PA}$ & & & & & & & & & & & \\
\hline 36 & Poaceae - Brachiaria $s p$ & PA & & & & $\mathrm{PD}$ & & & & & & & \\
\hline 37 & Mimosaceae - Peptadenia moniliforme & PIO & & & & & & & & & & & \\
\hline 39 & Asteraceae - Baccharis dracunculifolia & & $\mathrm{PD}$ & & & & & & & & & & \\
\hline 42 & Lamiaceae - Hyptis eriophylla & & & PII & & & & & & & & & \\
\hline 43 & Tipo Poaceae & & & $\mathrm{PIO}$ & & & & & & & & & \\
\hline 44 & Malvaceae - Wissadula subpetala & & & & PA & & & & & & & & \\
\hline 45 & Tipo Rubiaceae & & & & PII & & & & & & & & \\
\hline 46 & Myrtaceae - Eugenia aurata & & & & & & $\mathrm{PIO}$ & & & & & & \\
\hline 47 & Caesalpiniaceae - Caesalpinia sp. & & & & & & & PIO & & & & & \\
\hline 49 & Tipo Asteraceae & & & & & & & & PD & PA & & & \\
\hline 50 & Asteraceae - Vernonia cognata & & & & & & & & PII & & & & \\
\hline 52 & Coniferae - Pinus sp. & & & & & & & & & & PIO & & \\
\hline 53 & Tipo Passifloraceae & & & & & & & & & & $\mathrm{PD}$ & & \\
\hline 54 & Euphorbiaceae - Croton floribundus & & & & & & & & & & & & PA \\
\hline 55 & Arecaeae -Astrocaryum aculeatissimum & & & & & & & & & & & & $\mathrm{PIO}$ \\
\hline 56 & Tipo polínico não identificado & & & & & & & & & & PA & $\mathrm{PD}$ & \\
\hline 57 & Tipo Rutaceae & & & & & & & & & & & PII & \\
\hline
\end{tabular}

* Imagens dos pólens (aumento 40x), encontram-se em Anexos.

PD = pólen dominante ( $>45 \%), \mathrm{PA}=$ pólen acessório (15 a 45\%), PII = pólen isolado importante (3 a 15\%) e PIO = pólen isolado ocasional ( $<3 \%)$. 
Tabela 15. Espectro polínico das amostras de pólen, provenientes dos coletores instalados nas colméias do cerrado "sensu strictu", coletadas no município de Pirassununga-SP, de maio/2001 a abril/2002.

\begin{tabular}{|c|c|c|c|c|c|c|c|c|c|c|c|c|c|}
\hline \multirow[t]{2}{*}{ *Imagem } & \multirow{2}{*}{ Espécie botânica ou tipo polínico } & \multicolumn{12}{|c|}{ Espectro polínico/mês } \\
\hline & & jan & fev & mar & abr & mai & jun & jul & ago & set & out & nov & dez \\
\hline 3 & Amaranthaceae - Alternantheraficoidea & & & & $\mathrm{PA}$ & $\mathrm{PD}$ & $\mathrm{PA}$ & & & & & & \\
\hline 4 & Myrtaceae - Eucalyptus sp 1 & & & & & & & $\mathrm{PD}$ & & & $\mathrm{PA}$ & & \\
\hline 5 & Araliaceae - Didymopanax vinosum & PIO & PII & & $\mathrm{PA}$ & PIO & $\mathrm{PD}$ & & & & & & \\
\hline 7 & Solanaceae - Solanum sp. & & & $\mathrm{PA}$ & & & & & & & & & \\
\hline 8 & Tipo Brassicaceae & & PII & & & & & & & & & & \\
\hline 9 & Sapindaceae - Serjania sp. & & & & & & & PIO & & & & & \\
\hline 10 & Asteraceae - Vernonia polyanthes & & & & & & & & $\mathrm{PD}$ & & & & \\
\hline 11 & Asteraceae-Mikania sp. & & & & $\mathrm{PD}$ & $\mathrm{PA}$ & & & PIO & & & & \\
\hline 13 & Rutaceae-Citrus sp 1 & PIO & & & & & & PII & & $\mathrm{PD}$ & & & PIO \\
\hline 15 & Tipo Malvastrum & & & & & & & & & PII & & & \\
\hline 16 & Asteraceae - Eupatorium sp. & & $\mathrm{PD}$ & $\mathrm{PD}$ & & & PIO & & & & & PD & $\mathrm{PD}$ \\
\hline 17 & Asteraceae - Mikania hirsutissima & & & & & & & & & & PA & & \\
\hline 27 & Tipo Myrcia & & & & & & & & & & & & $\mathrm{PA}$ \\
\hline 30 & Bombacaceae - Eriotheca gracilips & & & & & PIO & & & & & & & \\
\hline 35 & Euphorbiaceae - Croton urucurana & $\mathrm{PA}$ & & & & & & & & & & & \\
\hline 36 & Poaceae - Brachiaria sp. & $\mathrm{PA}$ & PII & & & & & & & & & & \\
\hline 37 & Mimosaceae-Peptadenia moniliforme & & & & & & & & & & PII & & \\
\hline 38 & Asteraceae - Vigueira $s p$. & $\mathrm{PA}$ & & & & & & & & & & & \\
\hline 40 & Asteraceae - Montanoa sp. & & PA & & & & & & & & & & \\
\hline 41 & Malvaceae - Sida $s p$ & & PII & & & & & & & & & & \\
\hline 44 & Malvaceae - Wissadula subpetala & & & PII & & & & & PII & & PIO & & \\
\hline 48 & Tipo Solanaceae & & & & & & & PII & & & & PIO & \\
\hline 50 & Asteraceae - Vernonia cognata & & & & & & & & & $\mathrm{PA}$ & & & \\
\hline 51 & Convulvulaceae - Merremia macrocalix & & & & & & & & PII & & & & \\
\hline 54 & Euphorbiaceae - Croton floribundus & & & & & & & & & & PII & PII & \\
\hline 55 & Arecaeae - Astrocaryum aculeatissimum & & & & & & & & & & PIO & PIO & \\
\hline 58 & Poaceae - Zea mays & & & & & & & & & & & PII & \\
\hline
\end{tabular}

* Imagens dos pólens (aumento 40x), encontram-se em Anexos.

$\mathrm{PD}=$ pólen dominante $(>45 \%), \mathrm{PA}=$ pólen acessório $(15$ a 45\%), PII = pólen isolado importante $(3$ a $15 \%)$ e PIO = pólen isolado ocasional $(<3 \%)$. 
Observou-se como pólen dominante (>45\%) os tipos: Baccharis sp. (Asteraceae), Baccharis dracunculifolia (Asteraceae), Brachiaria sp. (Poaceae) e tipo Asteraceae no cerradão; Eupatorium sp. (Asteraceae), Didymopanax vinosum (Araliaceae), Mikania sp. (Asteraceae) e Citrus sp. (Rutaceae) no cerradão e cerrado "sensu strictu"; Alternanthera ficoidea (Amaranthaceae), Eucalyptus sp. (Myrtaceae) e Vernonia polyanthes (Asteraceae) no cerrado "sensu stictu" (Figuras 16 e 17).

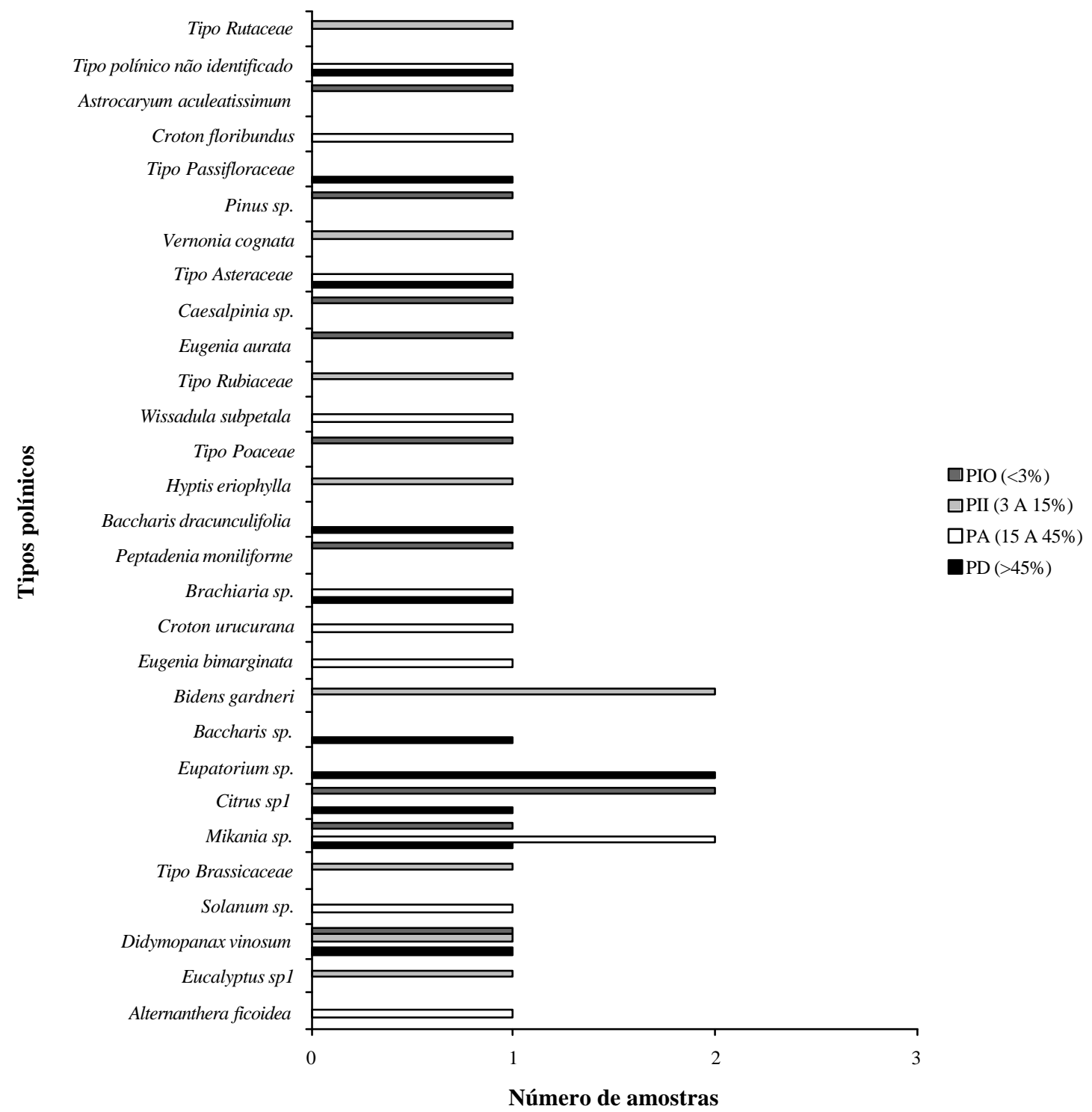

Figura - 16 Classificação dos tipos polínicos quanto a sua ocorrência nas amostras de pólen dos coletores instalados no cerradão do município de Pirassununga-SP, de maio/2001 a abril/2002. 
As espécies mais freqüentes de pólens provenientes dos coletores instalados nas colméias do cerradão foram: Mikania sp., que aparece durante 4 meses de coletas; e Citrus sp 1 e Didymopanax vinosum, em 3 meses de coletas.

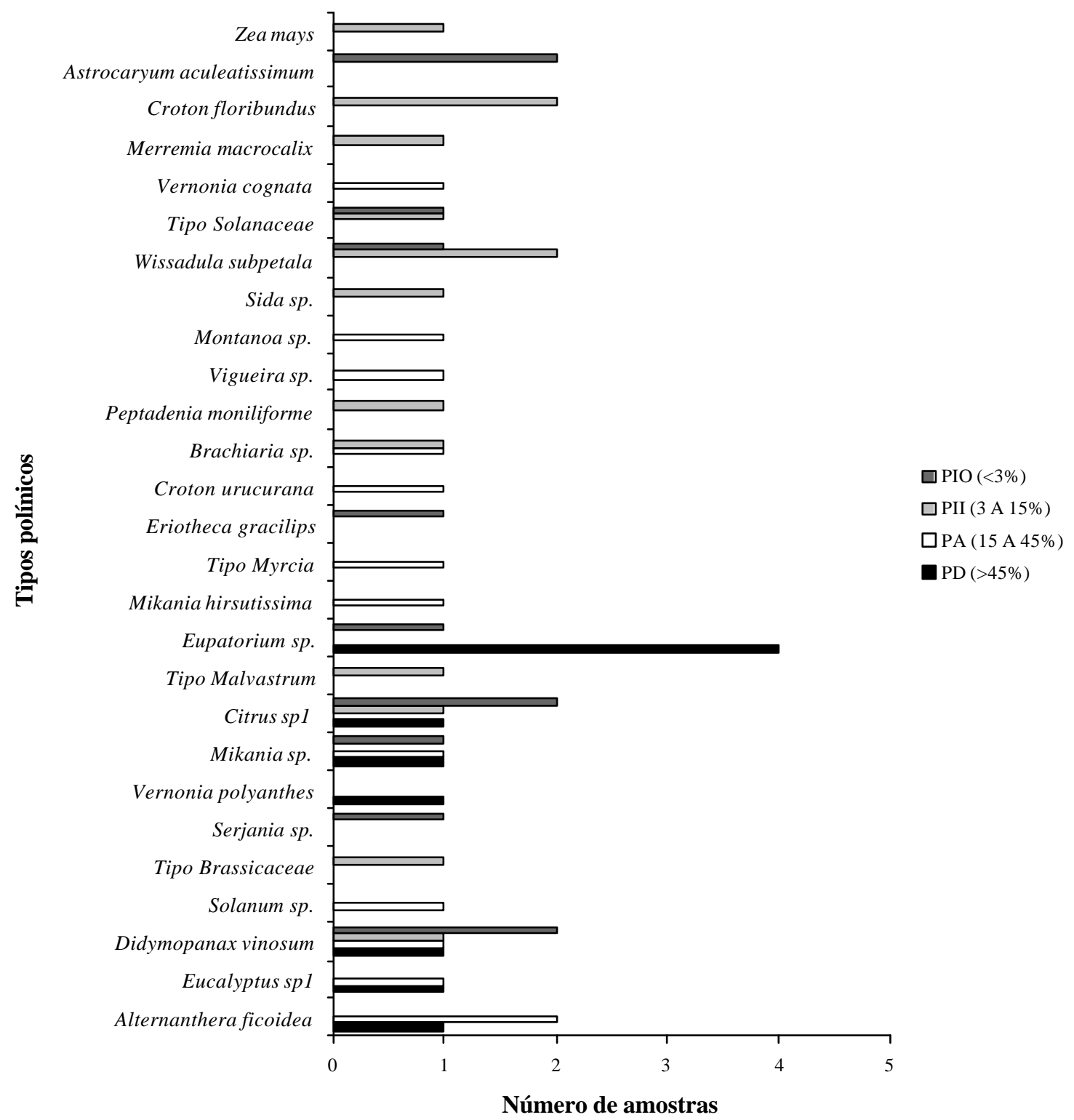

Figura - 17 Classificação dos tipos polínicos quanto a sua ocorrência nas amostras de pólen dos coletores instalados no cerrado "sensu strictu" do município de Pirassununga-SP, de maio/2001 a abril/2002. 
As espécies mais frequientes de pólens provenientes de coletores instalados nas colméias do cerrado "sensu strictu" foram: Eupatorium sp. e Didymopanax vinosum, que apareceram durante 5 meses de coletas; Citrus sp1, presente em 4 meses e Mikania sp., Alternanthera ficoidea e Wissadula subpetala, que foram observadas em 3 meses de coletas nesta área.

$\mathrm{Na}$ distribuição dos tipos polínicos por família (Figura 18) observa-se que a maior diversidade de espécies pertence a Asteraceae com 19\% dos tipos polínicos, seguida por Myrtaceae com 8,6\% e Mimosaceae com 7\%.

Costa (2002) pesquisando fontes de pólen utilizadas por operárias de Apis mellifera no município de Cruz das Almas-BA, também encontrou Asteraceae como a família com maior número de tipos polínicos.

As análises polínicas das amostras estudadas mostraram uma grande participação dos pólens isolados importantes e ocasionais, sendo encontrados em várias amostras. Barth (1970b) menciona que quanto a quantidade de néctar e pólen fornecidos pela planta, estas espécies têm pouca importância, entretanto, quando o interesse é a origem e procedência geográfica das amostras estes pólens tornam-se significativos. 


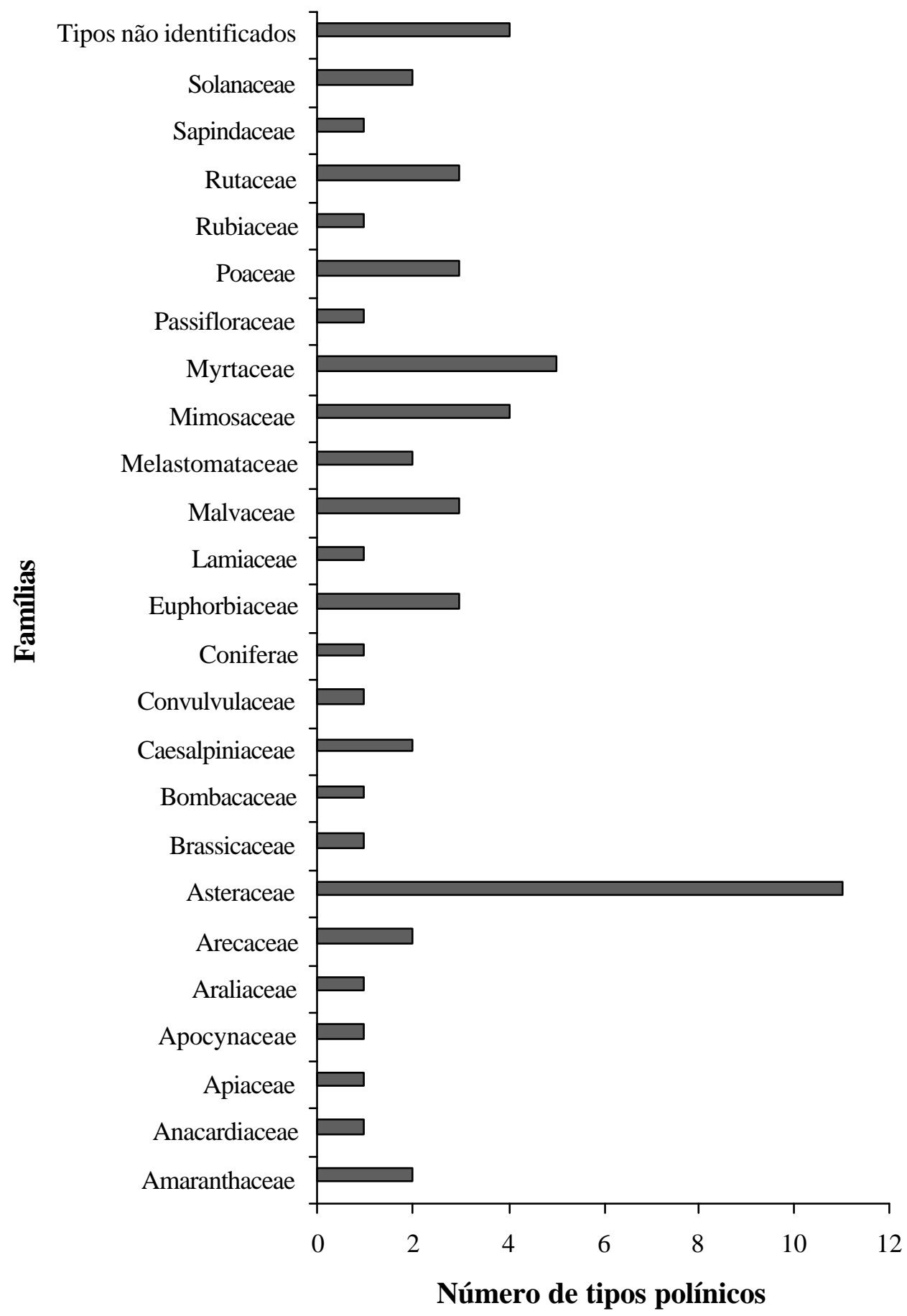

Figura 18 - Número de tipos polínicos por família botânica encontrado nas amostras de mel e de grãos de pólen coletados nas colméias de Apis mellifera no cerrado de PirassunungaSP, de maio/2001 a abril/2002. 


\section{CONCLUSÕES}

A comunidade de abelhas no cerrado seguiu o padrão geral encontrado nas comunidades neotropic ais, apresentando muitas espécies com poucos indivíduos e poucas espécies com muitos indivíduos.

A família Apidae (sensu latu) foi a mais rica em espécies e a mais abundante.

Das espécies predominantes encontradas para cada área de cerrado, a única comum foi Apis mellífera. Embora muito próximas as áreas apresentam uma diversidade de abelhas bastante distinta, provavelmente devido as diferenças de solo e vegetação que apresentam.

Foram encontradas plantas com períodos prolongados de florescimento lado a la do com plantas de períodos curtos, de modo que praticamente o ano todo tem-se plantas em floração, proporcionando recursos tróficos para as abelhas durante todos os meses.

A maior riqueza de espécies de plantas visitadas, em ordem decrescente, foi entre as famílias Asteraceae, Sapindaceae, Vochysiaceae, Malvaceae e Fabaceae. Com relação ao número de insetos visitantes destacaram -se, em ordem decrescente, as famílias Asteraceae, Araliaceae, Mimosaceae, Fabaceae e Sapindaceae. Didymopanax vinosum (Araliaceae) foi a espécie vegetal com maior número de abelhas visitantes.

Nas espécies de meliponídios estudadas obteve-se baixa produção, provavelmente devido ao número restrito de colônias encontradas nas áreas, em consequência da pouca disponibilidade de alimento e condições de nidificação para este grupo.

Os meses de maior produção de mel, para a Apis mellifera ocorreram de agosto a novembro, em contrapartida entre os meses de dezembro a fevereiro não foi possível a coleta de amostras.

As médias dos parâmetros físico-químicos análisados, das amostras de méis provenientes das duas áreas de cerrado, se enquadram nos padrões de normas em vigor.

Através das análises polínicas das amostras de mel e de pólen verificou-se que as 
abelhas também visitaram áreas vizinhas aos locais onde se encontravam as colméias, utilizandose principalmente de Eucalyptus sp. e Citrus sp.

De forma geral, as amostras de mel podem ser caracterizadas como poliflorais, com contribuição de várias espécies botânicas. A pequena correlação entre o pólen encontrado nas amostras de mel e o pólen amostrado dos coletores instalados nas colméias, dentro de cada mês, sugere que a fonte de néctar e de pólen muitas vezes não sejam as mesmas. 
ANEXOS 
Imagens dos tipos polínicos e/ou espécies botânicas dos pólens encontrados nas lâminas de mel e dos pólens dos coletores instalados nas colméias das áreas de cerrado do município de Pirassununga/SP, entre os meses de maio/2001 a abril/2002 (a - vista polar; b - vista equatorial).
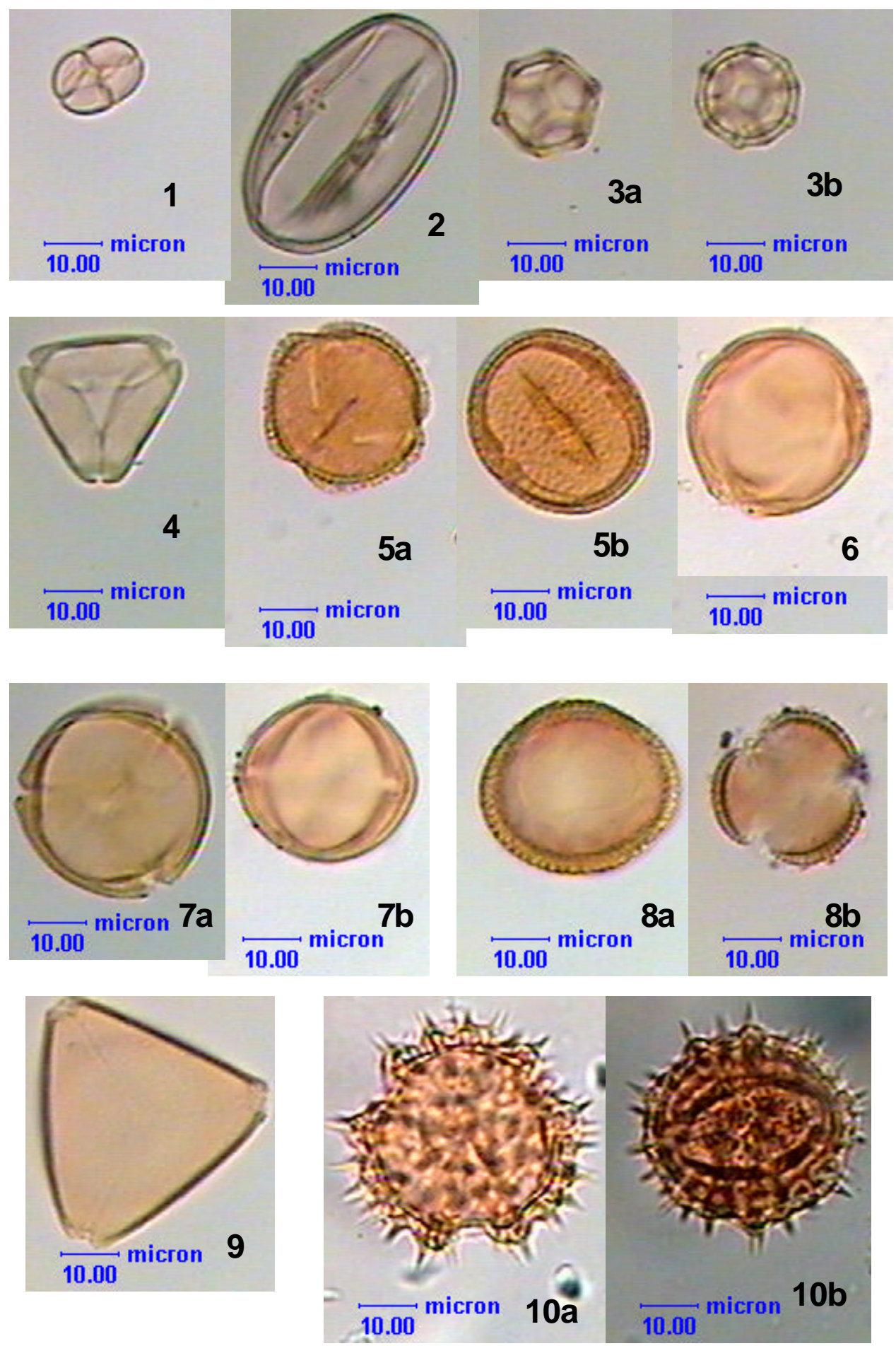
Imagens dos tipos polínicos e/ou espécies botânicas dos pólens encontrados nas lâminas de mel e dos pólens dos coletores instalados nas colméias das áreas de cerrado do município de Pirassununga/SP, entre os meses de maio/2001 a abril/2002 (a - vista polar; b - vista equatorial).
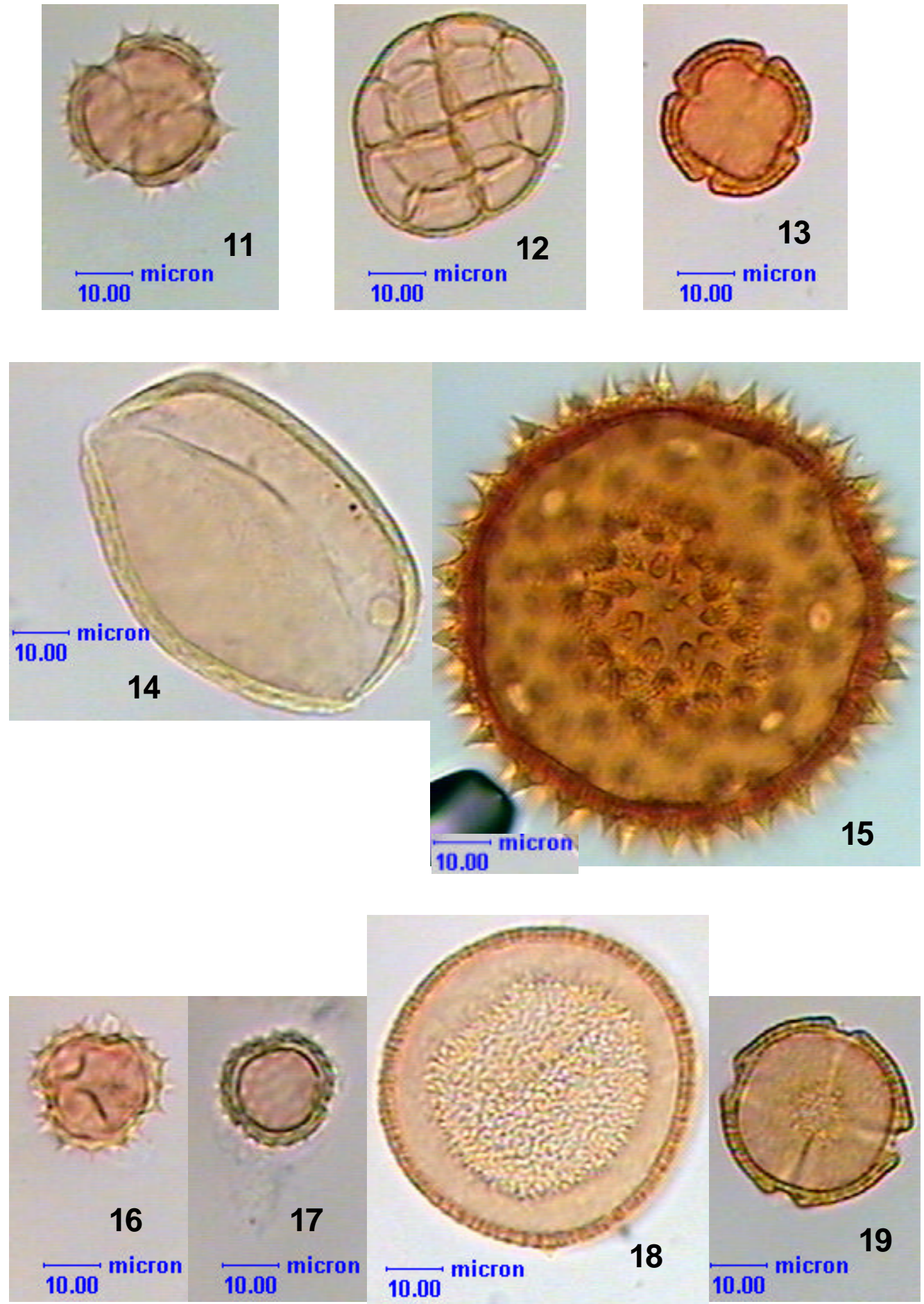
Imagens dos tipos polínicos e/ou espécies botânicas dos pólens encontrados nas lâminas de mel e dos pólens dos coletores instalados nas colméias das áreas de cerrado do município de Pirassununga/SP, entre os meses de maio/2001 a abril/2002 (a - vista polar; b - vista equatorial).
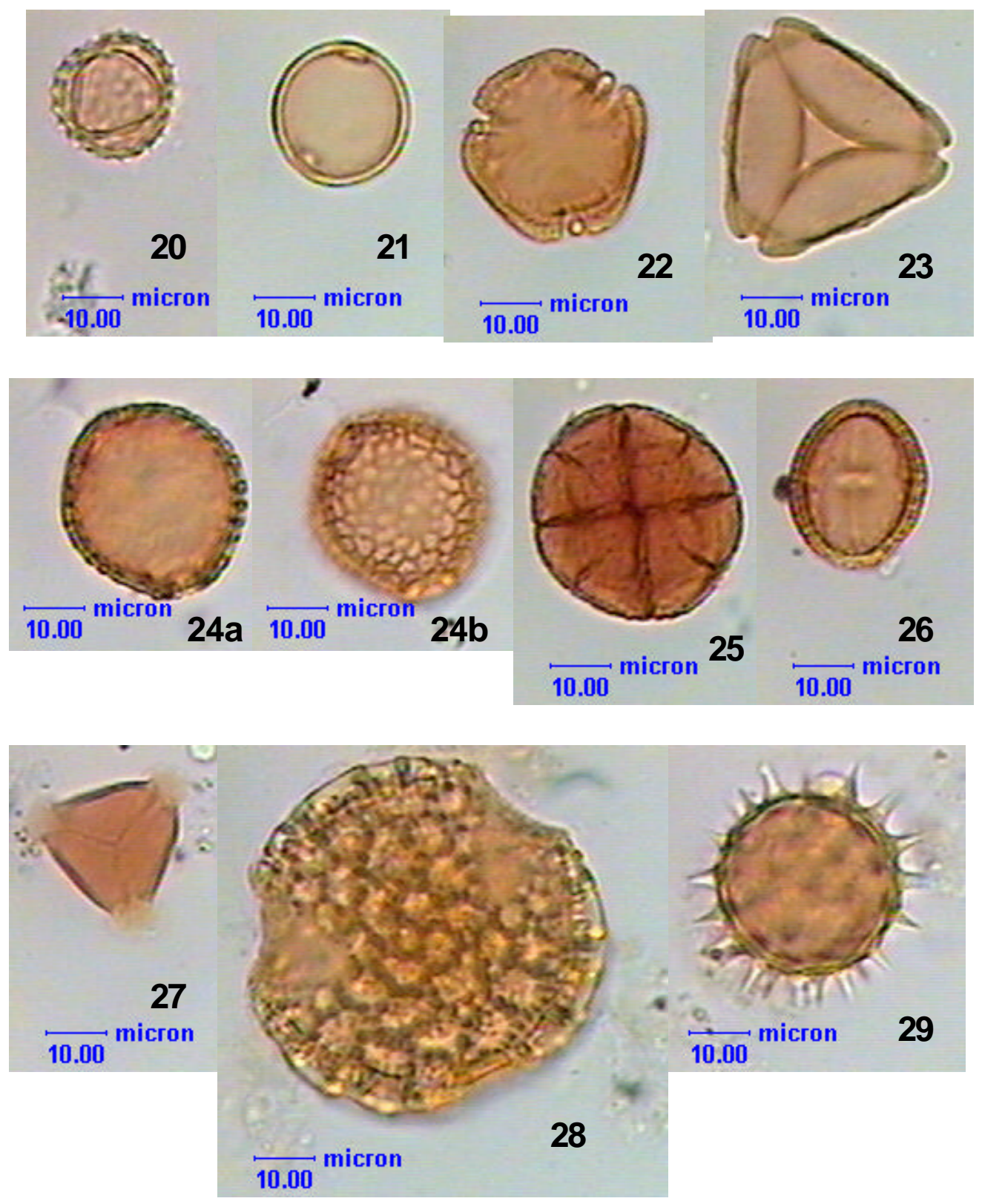
Imagens dos tipos polínicos e/ou espécies botânicas dos pólens encontrados nas lâminas de mel e dos pólens dos coletores instalados nas colméias das áreas de cerrado do município de Pirassununga/SP, entre os meses de maio/2001 a abril/2002 (a - vista polar; b - vista equatorial).
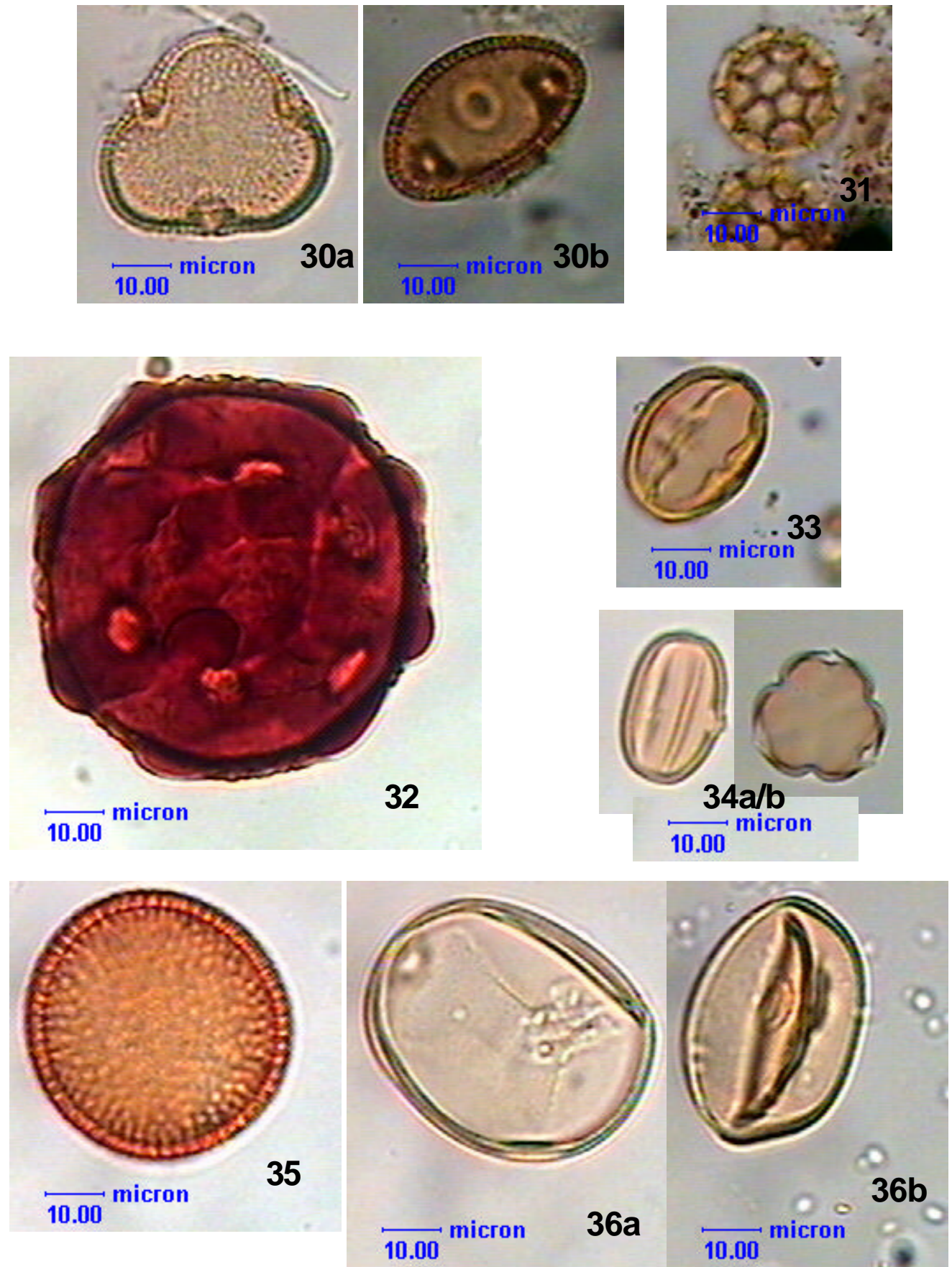
Imagens dos tipos polínicos e/ou espécies botânicas dos pólens encontrados nas lâminas de mel e dos pólens dos coletores instalados nas colméias das áreas de cerrado do município de Pirassununga/SP, entre os meses de maio/2001 a abril/2002 (a - vista polar; b - vista equatorial).
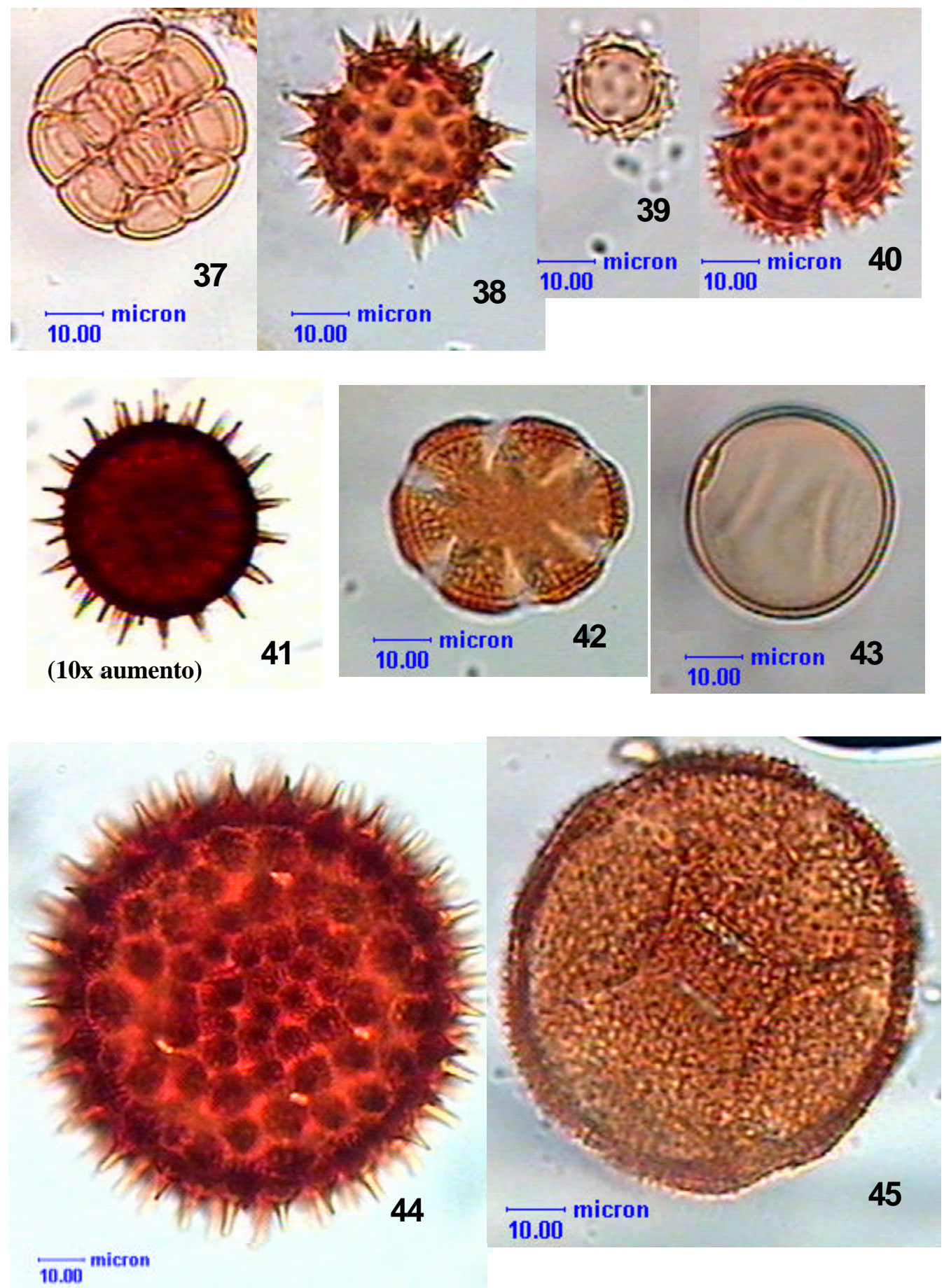
Imagens dos tipos polínicos e/ou espécies botânicas dos pólens encontrados nas lâminas de mel e dos pólens dos coletores instalados nas colméias das áreas de cerrado do município de Pirassununga/SP, entre os meses de maio/2001 a abril/2002 (a - vista polar; b - vista equatorial).
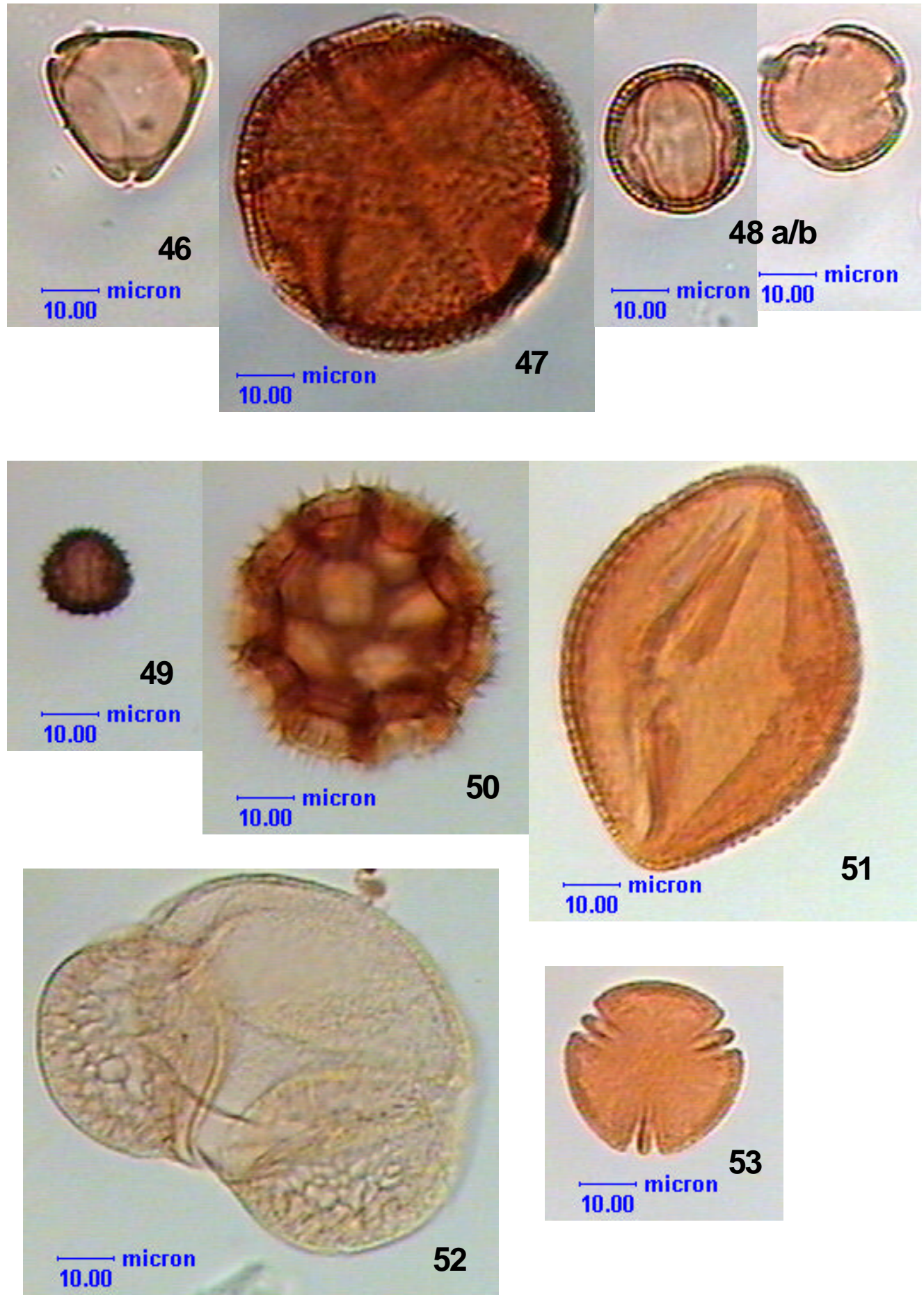
Imagens dos tipos polínicos e/ou espécies botânicas dos pólens encontrados nas lâminas de mel e dos pólens dos coletores instalados nas colméias das áreas de cerrado do município de Pirassununga/SP, entre os meses de maio/2001 a abril/2002 (a-vista polar; b-vista equatorial).
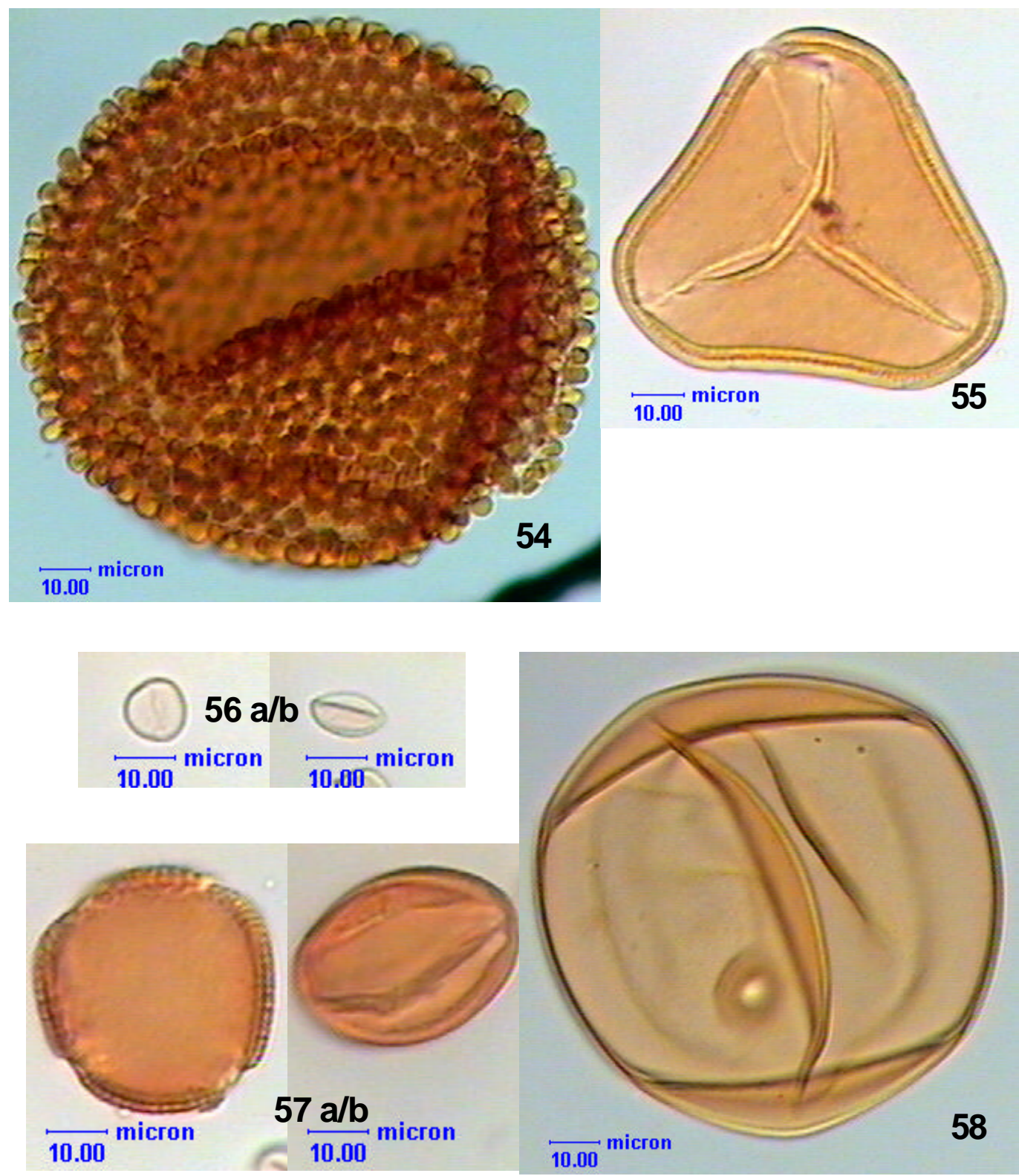


\section{REFERÊNCIAS BIBLIOGRÁFICAS}

ABDElnUR, P. A.; FURANI, S. R. C.; BATISTUTI, J. P. et al. Efeito do tempo de armazenamento e do tipo de embalagem nas características físico-químicas de méis. In: CONGRESSO BRASILEIRO DE APICULTURA, 12., Salvador, 1998. Anais. Salvador: Confederação Brasileira de Apicultura,1998. p.203.

ACCORTI, M.; PIAZZA, M.G.; ODDO, L. P. Electrical condutivity and ash content of honey. Apicoltore Modero, v. 77, n. 4, p. 165-167, 1986./ Resumo em Apicultural Abstracts, v.38, n.2, p.167, 1987/.

AGANIN, A. F. Electrical condutivity of several unifloral honeys. Trudy Saratovskogo Zootekhnicheskogo Inatituta, v. 21, p. 137-144, 1971./ Resumo em Apicultural Abstracts, v. 25, n. 1, p.144, 1973/.

ALCOFORADO-FILHO, F. G. Sustentabilidade do Semi-árido através da apicultura. In: CONGRESSO BRASILEIRO DE APICULTURA, 12., Salvador, 1998. Anais. Salvador: Confederação Brasileira de Apicultura,1998. p.61.

Al-KHALIFA, A. S.; AL-ARIFY, I. A. Physicochemical characteristics and pollen spectrum of some Saudi honeys. Food Chemistry, v. 67, n. 1, p. 21-25, 1999.

ALMEIDA, R. P.; MARCHINI, L. C. Determinação proteica de diferentes tipos de méis. In. CONGRESSO BRASILEIRO DE APICULTURA, 7., Salvador, 1986. Programa e resumo. Salvador: Confederação Brasileira de Apicultura, 1986. p. 58.

ALONSO, M. T. Vegetação. In: INSTITUTO BRASILEIRO DE GEOGRAFIA E ESTATÍSTICA. Geografia do Brasil - Região Sudeste. Rio de Janeiro, 1977. v. 3, p. $91-118$. 
AMARAL, A. D.; IMPERATRIZ-FONSECA, V. L.; GIOVANNINI, A. K. et al. Estudo comparativo entre amostras de méis com origem floral determinada; análise do teor de proteínas, lipídios e carboidratos totais. In: CONGRESSO BRASILEIRO DE APICULTURA, 7., Salvador, 1986. Anais. Salvador: Confederação Brasileira de Apicultura, 1986. p.60.

ANDRADE, P. B.; AMARAL, M. T.; ISABEL, P. et al. Physicochemical attributes and pollen spectrum of Portuguese heather honeys. Food Chemistry, v.66, n. 4, p. 503-510, 1999.

ARCHENTI, A. Chemical composition of honeys from Chubut province (Argentina). Revista de Ciências Agrárias, v. 5, n. 1/4, p. 12-28, 1984.

ATAGO Co. Ltda. Refratômetro para mel. Abelhas, v. 31, n. 362/363, p.9, 11-12, 41,44, 1988. /Resumo em CAB Abstracts on CD-ROM, 1987-89/.

AZEREDO, M. A. A.; AZEREDO, L. C. Características físico-químicas dos méis do município de São Fidélis-RJ. Ciência e Tecnologia de Alimento, v. 19, n. 1, p. 3-7, 1999.

BALDI CORONEL, B.; DALL'OGLLIO, A. M.; LEZCANO, S. Caracterización físico químico de las mieles de la Provincia de Entre Rios. Alimentación Latinoamericana, n.39, p.39-44,1993.

BALENOVIC, J.; PERKCVAC, M.; PAPIC, J. Hydroxymethylfurfural content and amylase activity in honey. Prehrambeno Tehnoloska Revija, v.26, n.4, p.143-146, 1988.

BARBOLA, I. F.; LAROCA, S. A comunidade de Apoidea (Hymenoptera) da Reserva Passa Dois (Lapa, Paraná, Brasil): I. Diversidade, abundância relativa e atividade sazonal. Acta Biológica Paranaense, v.22, n.1/4, p.91-113, 1993.

BARTH, O. M. Análise microscópicas de algumas amostras de mel. 1 - pólen dominante. Anais da Academia Brasileira de Ciência, v. 42, p.351-366. 1970a.

BARTH, O. M. Análise microscópicas de algumas amostras de mel. 2 - pólen acessório. Anais da Academia Brasileira de Ciência, v. 42, p.571-590. 1970 b.

BARTH, O. M. Análise microscópicas de algumas amostras de mel. 3 - pólen isolado. Anais da Academia Brasileira de Ciência, v. 42, p.747-772. 1970c.

BARTH, M. O. Análise microscópica de algumas amostras de mel; 6 Espectro polinico de algumas amostras de mel dos Estados da Bahia e do Ceará. Revista Brasileira de Biologia, v. 31, n. 4, p. 431-434, 1971. 
BARTH, M. O. O pólen no mel brasileiro. Rio de Janeiro: Gráfica Luxor, 1989. 152p.

BARTH, M. O. Pollen in monofloral honey from Brazil. Journal of Apicultural Research, v. 29, p.89-94, 1990.

BASTOS, D.H.M.; SILVA, J.R. Análise de méis produzidos na região Bragantina. Apicultura Atual, v. 12, n. 2, p. 121-134, 1994.

BASTOS, E. M. A. F. Grão de pólen e estruturas secretoras de plantas como indicadores da origem botânica do mel e da própolis. In: CONGRESSO BRASILEIRO DE APICULTURA, 12., Salvador, 1998 Anais. Salvador: Confederação Brasileira de Apicultura, 1998. p.71-72.

BASTOS, E. M.; BRANDÃO, M.; SILVEIRA, F. R. C. da. Espectro polínico dos méis produzidos no parque da Serra do Caraça - MG. Daphne, v. 5, n. 1, p. 40-45, 1995.

BATAlHA, M. A. Análise da vegetação da ARIE Pé-de-Gigante (Santa Rita do Passa Quatro). São Paulo, 1997. 257p. Dissertação (Mestrado)-Instituto de Biologia, Universidade de São Paulo.

BATH, P. K.; SINGH, N. A comparison between Helianthus annuus and Eucalyptus lanceolatus honeys. Food Chemistry, v. 67, n. 4, p. 389-397, 1999.

BAWA, K.S. Patterns of flowering in tropical plants. In.: JONES, G.E.; LITTLE, R.J. (Ed.) Handbook of experimental and pollination biology. New York: Van Nostrand Reinhold, 1983. p.394-410.

BEGON, M.; HARPER, J. L.; TOWNSEND, C. R. Ecology. 3. Ed. London. Blackwell Science, 1996. 1069p.

BIANCHI, E. M. Control de calidad de la miel. Santiago del Estero: Arte, 1986. p. 87.

BICELLI , C. R. L.; SILVEIRA NETO, S.; MENDES, A. C. B. Dinâmica populacional de insetos coletados em cultura de cacau na região de Altamira, Pará. II. Análise faunística. Agrotrópica, v.1, n.1, p.29-47, 1989.

BOGDANOV, S. Honey quality and international regulatory standards: review by the international honey commission. Bee World, v. 80, n. 2, p. 61-69, 1999.

BOGDANOV, S.; MARTIN, P.; LULLMANN, C. Harmonized methods of the european honey commission. Apidologie, v.2, n.11, p. 1-59, 1997. Extra. Issue.

BORTOLI, C. de; LAROCA, S. Estudo biocenótico em Apoidea (Hymenoptera) de uma área restrita em São José dos Pinhais (PR, Sul do Brasil), com notas comparativas. Dusenia, v.15, p.1-112, 1990. 
BRASIL. Leis, decretos, etc. Instrução Normativa 11, Diário Oficial, 20 de outubro de 2000. Seção 1, p.19696-19697. Aprova as Normas o Regulamento Técnico de Identidade e Qualidade do Mel.

BRICAGE, P. The amount of HMF in honeys does it have na effect on the health of the consumer?. Bulletin Technique Apicole, v.16, n.4, p.255-262, 1989. /Resumo em CAB Abstracts on CD-ROM, v.3A, 1990-91/.

BUTTA, A.; CASERIO, G.; BIZZOZERO, M. et al. Indagine sulla qualità merceologica e sulle carattrristiche microbiologiche di mieli in commericio. Industrie Alimentari, v. 22, n. 210, p.838-44, 1983.

CAMARGO, J. M. F.; MAZUCATO, M. Inventário da apifauna e flora apícola de Ribeirão Preto, SP, Brasil. Dusenia, v.14, n.2, p.55-87, 1984.

CAMARGO, J.M.F.; PEDRO, S.R.M. Sistemática de Meliponinae (Hymenoptera, Apidae): sobre a polaridade e o significado de alguns caracteres morfológicos. Naturalia, p.45-49, 1992. Número especial.

CAMILLO, E.; GARÓFALO, C.A. Analysis of the niche of two sympatric species of Bombus (Hymenoptera, Apidae) in southeastern Brasil. Journal of Tropical Ecology, v.5, p.81-92, 1989.

CAMPOS, G. Melato no mel e sua determinação através de diferentes metodologias. Belo Horizonte, 1998. 178p. Tese (Doutorado) - Escola de Veterinária, Universidade Federal de Minas Gerais.

CAMPOS, M.J.O. Estudos das interações entre a comunidade de Apoidea, na procura de recursos alimentares e a vegetação de cerrado na reserva de Corumbataí-SP. São Carlos, 1989. 114p. Tese (Doutorado) - Universidade Federal de São Carlos.

CARVALHO, C. A. L. de. Diversidade de abelhas (Hymenoptera, Apoidea) no Vale do rio Paraguaçu, município de Castro Alves, Estado da Bahia. Piracicaba-SP, 1999. 83p. Tese (Doutorado) - Escola Superior de Agricultura "Luíz de Queiroz", Universidade de São Paulo.

CARVALHO, C. A. L. de; MARCHINI, L. C.; SODRÉ, G. S. et al. Análises de amostras de méis provenientes do recôncavo da Bahia. In. ENCONTRO SOBRE ABELHAS, 4., Ribeirão Preto, 2000. Anais. Ribeirão Preto: Faculdade de Filosofia Ciências e Letras, 2000. p.352. 
CARVALHO, C. A. L. de; MARCHINI, L. C.; TEIXEIRA, G.M. et al. Características físicoquímicas de amostras de méis da Bahia. In: CONGRESSO BRASILEIRO DE APICULTURA, 12., Salvador, 1998. Anais. Salvador: Confederação Brasileira de Apicultura, 1998, p.200.

CARVALHO, C.A.L. de.; MARQUES, O.M. Abelhas (Hymenoptera, Apoidea) em Cruz das Almas - Bahia: 2. Espécies coletadas em leguminosa. Insecta, v.4, n.2, p.18-25, 1995.

CARVALHO, C.A.L. de; MARCHINI, L.C. Tipos polínicos coletados por Nannotrigona testaceicorns e Tetragonistica angustula (Hymenoptera: Apidae: Meliponinae). Scientia Agrícola, v. 7, n. 3, p.17-20, 1999a.

CARVALHO, C.A.L. de; MARCHINI, L.C. Abundancia de ninhos de Meliponinae (Hymenoptera: Apidae) em biótopo urbano no Município de Piracicaba-SP. Revista de Agricultura, v. 2, n.1, p.22-24, 1999b.

CARVALHO, C.A.L. de; MARCHINI, L.C.; MARQUES, O. M. Diversidade de Xylocopa spp. (Anthophoridae) em plantas de interesse econômico. In: CONGRESSO BRASILEIRO DE ENTOMOLOGIA, 16., Salvador, 1997. Resumos. Salvador: SEB, 1997. p. 208.

CASTRO, M.S. de. Plantas apícolas - identificação e caracterização. In.: BRANDÃO, A.L.S.; BOARETTO, M.A.C. (Coord.) Apicultura atual: diversificação de produtos. Vitória da Conquista: UEFS , DFZ, 1994. p.21-31.

CASTRO, M. S. A comunidade de abelhas (Hymenoptera: Apoidea) de uma área de caatinga arbórea entre os inselbergs de Milagres (12 53’S; 39 51'W), Bahia. São Paulo-SP. 2001. 191p. tese (Doutorado) - Instituto de Biociências da Universidade de São Paulo.

COLIN, M. E.; FLAMINI, C.; MALAUSSENE, J.; et al. The quality of commercial honey. Cahiers de Nutrition et de Dietetique, v.21, n.3, p.219-222, 1986. /Resumo em CAB Abstracts ou CD-ROM, v.2, 1987-89./

CORBET, S. A.; WILLIAMS, I. H.; OSBORNE, J. L. Bees and the pollination of crops and wild flowers in the European Community. Bee World. v. 72, n. 2, p.47-59. 1991.

CORNEJO, L. G. Tecnologia de miel. In: SEEMANN, P.; NEIRA, M. (Ed). Tecnologia de la produccion apicola. Valdivia: Universidad Austral de Chile, Facultad de Ciencias Agrarias, 1988. p.145-171. 
CORTOPASSI-LAURINO, M. Divisão de recursos tróficos entre abelhas sociais principalmente em Apis mellífera Linné e Trigona (Trigona) spinipes Fabricius (Apidae, Hymenoptera). São Paulo, 1982. 180p. Tese (Doutorado) - Instituto de Biociências, Universidade de São Paulo.

CORTOPASSI-LAURINO, M.; GELLI, D. S. Analyse pollinique, propriétés physico-chimiques et action antibactérienne des miels d'abeilles africanisées Apis mellifera et de Méliponinés du Brésil. Apidologie, v. 22, p. 61-73, 1991.

COSTA, L. S. M.; ALBUQUERQUE, M. L. S.; TURGO, L. C. et al. Determination of nonvolatile compounds of different botanical origin brazilian honeys. Food Chemistry, v. 65, p. 347-352, 1999.

COSTA, J. B. A.Fontes de pólen utilizadas por operárias de Apis mellifera L. no município de Cruz das Almas, Bahia. Cruz das Almas-BA, 2002. 55p. Dissertação (Mestrado) Universidade Federal da Bahia.

CRANE, E. Bees and beekeeping-science, practice and world resources. Neinemann. Newnes, 1990. 614 p.

CRANE, E. Honey: a comprehensive survey. London: Heinemann, 1975. 608p.

CRECENTE, R. P.; LATORRE, C. H. Pattern recognition analysis applied to classification of honeys from two geographic origins. Journal of Agricultural and Food Chemistry, v. 41, p. 560-564, 1993.

CURE, J. R.; BASTOS FILHO, G.S.; OLIVEIRA, M.J.F. de; et al. Levantamento de abelhas silvestres na zona da mata de Minas Gerais. I - Pastagem na Região de Viçosa (Hymenoptera, Apoidea). Revista Ceres, v.40, n.228, p.130-161, 1993.

DANTAS, J.O.; OLIVEIRA, D.A.; PEREIRA-NETO, A.; et al. In: CONGRESSO BRASILEIRO DE APICULTURA, 12., Salvador, 1998. Anais. Salvador: Confederação Brasileira de Apicultura, 1998. p. 215.

D'AMBROSIO, M.; MARCHESINI, A. Research on contamination by heavy metals in honey sample. Atti della Societa Italiana di Scienze Naturali e del Museo di Storia Naturale, v. 123, n. 213, p. 342-348, 1982. /Resumo em. Apicultural Abstracts, v. 35, n. 3, p.220, 1984./ 
DAYRELL, I. O.; VITAL, N. C. Comparação entre dois métodos oficiais para determinação de hidroximetilfurfural (HMF) em mel brasileiro. Ciência e Tecnologia de Alimento, v. 11, n. 1, p.137-141, 1991.

DEL LUNGO, T.; CIURLO, R.; NOVARI, G.; MALERBA, A. II Miele argentino: produzione, commercializzazione e caratteristiche. Industrie Alimentari, v.30, n. 292, p.361-366, abr. 1991.

DOUROJEANNI, M.J. Entomology and biodiversity conservation in Latin America. American Entomologist, v. 9, n.17, p.88-93, 1990.

DOZO, A. M. M. de Determinacion de azucares en mieles producidas en la provincia de Buenos Aris - Republica Argentina. In: CONGRESSO BRASILEIRO DE APICULTURA, 5.; CONGRESSO LATINO-IBERO-AMERICANO DE APICULTURA, 3 , Viçosa, 1980. Anais. Viçosa: Universidade Federal de Viçosa, 1980. p. 312-316.

DURKEE, L.H. A Pollen profile from woden bog in North-Central Iowa. Ecology, v. 52, n. 5, p.837-844. 1971.

EITEN, G. The cerrado vegetation of Brazil. Revista de Botânica. v. 38, p.201-341. 1972.

EL-SHERBINY, G. A.; RIZK, S.S.; EL-ASHWAH, F A. Chemical composition of citrus honey producede in A. R. E. Agricultural Research Review, v. 58, n. 3, p. 289-297, 1980.

ESCOBAR-MARTINEZ, C. A.; GIMÉNEZMEZA, G. G.; MENDOZA, Q. M. R. Mieles de abejas de flor paraguaya: composicion, tipificacion y norma lizacion. San Lorenzo: Ministerio de Agricultura y Ganaderia; Universidad Nacional de Asuncion; Asociacion Suiza para el Desarrollo y la Cooperacion, 1992. 31 p.

FARAJI-HAREMI, R.; HOSSEINI, Z. Chemical composition of honeys from Fars and Kohkiluyeh provinces of Iran. Iran Agricultural Research, v. 6, n. 2. p.73-81, 1987. /Resumo em CAB Abstracts on CD-ROM, 1990-91/.

FERNÁNDEZ-SALGUERO, J.; GÓMEZ, R. Aportación al estudio de los alimentos españoles de humedad baja. Alimentaria, v. 29, n. 229, p.83-85, jan./fev. 1992.

FINA, B. G. Florística e fitosociologia de uma área de cerradão, município de Pirassununga, SP. Rio Claro, 1999. 90p. Dissertação (Mestrado) - Instituto de Biociências, Universidade do Estado de São Paulo.

FINNAMORE, A.T.; MICHENER, C.D. Superfamily Apoidea. In.: GOULET, H.; HUBER, J. T. (Ed.) Hymenoptera of the world: an identification guide to families. Ottawa: Canada 
Communication Group, 1993. p.279-357.

FLECHTMANN, C. H. W.; CALDAS FLHO, C. F.; AMARAL, E. et al. Análise de méis do Estado de São Paulo. Boletim de Indústria Animal, v. 21, p. 65-73, 1963.

FREE, J.B. Insect pollination of crops . London: Academic Press, 1993. 684p.

FREITAS, B. M. Potencial de caatinga para a produção de pólen e néctar para a exploração apícola. Fortaleza, 1991. 140p. Dissertação (Mestrado)-Universidade Federal do Ceará.

FREITAS, B. M. A importância relativa de Apis mellifera e outras espécies de abelhas na polinização de culturas agrícolas. . In. ENCONTRO SOBRE ABELHAS, 3., Ribeirão Preto, 1998. Anais. Ribeirão Preto: Faculdade de Filosofia Ciências e Letras, p.10-20. 1998.

FRIAS TEJERA, I.; TORRE, A. H. de la Hidroxymethylfurfural e índice de diastase em mieles artesanales de la provincia de Santa Cruz de Tenerife. Alimentaria, v. 27, n. 216, p.55-58. out.1990.

FRÍAS, I.; HARDISSON, A. Estudio de los parámetros analíticos de interés en la miel. II. Azúcares, cenizas y contenido mineral y color. Alimentaria, v.28, n. 235, p.41-43, 1992.

GAJEK, O.; NABRRZYSKI, M.; GAJEWSKA, R. Metallic impurities in imported canned fruit and vegetables and in honey. Roczniki Panstwowego zakladu-Higieny, v. 38 n. 1, p. 14-20, 1987. /Resumo em Apicultural Abstracts, v. 42, n. 2, p. 171, 1971/.

GODOY, R.A.; BAWA, K.S. The Economic Value and Sustainable Harvest of Plants and Animals from the Tropical Forest: Assuptions, Hypotheses, and Methods. Economic Botany v. 47, n. 3, p. 215-219, 1993.

GODOY, R.A.; LUBOWSKI, R.; MARKANDAYA, A. A Method for the Economic Valuation of Non-timber Tropical Forest Products. Economic Botany v. 47, n. 3, p. 220-233, 1993.

GÓMEZ R.; CABEZAS, L.; ALCALÁ, M. et al. Determinacion y calculo de la actividad del agua en diferentes muestras de miel. Alimentaria, v.27, n.210, p.33-36, Mar. 1990.

GOMEZ, M. E. M.; HERNANDEZ, E. G.; GOMEZ, J. Y M. et al. Physicochemical analysis of Spanish commercial Eucaliptus honeys. Journal of Apicultural Research, v. 32, n. 3/4, p.121-126, 1993.

GOODLAND, R.; FERRI, M. G. Ecologia do cerrado. São Paulo: EDUSP; Belo Horizonte: Livraria Itatiaia, 1979. 193p.

GRISWOLD, T,; PARKER, F.D.; HANSON, P.E. The bees (Apidae). In.: HANSON, P.E.; GAULD, I.D.(Ed.) The hymenoptera of Costa Rica. Oxford: Oxford University Press, 
1995. p. 650-691.

HALFFTER, G.; EZCURRA, E. La diversidad biológica de Iberoamérica. http://www.wri.org/wri/biodiv/sp01.gbs.html\#que es (1 jun. 1996).

HANKIN, L. Analysis of honey. Bulletin, Connecticut Agricultural Experiment Station, n. 847, 1987, 6p. /Resumo em Apicultural Abstracts, v. 41, n. 2-4, p.165, 1990/.

HASE, W.; AIDA, Y. Studies on the quality of hney on the market in Japan with special reference to its relation to the "Codex Alimentarius". In: INTERNATIONAL CONGRESS OF APICULTURE, 30., Nagoya, Apimondia 1986. p. 338-342. /Resumo em Apicultural Abstracts, v.39, n.1, p.77, 1988/.

HEITHAUS, E.R. The role of plant-pollinator interactions in determining community structure. Annals of Missouri Botanical, v.61, p.675-691, 1974.

HEITHAUS, E.R. Community structure of neotropical flower visiting bees and wasps: diversity and phenology. Ecology, v.60, n.1, p.190-202, 1979.

HORN, H.; Alunos da disciplina Análise de Mel da Universidade de Hoheinheim, Alemanha. Méis brasileiros: resultados de análise físico-químico e palinológicas. In: CONGRESSO BRASILEIRO DE APICULTURA, 11 Piauí, 1996. Anais. Piauí: Confederação Brasileira de Apicultura, 1996, p.403-429.

HOWER, F.N. Plantas melíferas . Barcelona: Reverté, 1953. 35p.

IBRAHIM, S.H.; SOLIMAN, N.Z.; WISSA, H. Studies on the properties of the major Egyptian honey types and honey ripening. Agricultural Research Review, v. 55, n. 1, p.125-129, 1977. /Resumo em Apicultural Abstracts, v. 32, n. 1, p.52-53, 1981/.

IMPERATRIZ-FONSECA, V. L.; GIOVANNINI, A. GUIBI, L. S. et al. Preliminary study of Brasilian honeys. In: INTERNATIONAL APICULTURAL CONGRESSO, 30 ,Nogoya, 1987. Proceedings. London: International Bee Research Association, 1989. p. 312.

IMPERATRIZ-FONSECA, V.L.; KLEINERT-GIOVANNINI, A.; RAMALHO, M. Pollen harvest by eusocial in a non-natural community in Brasil. Journal of Tropical Ecology, v.5, p.239-242, 1989.

INTERNATIONAL TRADE FORUM Upswing in the honey market. International Trade Forum, v.13, n.3, p.21-31, 1977. /Resumo em Apicultural Abstracts, v.30, n.3, p.214, 1979/. 
ISSA, M. R.; JONG, D. de; HORN, H. Características físico-químicas de amostras de méis normais, aquecidos e misturados. In: CONGRESSO BRASILEIRO DE APICULTURA. 12 Salvador, 1998. Anais Salvador: Confederação Brasileira de Apicultura, 1998. p.209.

IVANOV, T. S.; CHERVENAKOVA, I. Contents of some macro-, oligo-, and trace elements in honey, royal jelly and pollen. Zhivotnovudni Nauki, v. 21, n.6, p.65-69, 1984. /Resumo em Apicultural Abstracts, v.37, n.3, p.246, 1986/.

IWAMA, S.; MELHEM, T. S. The pollen spectrum of the honey of Tetragonisca angustula angustula Latrelle (Apidae, Meliponinae). Apidologie, v. 10, n. 3, p.275-295, 1979.

JANSEN, D.H. Ecologia vegetal nos trópicos. São Paulo: EDUSP, 1980. 79p. (Coleção Temas de Biologia,7).

KASSAYE, A.; GARDEGABA, N. Moisture content determination of Ethiopian honey. In: INTERNATIONAL CONFERENCE ON APICULTURE IN TROPICAL CLIMATES, 4., Cairo, 1988. Proceedings. London: International Bee Research Association, 1989. p.265267. /Resumo em Apicultural Abstracts, v.41, n.3, p.260,1990/.

KERR, W. E.; BLUM,M; FALES, H. M. Comunication of food source between workers of Trigona (Trigona) spinipes. Revista Brasileira de Biologia. v. 41, n. 3, p. 619-623, 1981.

KERR, W.E.; CARVALHO, G.A; NASCIMENTO, V.A.; et al. Abelha uruçu: biologia, manejo e conservação. Belo Horizonte: Fundação Agangaú, 1996.144p.

KIM, J. G.; KIM, M. K.; LEE, S. H. Study on the content of oligosaccharides in honeys from differrent honey plants. Korean Journal of Apiculture, v.8, n.2, p.165-169, 1993. /Resumo em CAB Abstracts on CD-ROM, v. 4A, 1993-94/.

KNOLL, F. do R.N. Abundância relativa, sazonalizada e preferências florais de Apidae (Hymenoptera) em uma área urbana (23 33’S; 46 43’W). São Paulo, 1990. 127p. Tese (Doutorado) - Instituto de Biociências, Universidade de São Paulo.

KOEPPEN, W. Climatologia. México: Fundo de Cultura Econômica. 1948. 389p.

KOMATSU, S. S. Caracterização físico-química de méis de Apis mellifera L., 1758 (HYMENOPTERA: APIDAE) de diferentes municípios de São Paulo. Piracicaba-SP, 1996. 89p. Tese (Doutorado) - Escola Superior de Agricultura "Luíz de Queiroz”, Universidade de São Paulo.

KOMATSU, S. S.; MARCHINI, L. C. Teores de açúcares redutores e sacarose de amostras de méis de flores silvestres produzidos por Apis mellifera no Estado de São Paulo. In: 
CONGRESSO BRASILEIRO DE APICULTURA, 12 , Salvador, 1998. Anais. Salvador: Confederação Brasileira de Apicultura, 1998. p.344

LAROCA, S.; CURE, J. R.; BORTOLI, C. A associação de abelhas silvestres (Hymenoptera: Apoidea) de uma área restrita no interior da cidade de Curitiba (Brasil): uma abordagem biocenótica. Dusenia. v. 13, n. 3: p.93-117, 1982.

LASCEVE, G.; GONNET, M. Analyse por radioactivation du contenu mineral d'un miel.

Possibilité de preciser son origine. Apidologie, v. 5, n. 3, p.201-223, 1974.

LEWIS, T.; TAYLOR, L.R. Introduction to experimental ecology - a student guide to fieldwork and analisys. London: Academic Press, 1976. 401p.

LINDAUER, M.; KERR, W. E. Communication between the workers of stingless bees. Bee World. v. 41, p. 29-41, 65-71, 1960.

LOUVEAUX, J., MAURIZIO, A., VORWOHL, G., Methods of melissopalynology. Bee World, v. 51, p. 125-138. 1970.

LOUVEAUX, J., MAURIZIO, A., VORWOHL, G., Methods of melissopalynology. Bee World, v. 59, p. 139-157. 1978.

LOWER, E. S. Honey its properties and uses Part I, British Food Journal, v.98, n.939, p.84-87, jul/ aug. 1987a.

LOWER, E. S. Honey its properties and uses Part II, British Food Journal, v.89, n. 939, p. 84-87, July/Aug. 1987b.

LUDWIG, J. A.; REYNOLDS, J. F. Statistical Ecology - A primer on methods and computing. New York: John Wiley, 1988. 337p.

MAGALHÃES, E. de O.; SICUPIRA, P. R. TERRA, P. S. Levantamento preliminar da flora apícola Sul da Bahia. In: CONGRESSO BRASILEIRO DE APICULTURA. 11 , Piauí 1996. Anais. Piauí: Confederação Brasileira de Apicultores, 1996. p.326.

MANTOVANI, W. MARTINS, F. R. Florística do cerrado na reserva biológica de MogiGuaçu, SP. Acta Botânica Brasileira. v. 7, p. 33-60, 1993.

MARCHINI, L. C. Caracterização de amostras de méis de Apis mellifera L. 1758 (Hymenoptera: Apidae) do Estado de São Paulo, baseada em aspectos físico-químicos e biológicos. Piracicaba-SP, 2001. 83p. Tese (Livre Docência) - Escola Superior de Agricultura "Luíz de Queiroz", Universidade de São Paulo. 
MARCHINI, L. C.; CARVALHO, C. A. L. de; ROS, P. B. Tipos polínicos coletados por Partamona cuoira (HYMENOPTERA, APIDAE, MELIPONINAE ) In: INTERNATIONAL APICULTURAL CONGRESS, 35 (APIMONDIA) Belgium, 1997. Anais. Belgium, Apimondia Publishing House, Bucharest, 1997, p.290.

MARChINI, L. C.; RODRIGUES, A. C. L.; MORETI, A. C. de C. C. Características qualitativas de méis que passaram por diferentes tipos de descristalização. In: CONGRESSO BRASILEIRO DE APICULTURA, 12 Piauí, 1996. Anais. Piauí: Confederação Brasileira de Apicultura, 1996. p.348.

MARTINEZ, G. M. E.; GUERRA, H. E.; MONTILLA, G. S. et al. Physicochemical analysis of Spanish commercial Eucalyptus honey. Journal of Apicultural Research, v. 32, n. 3-4, p. 121-126, 1993.

MARTINS, C.F. Estrutura da comunidade de abelhas (Hymenoptera, Apoidea) na Caatinga (Casa Nova, BA) e na Chapada Diamantina (Lençois, BA). São Paulo, 1990. 139p. Tese (Doutorado) - Instituto de Biociências, Universidade de São Paulo.

MATEUS, S. Abundância relativa, fenologia e visita as flores pelos Apoidea do cerrado da estação ecológica de Jataí - Luiz Antônio - SP, 1998. Dissertação (Mestrado). Faculdade de Filosofia Ciências e Letra-Ribeirão Preto/SP, Universidade de São Paulo.

MATHESON, A.; BUCHMANN, S.L.; O’TOOLE, C.; WESTRICH, P.; WILLIAMS, I.H. The conservation of bees. London: Academic Press, 1996. 254p.

McGREGOR, S.E. La apicultura en los Estados unidos, México: Limusa, 1979. 93p.

MENDES, E.; PROENÇA, E. B.; FERREIRA, I. M. P. L. V. O. et al. Quality evaluation of portuguese honey. Carbohydrate Polymers, v. 37, n. 3, p. 219-223, 1998.

MESALLAN, A. S.; EL-SHAARAWY, M. I. Quality attributes of honey in Saudi Arabia. Food Chemistry, v. 25, n. 1, p.1-11, 1987.

MORAES, R. M.; TEIXEIRA, E. W. Análise do mel (Manual técnico). Pindamonhangaba: s. ed., 1988. 41p.

MORAES, R. M. de MANTOVANI, D. M. B Composição química de méis de diferentes fontes florais. In: CONGRESSO BRASILEIRO DE APICULTURA, 7 , Salvador, 1986. Programa e resumo. Salvador: Confderação Brasileira de Apicultura, 1986. p.58. 
MORAES, R.M. de.; BENEVIDES, L.H.T.S.; MENEZES, A. de. et al. A desumidificação do mel no Brasil. Apicultura \& Polinização, n. 31, p.27-29, 1989.

MORETI, A. C. de C. C.; CARVAlHO, C. A. L. de; MARCHINI, L. C. et al. Espectro polínico de amostras de méis de Apis mellifera. In: CONGRESSO BRASILEIRO DE APICULTURA, 12 , Salvador, 1998. Anais. Salvador: Confederação Brasileira de Apicultura, 1998 p.189.

MORETI, A. C. de C. C.; MARCHINI, L. C.: OlIVEIRA, P. C. F. Principais tipos polínicos observados em amostras de mel silvestre, produzido por abelhas (Apis mellifera L) no Estado de São Paulo. In: ENCONTRO SOBRE ABELHAS, 14 , Ribeirão Preto, 2000. Anais. Ribeirão Preto, Faculdade de Filosofia, Ciências e Letras, 2000, p. 345.

NAUTA, V. S. Alcume caratteristicha merceologiche e commerciali del miele. Industrie Alimentari, v. 22, n. 208, p. 624-629, set. 1983.

NEFF, J.L.; SIMPSON, B.B. Bees, pollination systems and plant diversity. In.: LASALLE, J.; GAULD, I.D. (Ed.) Hymenoptera and biodiversity. Wallingford: CAB International,.p.143-167. 1993.

NELSON, N. A photometric adaptation of the Somogyi method for the determination of glucose. Journal of Biological Chemistry. v.153, 375p. 1944.

OLIVEIRA, P.E. Abelhas e a polinização de plantas do cerrado. In: ENCONTRO SOBRE ABELHAS, 3 , Ribeirão preto, 1998. Anais, Ribeirão Preto. EDUSP. 1998. p.67-74

O'TOOLE, C. Diversity of native bees and agroecossystems. In.: LASALLE, J.; GAULD, I.D. (Ed.) Hymenoptera and biodiversity. Wallingford: CAB International,.p.169-196. 1993.

OLEK, A.; STEINKRAUS, K. H.; MATTICHK, L. R. et al. Carbohydrate composition of two nepalese honeys produced by Apis lobariosa and Apis cerana. Journal of Apicultural Research, v. 26, n. 3, p.203-204, 1987.

ORTIZ, V. A. The ash content of 69 honey samples from La Alcarria and neighbouring areas, collected in the period 1985-87. Cuadernos de Apicultura, n. 5, p.8-9, 1988. /Resumo em Apicultural Abstracts, v. 40, n. 4, p.360, 1989/.

PAMPLONA, B. C. Exame dos elementos químicos inorgânicos encontrados em méis brasileiros de Apis mellifera e suas relações físico-biológicas. São Paulo, 1989. 131p. Dissertação (Mestrado) - Instituto de Biociências, Universidade de São Paulo. 
PAPOFF, C. M.; CAMPUS, R. L.; CICU, M. F. I.; FARRIS, G. G. FLORIS, I.; RICCIARDELLI, D’ÁLBORE, G. Physical, chemical, microbiological and palinological characteristics of Somalian honeys. Apicoltura, n. 4, p. 147-72, 1988. /Resumo em CAB Abstractes on CD-ROM, v. 3A, 1990-91/.

PEDRO, S.R. de M. Sobre as abelhas bees (Hymenoptera, Apoidea) em um ecossistema de cerrado (Cajuru, NE do Estado de São Paulo): composição, fenologia e visita às flores. Ribeirão Preto, 1992. 200p. Dissertação (Mestrado) - Faculdade de Filosofia, Ciências e Letras de Ribeirão Preto - Universidade de São Paulo.

PENG, Z. F.; PAN, J. G. Protein content in honey and its effects on precipitation of beverage. Food Science, v. 12, p. 6-8, 1994.

PERÉZ, C.; CONCHELlO, P.; ARIÑO, A. et al. Estudio de algunos parametros fisicoquimicos en mieles monoflorales de Zaragoza. Alimentaria, v. 27, n. 213, p.59-61 Jun. 1990.

PERSANO-ODDO, L. P.; PIAZZA, MG; SABATINI, AG. Et al. Characterization of unifloral honeys. Apidologie, v. 26, p. 453-465, 1995.

PFAU, L. A.; RUHLE, E. R. Concurso de mel: método de avaliar a qualidade do mel. In: CONGRESSO BRASILEIRO DE APICULTURA, 7., Salvador, 1986. Programa e resumos. Salvador: Confederação Brasileira de Apicultura, 1986. p. 58.

PHADKE, R. P. Studies on Indian honeys. 1. Proximate composition na physico-chemical characteristics of Indian multifloral apiary honeys from Apis índica bee. Indian Bee Journal, v. 29, p. 14-26, 1967. /Resumo em Apicultural Abstracts, 1972/.

PIAZZA, M. G.; ACCORTI, M. HMF of domestic and foreign and honey sold in Italy. Apitalia, v. 10, p. 8-10, 1983. Resumo em CAB Abstractes on CD-ROM, v. 1, 1984-86.

PONCINI, L.; PRASAD, B.; SINGH, S. K. WIMMER, F. L. A survey of some Fijian honeys. New Zealand Journal of Science, v. 27, n. 2, p. 141-144, 1984. /Resumo em CAB Abstracts on CD-ROM, v.1, 1984-86/.

PONCINI, L.; WIMMER, F. L. The composition of some Fijian honeys. Fiji Agricultural Journal, v. 45, n. 1, p. 25-29, 1983. Resumo em CAB Abstracts on CD-ROM, v.1, 1984-86/.

PREGNOLATO, W. Normas analíticas do Instituto Adolfo Lutz, v. 1. Métodos químicos e físicos para analise de alimentos. In PREGNOLATO, W.; PREGNOLATO, N. P. (Coord). 3. ed. São Paulo: Instituto Adolfo Lutz, 1985. 533p. 
PROCTOR, M.; YEO, P.; LACK, A. The natural history of pollination. London: Harper Collins, 1996. 479p.

RAMALHO, M.; KLEINERT-GIOVANNINI, A.; IMPERATRIZ-FONSECA, V.L. Utilization of floral resourses by species ofMelipona (Apidae, Meliponinae): floral preferences. Apidologie, v.20, p.185-195, 1989.

RATTER, J. A. Notes on the vegetation of Fazenda Água Limpa (Brasília - DF, Brasil). Edinbrurg, Royal Botanical Garden. v. 7, n.12, p.12-13, 1980.

REIO, L.; ENGLUND, L. Honey and its composition. Var Föda, v. 37, n. 2, p. 42-62, 1985. /Resumo em CAB Abstracts on CD-ROM, 1987-89/.

REIS, M. S. E MARIOT, A. Diversidade natural e aspectos agronômicos de plantas medicinais. In: SIMÕES, C.M. O.; SCHENKEL, E. P.; GOSMAN, G.; MELLO, J. C. P.; MENTZ, L. A.; PETROVICK, P.R. (ORG.) Farmagnosia. Da planta ao medicamento. Porto Alegre: Ed. UFSC / Ed. UFRGS. p. 39-60, 1999.

RENDÓN, S. R. Estudio de la composicion fisico-quimica de las mieles extremenas y extranjeras. In: CONGRESSO IBERO LATINOAMERICANO DE APICULTURA, 5 , Uruguai, 1996. Anais., Mercedes: Intendência Municipal de Soriano. p.174-83, 1996

ROIG-ALSINA, A.; MICHENER, C.D. Studies of the phylogeny and classification of longtogued bees (Hymenoptera, Apoidea). The University of Kansas Science Bulletin, v.55, n. $4 / 5$, p.123-173, 1993.

ROUBIK, D.W. Ecology and natural history of tropical bees. Cambrige: Cambridge University Press, 1989. 514p.

SAKAGAMI, S.F.; LAROCA, S. Relative abundance, phenology and flower visits of Apid bees in Eastern Paraná, South Brazil (Hym., Apidae). Kontyü, v.39, n.3, p.213-230, 1971.

SAKAGAMI, S.F.; LAROCA, S.; MOURE, J.S. Wild bees biocenotics in São José dos Pinhais (PR), South Brazil - preliminary report. Journal of the Faculty of Science, Hokkaido University. Series VI, Zoology, v.6, p.253-291, 1967.

SAKAGAMI, S.F.; MATSUMURA, T. Relative abundance, phenology and flower PREFERENCE OF ANDRENID BEES IN Sapporo, north Japan (Hym., Apoidae) Japanese Journal of Ecology, v.17, n.6, p.237-250, 1967. 
SALASHINSKII, N. A.; BARANOVA, Z. A.; KIBENKO, G. V. Comparison of characteristics of honey. Tovarovedenie, v. 13, p. 15-16, 1980. /Resumo em Apicultural Abstravts, v. 33, n. 4, p.295, 1982/.

SALINAS, F.; ESOINOSA-MANSILLA, A. BERZAS-VEVADO, J.J. Flow-injection determination of HMF in honey by Winkler method. Fresenius, Journal of Analytical Chemistry, v. 340, n. 4, p.250-252. 1991.

SANCHO, M. T.; MUNIATEGUI, S.; HUIDOBRO, J. F. et al. Aging of honey. Journal of Agricultural and Food Chemistry,, v. 40, n. 4, p. 250-255, 1992.

SANTOS, C. F. O. Análise polínica de alguns méis do Estado de São Paulo. In: CONGRESSO BRASILEIRO DE APICULTURA, 3. Piracicaba, 1974. Anais Piracicaba: ESALQ, 1974. p. 273-278.

SANTOS, C. F. O. Avaliação do período de florescimento das plantas apícolas no ano de 1960, através do pólen contido nos méis e dos coletados pelas abelhas (Apis mellifera) Anais Escola Superior de Agricultura "Luiz de Queiroz. v. 21, p.253-264, 1964.

SANTOS, C. F. O. Morfologia e valor taxonômico do pólen das principais plantas apícolas. Piracicaba, 1961. 92p. Tese (Mestrado). Escola Superior de Agricultura "Luiz de Queiroz", Universidade de São Paulo.

SCHWARTZ FILHO, D. A comunidade de abelhas silvestres (Hymenoptera, Apoidea) da Ilha das Cobras (Paraná, Brasil): aspectos ecológicos e biogeográficos. Curitiba, 1993. 77p. Dissertação (Mestrado) - Universidade Federal do Paraná.

SEEMANN, P.; NEIRA, M. Tecnología de la producción apícola. Valdivia: Universidad Austral de Chile Facultad de Ciencias Agrarias Empaste, 1988. 202p.

SEIJO, M.C.; AIRA, M.J.; IGLESIAS, I. et al. Palynological characterization of honey from La Coruña province (NW Spain). Journal of Apicultural Research, v. 31, n. 3/4, p.149-155, 1992.

SILBERBAUER-GOTTSBERGER, I.; GOTTSBERGER, G. A polinização de plantas do cerrado. Revista Brasileira de Biologia. v. 48, n. 4: p. 651-663, 1988.

SHAVONOV, M.; IBRISHIMOV, N. Assessment of trace elements in the environment on the basis of honey foraging activity. Acta Microbiologica, Virologica et Immunologica. v.2, p.105-108, 1975. /Resumo em Apicultural Abstracts, v.28, n.4, p.176, 1977/.

SILVEIRA NETO, S.; NAKANO, O.; VILA NOVA, N.A. Manual de ecologia dos insetos. 
Piracicaba-SP: Ceres, 1976. 419p.

SILVEIRA, F.A. A flora apícola: um desafio à apicultura brasileira. Informe Agropecuário, v.9, n.106, p.26-55, 1983.

SILVEIRA, F.A.. Abelhas silvestres (Hymenoptera, Apoidea) e suas fontes de alimento no cerrado da Estação Florestal de Experimentação de Praopeba, MG. Viçosa, 1989. 51p. Dissertação (Mestrado) - Universidade Federal de Viçosa.

SILVEIRA, F. A.; ROCHA, L. B. da; CURE, J. R. et al. Abelhas silvestres (Hymenoptera, Apoidea) da zona da mata de Minas Gerais. II. Diversidade, abundância e fontes de alimento em uma pastagem abandonada em Ponte Nova. Revista Brasileira de Entomologia, v.37, n.3, p.595-610, 1993.

SIMAL, J.; HUIDOBRO, J. Parámetros de calidade de la miel III. Acidez (pH, libre, lactónica \& total) e índice de formol. Offarm, v. 3 n. 9, p. 532, 1984.

SIMPSON, B.B.; NEFF, J.L. Foral rewards: alternatives to pollen and nectar. Annals of the Missouri Botanical Garden, v.68, p.301-322, 1981.

SMITH, H. Activation analysis in forensic science using radiochemical separations. In: INTERNERNATIONAL CONFERENCE. ON FORENSIC ATIVITY. São Diego, 1966 Proceedings. San Diego: Ed. Guinn, 1966, p.176.

SODRÉ, G. da S. Características físico-químicas e análises polínicas de amostras de méis de Apis mellifera L., 1758 (HYMENOPTERA: APIDAE) da região litoral norte do Estado da Bahia. Piracicaba-SP, 2000. 83p. Dissertação (Mestrado) - Escola Superior de Agricultura "Luíz de Queiroz", Universidade de São Paulo.

SOFIA, S. H. As abelhas e suas visitas às flores em duas áreas urbanas. Rio Claro-SP, 1996. 236p. Tese (Doutorado) - Instituto de Biociências, Universidade do Estado de São Paulo.

SPETTOLI, P.; CECCHINI, A.; MATCOVICH, P. Indigine sulle caratteristiche fisicochimiche di mieli del Friuli Orientale. Industrie Alimentari, v. 22, n. 210, p. 849-858, 1983.

STEFANINI, R. Variability and analysis of Italian honeys. Apiacta, v. 19, n. 4, p.109-114. 1984. STONOGA, V. I.; FREITAS, R. J. S. de. Conteúdo de água e açúcares em mel de abelha Boletim do Centro de Pesquisa e Processamento de Alimentos, v. 9, n. 1, p. 13-16, 1991.

STRICKER, K. Specialization and foraging efficiency of solitary bees. Ecology. v. 60, p.9981009, 1979. 
TABIO, C.; ALVAREZ, J.D.; BERISIARTU, M. Preliminary characterization of some physico-chemical and organoleptic characteristics of Citrus honeys from Jaguey Grande, Matanzas. Ciencia y Tecnica en la Agricultura, Apicultura, v. 3, p.29-39, 1987.

TEMIZ, A. I. Composition and characteristics of honeys from the Izmir region, and effects of different storage methods. Ege Bolge Zirai Arastirma Enstitusu Yayinlari, v. 31, n. 11, p.113, 1983. /Resumo em CAB Abstracts on CD-ROM, 1984-86/.

THRASYVOULOU, A. The use of HMF and diastase as criteria of quality of Greek honey.

Journal of Apicultural Research, v. 25, n. 3, p. 186-195, 1986.

THRASYVOULOU, A. KARANASIOS, B.; INFANTIDIS, M. Some characteristics of Greek commercial honey. Scientific Annals of the School of Agriculture, v. 25, p. 51-63, 1982. /Resumo em CAB Abstracts on CD-ROM, v.1, 1984-86/.

THRASYVOULOU, A.; MANIKIS, J. Some physiochemical and microscopic characteristics of Greek unifloral honeys. Apidologie, v. 26, n. 4, p. 441-452, 1995.

THRASYVOULOU, A.; MANIKIS, J. TSELIOS, D. Liquefying crystallized honey with ultrasonic waves. Apidologie, v. 25, n. 3, p. 297-302, 1994.

TILMAN, D. Biodiversity: population versus ecosystem stability. Ecology, v.77, n.2, p.350$363,1996$.

TUVERI, F.; PROSPERI, S. Contributo alla conoscenza del miele prodotto in Sardegna. Industrie Alimentari, v. 24, n. 3, p.259-262, Mar. 1985.

UÑATES, M. A.; AGUILAR, A. B. PIOLA, H. D. et al. Estudio físico-químico de mieles de la provincia de San Luis-República Argentina. Archivos Latinoamericanos de Nutricion, v. 49, n. 2, p. 193-196, 1999.

VARJU, M. Mineralstojjzusammen setzung der Ungarischen Akazienhonigarten und deren zusammenhang mit dem Boden. Z. Lebensmitt. Untersuch, v. 22, n. 144, p. 308-312, 1970.

VERÍSSIMO, M. T. da L. Saiba o que é o HMF. Apicultura no Brasil, v. 4, n. 24, p.31, 1988. VERMEULEN, L.; PELERENTS, C. Suiker, fosfor en ijzerghalte van Belgische Honing. Medel. Landbouwhogesch. Gent., v. 30, n. 2, p. 527-541, 1965.

VIANA, B.F. Estudo da composição da fauna de Apidae e da flora apócola da Chapada Diamantina, Lençois, BA. São Paulo, 1992. 140p. Dissertação (Mestrado) - Instituto de Biociências, Universidade de São Paulo. 
VIDAL, R.; FREGOSI, E.V. de. Mel: características, análises físico-químicas, adulterações e transformações. Barretos: Instituto Tecnológico Científico "Roberto Rios", 1984. 95p.

VIT, P. Physical-chemical characteristics of commercial honeys from Venezuela. In: AUSTRALIAN AND INTERNATIONAL BEEKEEPING CONGRESS， 2., 1988. Beekeeping, 2000. Proceedings. Queensland: International Colour, 1988, p.227-228. /Resumo em Apicultural Abstracts, v.42, n.2, p.168, 1991/.

VIT, P.; MARTORELli, I. G. de; PALACIOS, S. L. Clasificación de mieles comerciales venezolanas. Archivos Latinoamericanos de Nutricion, v. 44, n. 1, p. 39-44, 1994.

WHITE JUNIOR, J. R. Honey. In: The hive and honeybee. Hamilton: Dadant, 1976, p.491-530.

WHITE JÚNIOR, J. W. Methods for determinung carbohydrates, hydroxymetilhyfurfural and proline in honey; Collaborative study. Journal of the Association of Official Analytical Chemists. v. 62, n. 3, p.515-526, 1979.

WHITE JÚNIOR, J. W. Hydroxymethylfurfural content of honey as na indicator of its adulteratino wiht invert sugars. Bee World, v.61, n. 1, p. 29-37, 1980.

WHITE JÚNIOR, J. W. Quality evaluation of honey: role of HMF and diastase assays. In: SEMINAR ON HONEY STANDARDS, TESTING PROCEDURES, AND QUALITY CONTROL, Riyadh, Saudo Arabia, 1991. Trabalos apresentados. Riyadh, 1992. p. 25-50. /Resumo em CAB Abstracts on CD-ROM, v.4A, 1993-94/.

WHITE JÚNIOR, J. W.; RUDYJ, O. N. The protein content of honey. Journal of Apicultural Research. v. 17 n. 4, p.234-244, 1978.

WHITE JÚNIOR, J.W. Honey. Advances in Food Research. v. 22. p. 287-374, 1978.

WIESE, H. (Coord.) Nova Apicultura. 6.ed. Porto Alegre: Agropecuária, 1985. 491p.

WOOTON, M.; RYALL, L. A comparison of Codex Alimentarius Commission and HPLC methods for 5-hidroxymethyl-2-furaldehyde determination in honey. Journal of Apicultural Research, v. 24, n. 2, p.120-124, 1975.

WITTMANN, D.; HOFFMAN, M. Bees of Rio Grande do Sul, Southern Brasil (Insecta, Hymenoptera, Apoidea). Iheringia. Série Zoológica, n.70, p.17-43, 1990.

ZANELLA, F.C.V.; SCHWARTZ FILHO, D.L.; LAROCA, S. Tropical bee island biogeography: diversity and abundance patterns. Biogeographica, v.74, n.3, p.103-115, 1998. 